\title{
A direction and principles for reshaping the Government's climate change communications and engagement strategy.
}

Submitted in partial fulfilment of the Master of Development Studies

March 2007

\author{
Alex Hannant \\ Victoria University of Wellington \\ New Zealand \\ alex@Ipnz.org
}




\section{Abstract}

Climate change is a global challenge that requires immediate individual and collective action. The self-evident fact that information alone is unable to motivate action suggests that effective communications and engagement will be critical in stimulating the required response. This research project explores how strategic thinking can be employed to support the New Zealand Government's climate change communication and engagement objectives.

Strategic thinking is the active and deliberate pursuit of synthesising evidence with a creative anticipation of what might be possible. Rather than work within parameters set by precedent and convention, it represents the deliberate intent to question, disrupt and design new courses of action.

This research explores the inertia in mainstream attitudes and behaviours towards climate change; relevant communications and social science best practice and theory; recent trends in New Zealand; and views and opinions from a diverse range of experts.

The research outcome is a set of interconnected and interdependent principles that serve to inform and lead the development of a national climate change communications and engagement strategy. 


\section{Acknowledgements}

Many thanks go to: Professor Vijay Naidu, Dr Sean Weaver, Dr Lance Beath, Nancy Linton, Jason Matangi, Dairne Poole, Associate Professor John McClure, Dr Charlotte Severne, Andy Linton, Dr Geoff Bertram, Peter Salmon, Melissa Waters, Shane Munn and Sandy Callister.

While I owe much to all these people, any errors or omissions in this research project are my own. 


\section{Author's Note}

"I don't believe that conceiving of the idea and marketing it are different... Every day you're modifying the idea. You're seeing new opportunities. You're seeing new nuances of problems. It's a continuous process. But it's hard to talk about it that way because of the way our language is constructed. Because people think about having an idea and implementing it." ${ }^{1}$

The course outline for this research project offers a flexible format: "A student may submit... GIS computer programs, short video productions, innovative intervention methodologies and so forth... A student should show initiative, optimise their expertise and make the most of University resources. Above all students are expected to become actively engaged in the process and take responsibility for their own project." ${ }^{2}$ I state this because the intent of this project is to deliberately merge research with advocacy. I see this intent as complementary to the Development Studies programme where attitude and action learning are integral means of tackling difficult problems without certain answers to achieve practical outcomes.

The approach employed for this project is based in the discipline of strategic thinking. Strategic thinking attempts to address the algorithmic and disconnected nature of problem solving by harnessing dynamic factors at play and designing solutions that are compelling to the context. There are no 'correct' courses of action that will automatically result in successful outcomes but many potential options for action whose success is dependent on the manner in which they are pursued and implemented. Strategic thinking is an active process of engaging with reality that emphasises human intent, choice and drive as critical components of the process. In this way, the strategist cannot be removed from the process of change; they are agents in the process and a catalyst for determining action and outcomes.

The challenge of developing solutions to realise the Government's climate change communication and engagement objectives is real and urgent. Given that the outcome of a successful strategy is accomplishment through action, it would be disingenuous to divorce the research process in this project from part of an overall personal intent to influence action and drive effective change.

Alex Hannant, April 2007

\footnotetext{
${ }^{1}$ Bill Drayton quoted in David Bornstein, "How to Change the World: Social Entrepreneurs and the Power of New Ideas", Oxford University Press, 2004, p. 119

${ }^{2}$ School of Geography, Environment and Earth Studies, "Development Studies Prospectus 2006", Victoria University of Wellington, 2006, p. 10
} 


\section{Contents}

Chapter 1 - Introduction, aim and objectives

$\begin{array}{ll}1.1 \text { Climate change } & 11\end{array}$

1.2 Development context 13

1.2.1 Temperature rise 13

1.2.2 Ice melt 13

1.2.3 Extreme events 14

1.2.4 Acidification of the oceans 14

1.2 .5 Indirect impacts $\quad 14$

$\begin{array}{ll}1.2 .6 \text { Self-interest } & 15\end{array}$

1.3 Where are we in New Zealand? 16

$\begin{array}{ll}1.4 \text { Purpose of research } & 17\end{array}$

$\begin{array}{ll}1.5 \text { Research Aim } & 17\end{array}$

$\begin{array}{ll}1.6 \text { Research Objectives } & 18\end{array}$

$\begin{array}{ll}\text { Chapter } 2 \text { - Background, approach and design } & 19\end{array}$

2.1 Background and personal motivation 19

$\begin{array}{ll}2.2 \text { Conceptual framework and approach } & 19\end{array}$

$\begin{array}{ll}2.3 \text { Research design } & 20\end{array}$

2.3.1 The strategy process $\quad 20$

2.3.2 Strategic thinking $\quad 20$

2.3.3 Model for thinking $\quad 21$

2.3.3.1 Intent 22

2.3.3.2 Engagement 22

2.4.3.3 Insight $\quad 23$

2.4.3.4 Evidence 23

2.4 Research scope $\quad 24$

2.5 Research and development methods 25

2.5.1 Research objective $1 \quad 25$

2.5.2 Research objective $2 \quad 25$

2.5.3 Research objective $3 \quad 26$

2.5.4 Research objective $4 \quad 26$

2.5.5 Research objective $5 \quad 27$

2.6 Definitions and assumptions $\quad 27$

2.7 Obstacles and limitations 28 
$\begin{array}{ll}3.1 \text { Scope } & 29\end{array}$

3.2 The 'perfect problem' 29

$\begin{array}{ll}3.3 \text { Short-term thinking } & 30\end{array}$

3.4 Complexity and the scientific discourse 31

3.5 Information and disinformation $\quad 32$

3.6 How we understand what we don't know 33

3.7 Climate change as 'weather' 34

3.8 A necessary evil 35

3.9 Small actions and good intentions 36

$\begin{array}{ll}3.10 \text { Technology will save us } & 37\end{array}$

3.11 Appealing to the greater good 38

$\begin{array}{ll}3.12 \text { Meaningful choices } & 39\end{array}$

3.13 Conflicting incentives $\quad 40$

3.14 Collective responsibility 41

3.15 Summary 42

Chapter 4 - Communications and behaviour change best practice and theory 44

4.1 Scope 44

4.2 Awareness, attitudes and behaviour 44

4.3 Engage - getting people involved $\quad 47$

$\begin{array}{ll}\text { 4.3.1 Information and communication } & 47\end{array}$

4.3.2 Relevance $\quad 48$

4.3.3 Message framing $\quad 49$

4.3.4 Credibility 51

4.3.5 Consensus $\quad 52$

4.3.6 Consequences $\quad 53$

4.3.7 Scenarios $\quad 54$

4.3.8 Storytelling $\quad 54$

4.3.9 Coordination and penetration $\quad 56$

4.3.10 Networks $\quad 56$

4.3.11 Dialogue and participation $\quad 58$

4.4 Enable - creating opportunities for action $\quad 59$

4.4.1 Participatory problem-solving and co-production $\quad 59$

$\begin{array}{ll}4.4 .2 \text { Resourcing 'co-produced' programmes } & 60\end{array}$

4.4.3 Linking action through technology $\quad 62$

4.4.4 Individual carbon trading schemes 63

4.5 Encourage - motivating behaviour 64 
4.5.1 Carrots and sticks

4.5.2 Prompts $\quad 65$

4.5.3 Specific actions 66

4.5.4 Low hanging fruit and acknowledgement $\quad 67$

4.5.5 Commitments 67

$\begin{array}{ll}\text { 4.5.6 Competition } & 67\end{array}$

4.6 Exemplify - leading and sustaining change 68

4.6.1 State leadership $\quad 68$

$\begin{array}{ll}\text { 4.6.2 Individual leadership } & 69\end{array}$

$\begin{array}{ll}4.7 \text { Summary } & 70\end{array}$

Chapter 5 - Research surveys: public attitudes and behaviours relevant to 72 climate change

$\begin{array}{ll}5.1 \text { Scope } & 72\end{array}$

5.2 What do New Zealanders think about climate change? 72

5.3 Perceptions about climate change and communication preferences amongst 18-35 73 year-olds

$\begin{array}{ll}5.4 \text { The effect of framing } & 74\end{array}$

5.5 What does business think?

5.6 What do New Zealanders value?

5.7 'Solution Seekers'

$\begin{array}{ll}5.8 \text { Trends in the UK } & 77\end{array}$

5.9 Summary $\quad 78$

Chapter 6 - Interview highlights $\quad \mathbf{8 0}$

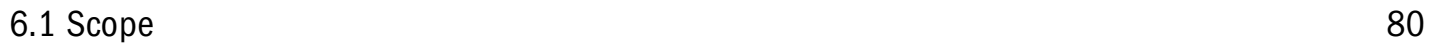

$\begin{array}{ll}6.2 \text { Interview participants } & 80\end{array}$

$\begin{array}{ll}6.3 \text { Leading themes } & 80\end{array}$

6.3.1 Thoughts on how the objectives might be achieved 80

6.3.2 Messages, vision and values $\quad 83$

6.3.3 Obstacles to engagement $\quad 85$

6.3.4 The role of leadership $\quad 86$

$\begin{array}{ll}6.3 .5 \text { Institutional structures } & 88\end{array}$

6.3.6 Community initiatives $\quad 89$

6.3.7 Insights from other areas $\quad 90$

6.3.8 What we need to know more about 91

6.3.9 Other thoughts 92

$\begin{array}{ll}6.4 \text { Summary } & 93\end{array}$ 
7.2 Introduction $\quad 94$

7.2.1 Specific targets, objectives and actions 96

$\begin{array}{ll}\text { 7.2.2 Research and learning } & 98\end{array}$

$\begin{array}{ll}7.2 .3 \text { Build a vision } & 100\end{array}$

7.2.4 Dedication, coordination and autonomy 101

$\begin{array}{ll}\text { 7.2.5 Establish a culture } & 102\end{array}$

7.2.6 Sector support 103

7.2.7 Develop brand and a resource centre 105

$\begin{array}{ll}\text { 7.2.8 Recruit champions } & 107\end{array}$

7.2.9 Co-produce and invest in innovation 109

$\begin{array}{ll}\text { 7.2.10 Align policy with intention } & 111\end{array}$

$\begin{array}{ll}\text { Chapter } 8 \text { - Conclusion } & 112\end{array}$

8.1 Scope 112

8.2 Research process 112

$\begin{array}{ll}8.3 \text { Research output } & 113\end{array}$

$\begin{array}{ll}8.4 \text { Research project } & 114\end{array}$

$\begin{array}{ll}8.5 \text { Final comments } & 115\end{array}$

$\begin{array}{ll}\text { References } & 116\end{array}$

$\begin{array}{ll}\text { R.1 Bibliography } & 116\end{array}$

R.2 Speeches, presentations and multimedia 122

$\begin{array}{ll}\text { R.3 Web resources } & 123\end{array}$

$\begin{array}{ll}\text { R.4 Websites } & 124\end{array}$

\section{Appendix 1 - Sleeping Giants}

$\begin{array}{ll}\text { A1.1 Information sheet } & 125\end{array}$

$\begin{array}{ll}\text { Appendix } 2 \text { - Interview process } & 126\end{array}$

$\begin{array}{ll}\text { A2.1 Ethics approval } & 126\end{array}$

$\begin{array}{ll}\text { A2.2 Contact } & 126\end{array}$

$\begin{array}{ll}\text { A2.3 Intenview schedule } & 126\end{array}$

$\begin{array}{ll}\text { A2.4 Structure } & 127\end{array}$

$\begin{array}{ll}\text { A2.5 Consent } & 127\end{array}$

$\begin{array}{ll}\text { A2.6 Sample interview questions } & 127\end{array}$

$\begin{array}{ll}\text { A2.7 Data collection and analysis } & 128\end{array}$

$\begin{array}{ll}\text { A2.8 Proof of ethics approval } & 129\end{array}$ 
Appendix 3 - Making change - Taking the initiative on climate change

\section{Tables}

Table 2.1 Research objective 1

Table 2.2 Research objective $2 \quad 25$

Table 2.3 Research objective $3 \quad 26$

Table 2.4 Research objective $4 \quad 26$

Table 2.5 Research objective $5 \quad 27$

Table 4.1 Sample responses of settlers, prospectors and pioneers to climate change 51

Table 4.2 An exploratory framework for a sustainable lifestyle 66

\section{Figures}

Figure 2.1 Model for strategic thinking $\quad 22$

Figure 2.2 The strategy process $\quad 24$

Figure 3.1 Mismatch between natural short-term focus and focus required for climate 31 change

Figure 4.1 Stern's Attitude-Behaviour-Context Model $\quad 45$

Figure 4.2 Evidence-based model of behaviour change 47

Figure 7.1 Leading Principles for the New Zealand Government's climate change 95 communications and engagement strategy 
"For all stabilization strategies, the biggest problem does not seem to be the technologies or the costs, but overcoming the many political, social and behavioural barriers to implementing mitigation options." ${ }^{3}$

${ }^{3}$ Bert Metz and Detlef van Vuuren, "How, and at What Costs, can Low-Level Stabilization be Achieved? - An Overview", in Hans Joachim Schellnhuber et al (eds.), Avoiding Dangerous Climate Change, Cambridge University Press, 2006, p. 344 


\section{Chapter 1}

\section{Introduction, aim and objectives}

In 'Climate Change Solutions: Whole of Government Climate Change Work Programmes', the New Zealand government states, "[a] number of short-term issues have the potential to impact on the buy-in to messages about the long-term picture. The Kyoto Net Position, government review of climate change policies, discontinuation of the proposed Carbon Tax and disagreement with forestry owners over carbon credits have recently distracted New Zealand from addressing the most serious long-term environmental issue the country has ever faced." " The suggestion that New Zealand's inertia in responding to climate change is a result of specific issues needs to be explored. Could it be that these politicised issues are symptoms of a more systemic problem? Or if indeed policies designed to mitigate climate change have resulted in paralysing public opinion, why has this happened and how can this bottleneck be resolved?

The self-evident fact that information alone is unable to change attitudes and motivate action on climate change suggests that effective communication is critical to stimulating the required response. The practice of strategic thinking demands looking beyond the first evidence of a problem and the conventional ways of tackling it. When a challenge such as climate change demands substantial, revolutionary and long-term change, this intent provides the basis for creating a coherent and effective way forward. Given that climate change requires immediate individual and collective attention, this research project will employ a strategic thinking approach (as defined in Chapter 2) to contribute to the development of effective climate change communications and engagement in New Zealand.

\subsection{Climate change}

The greenhouse effect keeps the planet approximately $30^{\circ} \mathrm{C}$ warmer than it would be otherwise. ${ }^{5}$ The phenomenon of global warming provides the basis for human civilisation and life as we know it. This has been understood for over a hundred years. ${ }^{6}$ Simply defined, carbon dioxide and other constituent greenhouse gases (GHGs) allow heat from the sun into the atmosphere then trap it like a blanket. While the greenhouse effect is natural, human civilisation (primarily developed nations) has greatly increased its intensity. Rapid industrialisation has not only increased the concentration of GHGs in the atmosphere, it has also reduced the planet's capacity to absorb GHGs through land-use

\footnotetext{
${ }^{4}$ New Zealand Government, "Climate Change Solutions: Whole of Government Climate Change Work Programmes', June 2006, p. 97, accessed at http://www.climatechange.govt.nz/resources/reports/index.html on 4th September 2006

5 “Joint science academies' statement: Global response to climate change", 2005 accessed at http:// www.royalsoc.ac.uk/document.asp?latest $=1 \& i d=3222$ on $21^{\text {st }}$ September 2006

${ }^{6}$ Ian Axford, "Climate change: reflections on the science", in Jonathan Boston et al. (eds.), Confronting Climate Change, Victoria University Press, Wellington, 2006, p. 61-64
} 
and deforestation. The problem is complex but the basic equation is simple - the more GHGs in the atmosphere, the more heat is trapped. An increased mean global temperature impacts on our planet in a variety of interrelated ways and results in what is commonly referred to as climate change.

The level of GHGs emitted into the atmosphere has risen dramatically since 1750 and is now higher than at any other time in the past 650,000 years. ${ }^{7}$ The global mean temperature has risen by $0.7^{\circ} \mathrm{C}$ since $1900 .{ }^{8}$ Of the 928 papers referring to 'global climate change' published in science journals between 1993 and 2003, not one of them disagreed with the consensus position that the anthropogenic emission of carbon dioxide is leading to global warming. ${ }^{9}$ Uncertainty regarding climate change now only concerns the effects and impacts - what, when and how much?

Evidence of climate change is becoming increasingly conspicuous. The ten hottest years on record have occurred in the last fourteen years. In the winter of 2005, a record proportion of the Arctic Ocean didn't freeze. The number of category four and five hurricanes has doubled in the last 30 years, and 279 species of plants and animals have been found to be migrating towards the poles to retain environmental conditions suitable for their sustained survival. ${ }^{10}$ Although it is difficult to attribute costs directly to climate change, they are becoming too significant to ignore: the European heat wave in 2003 resulted in at least 35,000 additional deaths. ${ }^{11}$ The impact of the 2004 Atlantic hurricane season was unprecedented; the estimated fallout of Hurricane Katrina alone was US $\$ 156$ billion. ${ }^{12}$ According to one insurance company, extreme weather conditions have quintupled since 1950. ${ }^{13}$ Widespread droughts in Africa, the sub-continent, South America and Australia are resulting in mounting social, environmental and economic costs. In 2004, flood damage in New Zealand resulted in costs estimated to be $\$ 100$ million. ${ }^{14}$

Climate change brings other complications. There are predicted lags in the climate system that means significant delays between the cause and effect of our actions. ${ }^{15}$ Measurements are also subject to temporal and spatial variability. Positive feedbacks in the climate system mean that some of the effects of climate change will accelerate and intensify the process, for example permafrost melted by warming results in methane release from old bio-matter and increases the concentration of GHGs in the atmosphere. Ultimately, there may be tipping points in the climate system (what

\footnotetext{
${ }^{7}$ Urs Siegenthaler et al. "Stable carbon cycle-climate relationship during the late Pleistocene”, Science 310, 2005, p. 1313-1317

${ }^{8}$ Stern Review on the Economics of Climate Change, "What is the Economics of Climate Change", HM Treasury, London, $31^{\text {st }}$ January 2006 , p. 7

${ }^{9}$ Naomi Oreskes, "The Scientific Consensus on Climate Change", Science, Vol. 306, $3{ }^{\text {rd }}$ December 2004 , p. 1686.

${ }^{10}$ Al Gore, An Inconvenient Truth, Rodale, New York

${ }^{11}$ Shaoni Bhattacharya, "European Heatwave Caused 35,000 Deaths", NewScientist.com news service, $10^{\text {th }}$ October 2003

${ }^{12}$ Mark L. Burton, Michael J. Hicks, "Hurricane Katrina: Preliminary Estimates of Commercial and Public Sector Damages."

Marshall University: Center for Business and Economic Research. September, 2005, p. 8

${ }^{13}$ George Monbiot, Heat, Allen Lane, Victoria, 2006, p. 9

${ }^{14}$ Source: Insurance Council of New Zealand, accessed at

http://www.teara.govt.nz/EarthSeaAndSky/NaturalHazardsAndDisasters/Floods/1/ENZ-Resources/Standard/1/en on 13th December 2006

${ }^{15}$ Intergovernmental Panel on Climate Change (IPCC), "Synthesis Report”, Cambridge University Press, 2001, P 16
} 
scientists term 'non-linearities') where the planet's environment experiences abrupt and potentially irreversible changes. ${ }^{16}$

\subsection{Development context}

In an economically developed and technologically advanced society, it is easy to become distanced from the dependence human society has on services provided by natural systems - often their value does not even make the balance sheet. For the one billion plus people in the world who live in absolute poverty, ${ }^{17}$ the relationship with the natural environment is more immediate and precarious. The irony of climate change is that those least responsible for causing it are likely to be the ones most affected. The Intergovernmental Panel on Climate Change (IPCC) states "the projected distribution of economic impacts is such that it would increase the disparity in well-being between developed countries and developing countries." ${ }^{18}$ The greater the temperature increases, the greater the disparity. Although the effects of climate change are complex, unpredictable and regionally uneven, it is possible to make a number of assumptions about the likely impacts on developing countries.

\subsubsection{Temperature rise}

The IPCC predicts a rise in annual mean surface temperatures of between 1.4 and $5.8^{\circ} \mathrm{C}$ over the period 1990 to $2100 .{ }^{19} \mathrm{~A}$ mid-range temperature rise scenario will have a devastating effect on food security not only in the tropical and sub-tropical regions of the world but also in the mid-latitudes. As the British Foreign Minister stated in October 2006, "[t]emperature rises of just 2-3 degrees will see crop yields in Africa, the Middle East and South Asia fall by as much as 30 to 40 percent." ${ }^{20}$ Higher average temperatures will also stimulate the emergence and re-emergence of pests and diseases, and increase the vectors that carry disease.

\subsubsection{Ice melt}

1.7 billion people currently live in water-stressed countries; ${ }^{21}$ this number is expected to increase to 5 billion by $2025 .^{22}$ Retreating glaciers and snowlines will diminish water supply and exacerbate these stresses. The South Asian sub-continent and South America are both likely to suffer. Sea level

\footnotetext{
${ }^{16}$ Will Steffen, "Sleeping Giants: Surprises in the Climate and Earth System", in Jonathan Boston et al. (eds.), op. cit., 2006, p. 103-116

${ }_{17}$ United Nations, “In Larger Freedom: Towards Development, Security and Human Rights for All", 2005 accessed at http://www.un.org/largerfreedom on 26 October 2006

${ }_{18}^{1 P C C}$, "Impacts, Adaptation and Vulnerability: Summary for Policymakers", Cambridge University Press, 2001, p. 8

${ }^{19}$ IPCC, "The Scientific Basis: Summary for Policymakers", Cambridge University Press, Cambridge, 2001, P 13

${ }^{20}$ Margaret Beckett, "Foreign Policy and Climate Security", speech delivered in Berlin, 24 October 2006

${ }^{21}$ Water stress occurs when the demand for water exceeds the available amount during a certain period or when poor quality restricts its use. Water stress causes deterioration of fresh water resources in terms of quantity and quality (source UNDP).

${ }^{22}$ IPCC, "Impacts, Adaptation and Vulnerability: Summary for Policymakers", op. cit., p. 9
} 
rise is predicted to be between 0.09 and 0.88 metres over the period 1990 to $2100 .^{23}$ Higher sea levels will have catastrophic implications for small Pacific states and low-lying countries such as Bangladesh, who are already challenged by the salination of drinking water and agricultural land.

\subsubsection{Extreme events}

Increased precipitation will lead to more extensive flooding. These impacts will be accentuated in areas where drought has hardened the earth and increased the likelihood of flash floods. Flooding leads to soil erosion, landslides and extensive damage to dwellings and livelihoods. The Asian monsoon is sensitive to small temperature changes and stands to wreak havoc across the subcontinent. In July 2005, Mumbai received 37 inches of rain in 24 hours, the largest downpour recorded in an Indian city. ${ }^{24}$ The increased incidence of heat waves will result in illness and death, especially amongst the old and very young. Increased storm surges will have a significant impact on coastal settlements.

\subsubsection{Acidification of the oceans}

The ocean absorbs carbon dioxide from the atmosphere, forms carbonic acid and reduces the $\mathrm{pH}$ of the water. The oceans have already absorbed fifty percent of the carbon dioxide that we have produced since the industrial revolution. ${ }^{25}$ The lowering of the ocean's $\mathrm{pH}$ has a significant impact on the ability of small marine organisms to form shells. These organisms play a crucial role at the bottom of the marine food chain. Acidification also damages coral. Impacts on marine bio-diversity and the coral reefs have significant implications for the communities who are dependent on already depleted fisheries for their subsistence and livelihood.

\subsubsection{Indirect impacts}

Indirect impacts have further implications for developing countries. In a discussion paper written for the US Defense Department, Peter Schwartz presents a scenario where the effects of climate change and the resultant reduction in the environment's 'carrying capacity' in terms of food, water and energy quickly lead to security issues. It is easy to imagine that if global food supplies are compromised, conflict will quickly occur where peace and economic relations have previously been maintained. ${ }^{26}$

\footnotetext{
${ }^{23}$ IPCC, "The Scientific Basis: Summary for Policymakers", op. cit., P 16

${ }^{24}$ Al Gore, op. cit, p. 110

${ }^{25}$ Carol Turley, "Ocean Acidification and its Impacts", in Will Steffen, "Sleeping Giants: Surprises in the Climate and Earth System", in Jonathan Boston et al. (eds.), op. cit., p. 125-132

${ }_{26}$ Peter Schwartz and Doug Randall, "An Abrupt Climate Change Scenario and Its Implications for United States National Security", October 2003 accessed at http://www.environmentaldefense.org/ documents/3566_AbruptClimateChange.pdf on $17^{\text {th }}$ July 2006
} 
Energy security is also threatened by extreme weather events that undermine the stability of ports and drilling rigs. Glacier retreat and ice cap melt will impact on hydro-electricity and melting permafrost will weaken pipelines. Energy insecurity jeopardises the social and economic services that improve people's capabilities and ameliorate the affects of poverty. The cumulative affect of all these factors will be to undermine the very basis of governance and productivity. With less capital and more desperate circumstances, the fabric of civilisation itself becomes threatened: "When people are exposed to the stresses caused by overpopulation, resource scarcity, environmental degradation, as they feel the security upon which they and their families depend progressively slipping away, so we see the slide down the spectrum from stability to instability." ${ }^{27}$ Consequently, action and support from developed countries on climate change has to be seen in the context of an overall responsibility to promote sustainable development and to fight poverty as expressed in the Millennium Development Goals. ${ }^{28}$

\subsubsection{Self-interest}

Outreach to developing countries is also a matter of self-interest. Beyond concerns of adaptation, developing countries will play a crucial role in mitigating future GHG emissions. The International Energy Agency predicts there will be a 50 percent increase in energy-related carbon dioxide emissions by 2030. Developing countries will account for 75 percent of this increase. ${ }^{29}$ As the Stern Review's discussion paper asserts: "Whilst most of the emissions have come from the small fraction of the global population that is relatively rich, future growth in emissions will be dominated by developing countries." ${ }^{30}$ Land-use and deforestation are also crucial issues. Apart from the oceans, the planet's biggest carbon sinks are tropical rain forests. The largest of these are under the stewardship of developing countries in South America, Central America, Central Africa and South East Asia. While these forests play a vital role in absorbing carbon dioxide they also represent a primary economic resource. Further reduction of the planet's carbon sinks will increase the risk of more drastic climate change.

Another political risk is the likelihood of forced migration. Given that people smuggling is already estimated to be the world's largest illegal industry ${ }^{31}$ and the heightened tension with regard to global security issues, the advent of an escalating number of refugees due to climate change paints a bleak and politically fraught picture.

\footnotetext{
${ }^{27}$ Margaret Beckett, op. cit.

${ }^{28}$ United Nations, "Millennium Declaration" accessed at http://www.un.org/millenniumgoals/ on $13^{\text {th }}$ December 2006

${ }^{29}$ IEA, "World Energy Outlook 2005", accessed at http://www.worldenergyoutlook.org/high.asp on $13^{\text {th }}$ October 2006

${ }^{30}$ Stern Review on the Economics of Climate Change, op. cit., p. 11

${ }^{31}$ BBC News, "Human Smuggling Eclipses Drugs Trade", 20th June 2002 accessed at

http://news.bbc.co.uk/2/hi/2056662.stm on 26th October 2006
} 


\subsection{Where are we in New Zealand?}

Climate change is a tragedy of the commons. Individual countries, sectors and companies capture the benefits of emitting while the costs are dumped on others through atmospheric impacts. To be truly effective, climate change controls and incentives to change behaviour need to be universal. However, this cannot be used as an excuse by governments and individuals to postpone action until such agreements are reached. An effective response to climate change requires leadership. This starts with developed countries, such as New Zealand, getting their own house in order.

A dangerous level of climate change is defined by the European Union (EU) as an increase in the global mean surface temperature of $2^{\circ} \mathrm{C}$ or more above pre-industrial levels. To avoid this, developed countries like New Zealand will be required to stabilise and then cut their current GHG emissions by more than 70 percent by $2050 .^{32}$ Timing is also critical: the longer action is delayed the steeper the reduction track will become and the harder climate change will be to manage. However, like much of the developed world, New Zealand is struggling to come to terms with this realisation.

The Government's stated intention to develop a cohesive and strategic way forward is constrained by a number of factors and not least by the ambivalence found in mainstream attitudes and behaviours. Debate over climate change remains discursive and both individual and collective action falls short of what is required. Implicit and explicit examples of scepticism and misconception are still regularly found in the mainstream media and interest groups politicise the issue as they jockey for position. Policy instruments designed to tackle climate change are largely misunderstood and GHG emissions continue to rise. $^{33}$

Research undertaken by the New Zealand Business Council for Sustainable Development (NZBCSD) has found that the 'middle majority' of New Zealanders have core values focused around lifestyle and the natural environment. ${ }^{34}$ However, while New Zealanders are clear about what they value, they struggle to develop these values into a coherent vision for their future. Although there is support for the principle of 'sustainable development' (when the concept is communicated clearly), commitment to personal action is generally deferred. While issues such as water, energy and waste are easily related to, climate change remains a more difficult and abstract topic. Without understanding and designing ways to bridge these disconnects, it is likely that political noise will continue to occupy and stall the agenda at the expense of a consensual and committed long-term response.

\footnotetext{
32 Jonathan Boston, “Opening Remarks for Symposium on Climate Change: The Policy Challenges”, Institute of Policy Studies, School of Victoria University of Wellington, $6^{\text {th }}$ October 2006

${ }^{33}$ Ministry for the Environment, "National Inventory Report: 1990-2004", April 2006 accessed at

http:// www.climatechange.govt.nz/resources/reports/nir-apr06/html/page4.html on 23rd December 2006

${ }^{34}$ UMR Research, "Summary Report: A Qualitative and Quantitative Study", New Zealand Business Council for Sustainable Development, November 2005
} 


\subsection{Purpose of research}

Individuals underestimate their own power. While one UK research study shows that only 7 percent of respondents felt that individuals could have a 'large influence on climate change, ${ }^{35}$ another indicates that 70 percent of the UK's total energy demand is attributable to household demand for final goods and services. ${ }^{36}$ While this latent power may not have immediate currency, individuals can have a significant influence on climate change through voting, consumption and individual and community action.

The New Zealand Government's target outcome for the 'Climate Change Communications and Engagement Programme' is: 'Well informed and well motivated sectors positively and effectively contributing to the progression of climate change policy and its implementation." ${ }^{37}$ The key objectives are:

1. For the people of New Zealand to:

a. understand that the effects of climate change are here; that there are national and local implications for us all;

b. shift their thinking towards longer-term action (buy-in) on reducing greenhouse gas emissions;

c. begin preparing for the effects of climate change.

2. To place New Zealand climate change policy on the centre stage nationally and internationally in terms of its vision and innovative approach; that is, to show leadership while stressing the importance of acting at all times in New Zealand's interest.

3. To ensure that policy development and decisions are well informed.

Realising the Government's communication and engagement outcomes is a critical part of achieving an effective national response to climate change. The purpose of this research project is to inform thinking about how the Government's communications and engagement objectives can be achieved, and thereby also contribute to New Zealand's commitment to the Millennium Development Goals.

\subsection{Research Aim}

The aim of this research is to contribute to the development of an integrated, effective and evidencebased communications and engagement strategy for climate change in New Zealand. The central research question is: 'What leading principles should drive the development of the New Zealand government's climate change communications and engagement strategy?'

\footnotetext{
${ }^{35}$ Department of Environment, Food and Rural Affairs (DEFRA), "Top line Summary Attitudes to Climate Change - Wave 13", Centre of Information, UK, March 2005-2006

${ }^{36}$ Tim Jackson, "Details of the Sciencetific Programme of the ERSC Research Group on Lifestyle, Values and Energy Consumption (RESOLVE)", accessed at http://www.surrey.ac.uk/resolve/ on $14^{\text {th }}$ January 2006

${ }^{37}$ New Zealand Government, op. cit., p. 97
} 


\subsection{Research Objectives}

Responding to the following questions will constitute the objectives of this research project:

1. According to the literature in this field, why is there inertia in attitudes and behaviours towards climate change?

2. How can theory and best practice concerning attitude and behaviour change inform thinking about the Government's climate change communications and engagement objectives?

3. What do recent research surveys tell us about public attitudes and behaviours with regard to climate change in New Zealand?

4. What insight can practitioners in related areas provide, with regard to the New Zealand Government's climate change communications and engagement objectives?

5. What leading principles should drive the development of the New Zealand Government's climate change communications and engagement strategy? 


\section{Chapter 2}

\section{Background, approach and design}

\subsection{Background and personal motivation}

This research project began with the development of a communications resource about climate change. In March 2006, Victoria University hosted 'Climate Change and Governance', an international conference at the Museum of New Zealand Te Papa Tongarewa. The conference explored the potential impacts of climate change and the options for accelerated action by governments, business and the wider community. Working with a small design and production company, Airplane Studios, ${ }^{38}$ we took this opportunity to co-ordinate a series of interviews with conference speakers and produce a DVD resource - 'Sleeping Giants: Climate Change Science, Policy and Action' (see Appendix 1). The project was run on a not-for-profit basis in order to maximise outreach and distribution opportunities. In partnership with a network of organisations, including Victoria University, we distributed 4,500 DVDs across government agencies, businesses, community groups and education institutions. Reflecting on what 'Sleeping Giants' did and didn't achieve were the principle stimuli for conducting this investigation.

\subsection{Conceptual framework and approach}

Epistemology can be defined as the nature of the relationship between the researcher and what can be known. ${ }^{39}$ This relationship determines the way in which research is carried out and what outcomes are sought. This research enquiry emerges from a hybrid position. The basic premise, that climate change is real and measurable is based on scientific inquiry. However, the proposition that climate change can and needs to be communicated in particular ways to stimulate attitudes and action, recognises that information is interpreted subjectively. In this sense my epistemology is best described as 'critical realism', a position that, very briefly summarised, "maintains that there exists an objectively knowable, mind-independent reality, whilst acknowledging the roles of perception and cognition. ${ }^{40}$ As this investigation implicitly aims to promote new social norms and behaviours with regard to how humans relate to the natural world, my position can further be defined as 'critical naturalism,. ${ }^{41}$ Critical naturalism "seeks to identify the mechanisms producing social events" and perceives that "human agency is made possible by social structures that themselves require the

\footnotetext{
${ }^{38}$ http://www.airplane.co.nz

39 Egon G. Guba and Yvonna S. Lincoln, "Competing paradigms in Qualitative Research", Handbook of Qualitative Research, Sage Publications, 1994, p. 108

40 "Critical Realism" accessed at http://en.wikipedia.org/wiki/Critical_realism on 6th November 2006

${ }^{41}$ Roy Bhaskar, The Possibility of Naturalism, ( $3^{\text {rd }}$ Edition), Routledge, London, 1998
} 
reproduction of certain actions/pre-conditions." ${ }^{42}$ My understanding of this is that through reflection and intelligent action we are capable of changing the structures that determine the way we behave; individuals can influence structures as much as structures inevitably influence individuals.

\subsection{Research design}

\subsubsection{The strategy process}

Strategy is a way of informing intent and turning that intent into action. It is a process of review, determining future outcomes and constructing a way of achieving them. Strategy is a craft of asking questions and making decisions. The questions at the heart of the strategy process are:

- what is the issue?

- where are we now and where are we going?

- where do we want to get to?

- how do we get there?

- who do we have to involve - and how?

- what tools and techniques should we use? ${ }^{43}$

Successful strategies rely on a combination of methods and skills, some of which are contrary. Strategy demands vision and values, yet also detached analytical reasoning. Good strategy demands creativity but also rigour. As a result, sound strategy development has different phases, the first of which is strategic thinking.

\subsubsection{Strategic thinking}

When faced with uncertainty it is natural to rely on what seems most certain. Consequently, traditional approaches to strategy development often conform to quasi-scientific extrapolations or deductions of 'facts' at the expense of creativity. ${ }^{44}$ This 'form filling' ${ }^{45}$ approach to strategy contrives to be mechanical, hierarchical and incremental. It tends to allow future thinking to be dominated by 'business as usual' scenarios and limits opportunities for transformational change. However, many recent approaches to strategy development make a deliberate attempt to disrupt the "business as usual' and scientific mindsets from the outset. This divergent and potentially heretical approach has commonly been called 'strategic thinking'. While 'strategic thinking' is not a formal school of thought, leading theorists agree that it is not simply thinking about strategy - it is a certain way of thinking. ${ }^{46}$

\footnotetext{
42 “Critical Realism” accessed at http://en.wikipedia.org/wiki/Critical realism on 6th November 2006

${ }^{43}$ Prime Minister's Strategy Unit, "Strategy Survival Guide”, UK Cabinet Office, July 2004, p. 8

${ }^{44}$ Jeanne Liedtka, "Strategy as design", in Rotman Management, Winter 2004, p. 15

${ }^{45}$ C.K. Prahalad and Gary Hamel, Competing for the Future, Harvard School Press, Boston, 1994

${ }^{46}$ Jeanne Liedtka, “Strategic Thinking: Can it be Taught?", Long Range Planning, Vol. 31, 1998, p. 120-129
} 
Strategic thinking can be understood as the imagination of evidence; it is an abductive process. It develops a synthesised understanding of causes, trends, opportunities and threats and marries it with a creative anticipation of what might be possible. Rather than work within parameters set by precedent and convention it represents the deliberate intent to question, disrupt and invent new ways to achieve objectives. In this respect, strategic thinking can be compared to design, "the ability to reach into the mystery of some seemingly intractable problem... and apply the creativity, innovation and mastery necessary to convert the mystery to a heuristic - a way of knowing and understanding." ${ }^{47}$ Design is a way of engaging: "[D]esign, stripped to its essence, can be defined as the [aspect of] human nature to shape and make our environment in ways without precedent in nature, to serve our needs and give meaning to our lives." ${ }^{48}$ Design is an integration of evidence, insight, engagement and intent. At its best, strategic or design thinking is a workshop where ideas and opportunities are prototyped, tested and refined. Freedom to respond to the task in hand in unconventional and experimental ways cannot be separated from the ability to develop creative and innovative solutions. In this respect, this research inquiry defines strategic thinking as the active and deliberate pursuit of creating informed solutions that fulfil specific objectives and resonate with the end-user.

\subsubsection{Model for thinking}

The strategic thinking model proposed in Figure 3.1 draws strongly on the literature in this area, specifically 'The Strategy Survival Guide', published by the Prime Minister's Strategy Unit (UK), and Jeanne Liedtka's succinct five-element model. ${ }^{49}$ The elements interact with each other in an iterative and progressive way. They work in unity to clarify, question and provide insight into the information, context and objectives at hand.

\footnotetext{
${ }^{47}$ Dean Roger Martin, “The Design of Business”, in Rotman Management, Winter 2004, p. 9

${ }^{48}$ John Heskett, Toothpicks and Logos: Design in Everyday Life, Oxford University Press, 2002, p. 1

${ }^{49}$ Jeanne Liedtka, "Strategy as design”, op. cit., p. 12-15 and “Strategic Thinking: Can it be Taught?", op. cit., p. 120-129
} 


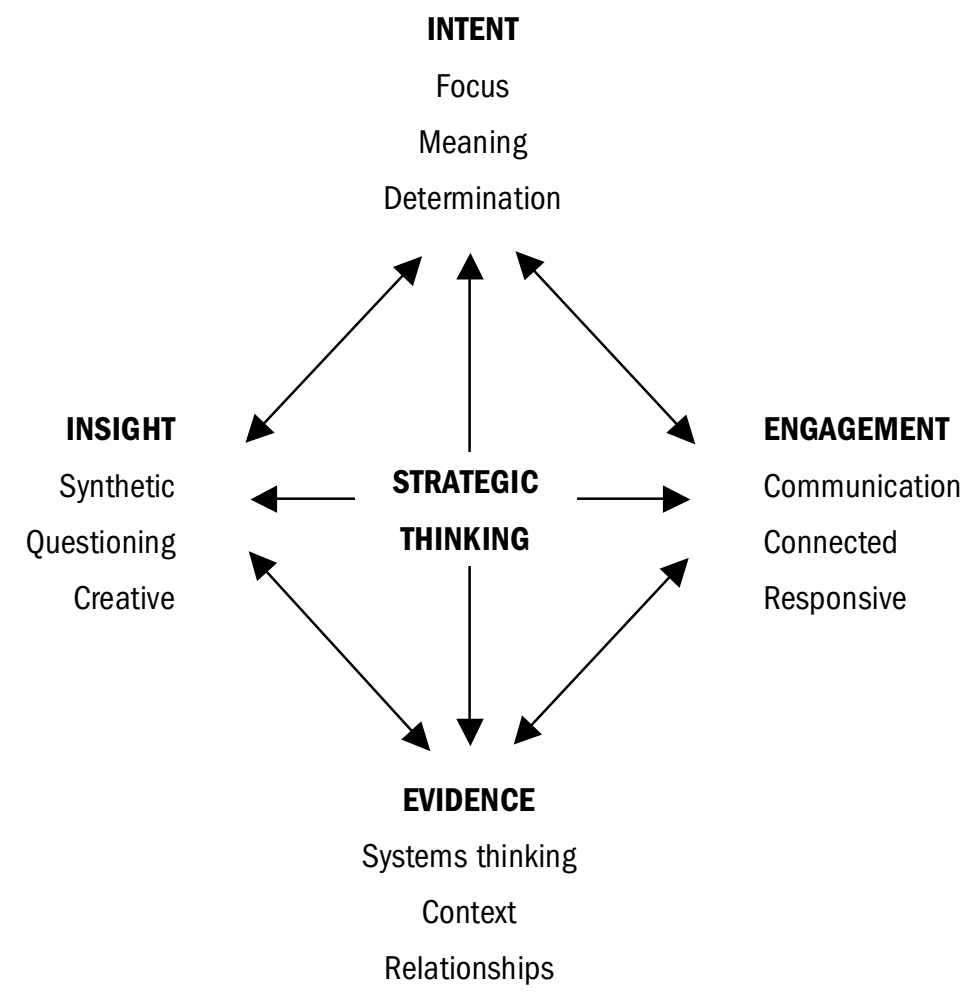

Figure 2.1 Model for strategic thinking

\subsubsection{Intent}

Intent is about vision, an ambitious focus of discipline and clarity. Intent gives clarification and simplicity to a strategy because it eliminates the inconsistencies that would offer all things to all people. By being committed to tangible change, intent stops elements of a strategy being contradictory and engages thinking with the true 'stretch' required to fulfil the stated vision. Intent also transforms a strategy into an emotional journey rather than intellectual exercise; it offers a sense of direction, discovery and destiny. ${ }^{50}$ Quite simply, intent is critical because it provides meaning.

\subsubsection{Engagement}

Principally, engagement is significant for three reasons: development, credibility and cohesion. The first matter relates to engagement being critical to the development process. Designs are prototypes that need to be tested and evolved. Engagement is a critical means of testing assumptions and generating new insights. The extent to which interaction should influence key elements of design is a moot point. Too little engagement and the designer shuts off the opportunity of valuable input and risks alienating the end-user. Too much engagement and the design process risks being railroaded by mediocrity. The happy medium is a matter of skill, judgement and context. A sound reference

${ }^{50}$ C.K. Prahalad and Gary Hamel, op. cit. 
point comes from the architectural firm, Duany Plater-Zyberk: "Control boundaries but not the conversation." ${ }^{51}$

Credibility is an issue because strategy is designed not discovered. It is based on values and therefore relies on persuasion to generate participation: "Strategic choices can never be proven to be 'right', they remain always contestable and must be made compelling to others in order to be realised. ${ }^{52}$ The way in which a strategy communicates is critical to the way it operates. As with design, emotional attachment combined with functionality is a primary criterion for success: "Good designs succeed by persuading, and great designs by inspiring." ${ }^{53}$

Engagement is also an essential element of execution. A military adage counsels that all plans go awry upon engagement - a strategy that relies on top-down directions for cohesion is flawed. A successful strategy is directed by a shared vision and motivated by ownership and opportunity. "Implementing practices, executing strategy and accomplishing organizational change all require the coordinated actions of many people, whose commitment to an idea is greatest when they feel ownership. ${ }^{54}$ Engagement is the means of sharing the vision and providing ownership.

\subsubsection{Insight}

Insight is the means of reconciling the current reality with the future intent. In this sense, it is necessarily a dialectic process - what has to change, what can realistically work, what are the trade offs? The tension between the objectives and constraints provides a creative opportunity. Solutions are conceived through an iterative process of hypothesis generation and testing - 'what if...?', 'If..., then...' Insight is creative and critical, spontaneous and reflective; it is the means of fusing imagination with reality.

\subsubsection{Evidence}

Evidence-based practice has been defined as: "The conscientious, explicit and judicious use of the best current evidence in making decisions." ${ }^{55}$ While one might assume this would be a standard approach, ideological and experiential factors often influence critical decisions. For strategic thinking, which is primarily both a matter of choice and the achievement of specific outcomes, it is appropriate that in the first instance the best evidence be gathered and considered. Gathering evidence is based on a systems-thinking perspective and attempts to consider the whole picture, end to end, as well as the relationships and interdependencies therein: "Systems thinking is a discipline for seeing wholes. It is a framework for seeing inter-relationships rather than things, for

\footnotetext{
51 Jeanne Liedtka and Henry Mintzberg, “Time for Design”, Design Management Journal, Spring 2006

52 Jeanne Liedtka, "Strategy as design", in Rotman Management, op. cit., p. 14

${ }^{53} \mathrm{Ibid}$, p. 15

${ }^{54}$ Jeffrey Pfeffer and Robert I. Sutton, “Evidence-Based Management”, Harvard Business Review, Vol. 84 issue 1, January 2006, p. 71

${ }_{55}$ David Sackett quoted in Jeffrey Pfeffer and Robert I. Sutton, op. cit. p. 63
} 
seeing patterns of change rather than static snapshots." ${ }^{56}$ By taking into account the relationships between trends, theories and events, one becomes conscious of not only cause and effect but also feedback and delay. This encourages consideration of interactions over time and focuses attention on long-term impacts.

\subsection{Research scope}

Strategic thinking is the divergent and creative phase that informs intent, develops possible solutions and establishes the guiding principles for the subsequent phase of strategic planning. Strategic planning is an analytical and convergent phase that appraises options and feasibility to set specific courses of action. Guiding principles are critical in strategic planning because they provide structure and coherence when making trade-offs and choosing between alternative options. Strategic thinking and strategic planning are complementary and interdependent activities. In practice, the strategy process may demand an iterative but progressive shuttling between these two phases of divergence and alignment. ${ }^{57}$ Due to being outside the actual Government strategy process, this research project focuses on, and is limited to, the strategic thinking phase. The research scope is demarked within the context of the whole strategy process in Figure 2.2.

\section{Stage}

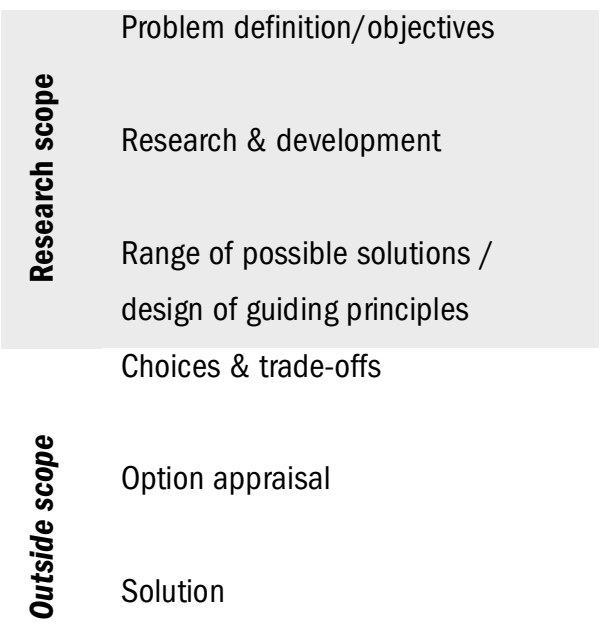

Figure 2.2 The strategy process ${ }^{58}$
Strategy process

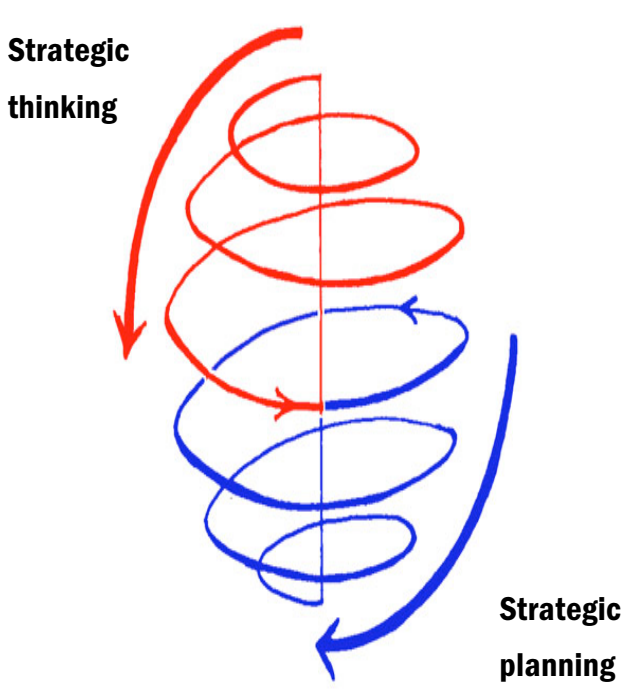

Chapter

reference

1,3

$4,5,6$

7

$\mathrm{n} / \mathrm{a}$

$\mathrm{n} / \mathrm{a}$

n/a

\footnotetext{
${ }^{56}$ Peter Senge, The Fifth Discipline, Random House, Sydney, 1990, p. 68

${ }^{57}$ Jeanne Liedtka, “Linking Strategic Thinking with Strategic Planning”, Strategy and Leadership, October 1998, p. 120-129

${ }^{58}$ Adapted from 'Strategic Solution Generation', Prime Minister's Strategy Unit, op. cit., p. 8
} 


\subsection{Research and development methods}

2.5.1 Research objective 1: According to the literature in this field, why is there inertia in attitudes and behaviours towards climate change?

\begin{tabular}{|c|c|}
\hline Purpose & $\begin{array}{l}\text { To better define the problem and clarify why there is inertia in attitudes and } \\
\text { behaviours towards climate change. }\end{array}$ \\
\hline Procedure & $\begin{array}{l}\text { Conduct a literature review of relevant sources identified by: } \\
\text { - searching library databases. } \\
\text { - reviewing the websites of relevant organisations. } \\
\text { - using mainstream internet search engines. } \\
\text { - identifying leading commentators and practitioners by cross referencing } \\
\text { citations. } \\
\text { - receiving input from individuals actively involved in communicating } \\
\text { climate change. }\end{array}$ \\
\hline Sample set & $\begin{array}{l}\text { Relevant sources from management studies, communications, marketing, } \\
\text { social marketing, development studies, environmental studies, social } \\
\text { psychology and strategic policy development. }\end{array}$ \\
\hline $\begin{array}{l}\text { Presentation of } \\
\text { results }\end{array}$ & $\begin{array}{l}\text { A literature review of key themes covering the structural, narrative and } \\
\text { psychological barriers to engaging with climate change. }\end{array}$ \\
\hline
\end{tabular}

Table 2.1 Research objective 1

\subsubsection{Research objective 2: How can theory and best practice concerning} communications and behaviour change inform thinking about the Government's climate change communications and engagement objectives?

\begin{tabular}{|l|l|}
\hline Purpose & $\begin{array}{l}\text { To develop an evidence base of relevant theory and best practice relating to } \\
\text { climate change communications and engagement. To help identify the } \\
\text { leading principles that should drive the New Zealand Government's } \\
\text { communication and engagement strategy. }\end{array}$ \\
\hline Procedure & $\begin{array}{l}\text { Follow-up on sources: } \\
- \text { developed in the literature review } \\
- \text { from interview participants and other individuals working in areas related } \\
\text { to climate change and sustainable development } \\
- \text { uncovered in broader activities and reading. } \\
\text { Relevant sources from management studies, communications, marketing, } \\
\text { social marketing, development studies, environmental studies, social }\end{array}$ \\
\hline Sample set &
\end{tabular}




\begin{tabular}{|l|l|}
\hline $\begin{array}{l}\text { Presentation } \\
\text { results }\end{array}$ & of \\
& $\begin{array}{l}\text { A distillation of key points presented through themes that are inclusive of } \\
\text { the Government's communication and engagement objectives i.e. raising } \\
\text { awareness, influencing attitudes, changing behaviour, demonstrating } \\
\text { leadership and linkages to policy. }\end{array}$ \\
\hline
\end{tabular}

Table 2.2 Research objective 2

2.5.3 Research objective 3: What do recent research surveys tell us about public attitudes and behaviours with regard to climate change in New Zealand?

\begin{tabular}{|l|l|}
\hline Purpose & $\begin{array}{l}\text { To develop an understanding of where the New Zealand public 'is' on } \\
\text { climate change. To provide a basis for exploring the gap between the } \\
\text { present situation and the Government's objectives. }\end{array}$ \\
\hline Procedure & $\begin{array}{l}\text { Contact with major research firms, government agencies and academic } \\
\text { colleagues as to the scope and availability of relevant data. }\end{array}$ \\
\hline Sample set & $\begin{array}{l}\text { Surveys undertaken in the last two years that relate to climate change, } \\
\text { sustainable consumption and social values. Possibly include research } \\
\text { specifically relating to attitudes towards climate change from other } \\
\text { countries for comparison. }\end{array}$ \\
\hline $\begin{array}{l}\text { Presentation } \\
\text { results }\end{array}$ & $\begin{array}{l}\text { List of research studies explored. Summarise significant data from each } \\
\text { study. }\end{array}$ \\
\hline
\end{tabular}

Table 2.3 Research objective 3

2.5.4 Research objective 4: What insight can practitioners in related areas provide, with regard to the New Zealand Government's climate change communications and engagement objectives?

\begin{tabular}{|l|l|}
\hline Purpose & $\begin{array}{l}\text { To explore and create new insights into the Government's objectives by } \\
\text { engaging with a diverse range of individuals with relevant but diverse } \\
\text { backgrounds. To test ideas and assumptions. }\end{array}$ \\
\hline Procedure & $\begin{array}{l}\text { Nine semi-structured interviews (see Appendix 2). Interviews are designed } \\
\text { to allow a free flow of conversation driven by the participants' opinion, } \\
\text { experience and expertise as they relate to the Government's climate change } \\
\text { communications and engagement objectives. }\end{array}$ \\
\hline Sample set & $\begin{array}{l}\text { All interviews will be based in Wellington. Interviewees will be selected on } \\
\text { the basis of their expertise and/or understanding of climate change related }\end{array}$ \\
\hline
\end{tabular}




\begin{tabular}{|l|l|}
\hline $\begin{array}{l}\text { Presentation } \\
\text { results }\end{array}$ & $\begin{array}{l}\text { issues. A full list of interview participants can be found in Appendix } 2 . \\
\text { A synthesis of the results will be presented in bullet points under leading } \\
\text { themes in an aggregated and non-attributed manner. }\end{array}$ \\
\hline
\end{tabular}

Table 2.4 Research objective 4

\subsubsection{Research objective 5: What leading principles should drive the development of the New Zealand Government's climate change communications and engagement strategy?}

\begin{tabular}{|l|l|}
\hline Purpose & $\begin{array}{l}\text { To develop a framework of leading principles that can contribute to the New } \\
\text { Zealand Government's climate change communications and engagement } \\
\text { strategy development. } \\
\text { A reflective, synthetic and abductive process based on research outcomes. }\end{array}$ \\
\hline Procedure & The outcomes of research objectives 1-4 \\
\hline $\begin{array}{l}\text { Presentation } \\
\text { results }\end{array}$ & $\begin{array}{l}\text { A framework based on the 'Ministry of Health's Revised Mental Health } \\
\text { Strategy'. }{ }^{59} \text { This format has a precedent within the New Zealand } \\
\text { Government and the structure is simple and succinct. The use of 'Leading } \\
\text { Challenges', (in this project, 'Leading Principles') allows interdependent } \\
\text { drivers of action to be presented without hierarchy or complication. }\end{array}$ \\
\hline
\end{tabular}

Table 2.5 Research objective 5

\subsection{Definitions and assumptions}

This research enquiry adopts the United Nations Framework Convention on Climate Change (UNFCCC) definition for climate change, namely: "A change of climate which is attributed directly or indirectly to human activity that alters the composition of the global atmosphere and which is in addition to natural climate variability observed over comparable time periods." ${ }^{60}$ The UNFCCC uses the term 'climate variability' when referring to natural causes. The primary assumption of this research enquiry is that climate change is happening and that given the current projections, as outlined by the IPCC, it will have significant and potentially irreversible harmful affects on human civilisation.

\footnotetext{
${ }^{59}$ Ministry of Health, "Te Tahuhu - Improving Mental Health 2005-2015", 2005
}

${ }^{60}$ UNFCCC, "Framework Convention on Climate Change", Article 1, 1992, p. 3 


\subsection{Obstacles and limitations}

The scope of the research is ambitious for an individual to attempt. Strategic thinking works best when undertaken by a team who are able to converse and reflect on aspects of their investigation on a regular and cohesive basis.

While taking an interdisciplinary approach was a necessary aspect of the scope of the investigation, the trade-off was not being able to do justice to all relevant literature and the likelihood of dealing with some areas simplistically and superficially.

Over the period of undertaking this research project, public debate on climate change has shifted rapidly. No new evidence was considered after $28^{\text {th }}$ February 2007. 


\section{Chapter 3}

\section{Problems with the climate change story}

\subsection{Scope}

A literature review is a means to develop more insightful questions about the intended area of research. ${ }^{61}$ Accordingly, this chapter is intended to identify obstacles to the communication of climate change and possible points of leverage that can be explored later in the research.

The scope of this literature review includes literature that specifically relates to influencing public opinion, discourse analysis, social theory, climate change communications, sustainability communications, risk perception and behaviour change. The literature that specifically relates to climate change and sustainability communications is largely contemporary, reflecting the emergent thinking in this area. It is often the output of consultancies, organisations and agencies that have an active interest in increasing the effectiveness of communications and social marketing campaigns. The sources were identified by reviewing the websites of relevant organisations, identifying leading commentators and practitioners by cross referencing citations, searching library databases, using mainstream internet search engines and receiving input from individuals actively involved in communicating climate change and the promotion of sustainable development.

\subsection{The 'perfect problem'}

Climate change poses a communications riddle. While research studies from the UK, Sweden, the USA and New Zealand indicate that the majority of people believe climate change is happening and are concerned about it, they also find that people feel unsure about what climate change actually is, how it is caused, how serious it is, what it means to them personally and what can be done about it. $^{62}$ So while there is widespread acknowledgement of the threat, there is little substantive engagement with the problem. Daniel Abbasi, former Director at the Yale School of Forestry and Environment Studies, states: "The problem of climate change is almost perfectly designed to test the limits of any modern society's capacity for response - one might even call it the 'perfect problem' for its uniquely daunting confluence of forces." ${ }^{63}$ Within this confluence he cites perceived remoteness in both time and place, the complexity inherent in the subject matter, cultural filters that obscure and

\footnotetext{
${ }^{61}$ Robert K. Yin, Case Study Research: Design and Methods, Third Edition, Sage Publications, Thousand Oaks, 2003, P. 9

${ }^{62}$ Frameworks Institute, "Talking Global Warming”, The Climate Message Project, 2002, Jessica Cederberg Wodmar, Project Manager, "The National Climate Campaign", presented at the Ministry for the Environment on $6^{\text {th }}$ December 2006, DEFRA, op.cit, Tony Pilalis and Associates, "Perceptions and Opinions About Climate Change", Joule and the British Council, Wellington, May 2006

${ }^{63}$ Daniel Abbasi, “Americans and Climate Change: Closing the Gap Between Science and Action", Yale School of Forestry and Environment Studies, 2006, P. 17.
} 
politicise the problem, ingrained habits, institutional capacity to deal with the problem, incentive structures and motivational obstacles associated with collective action. Certainly it is safe to say that information about climate change does not necessarily lead to changes in attitude or behaviour.

\subsection{Short-term thinking}

Psychology tells us that people are naturally more focused on the immediate future than the longterm; this has implications for our ability to conceptualise and manage long-term risks. ${ }^{64}$ Richard Dawkins, author of The Selfish Gene, argues that sustainable behaviour is contrary to the evolutionary instinct because the survival of the fittest often amounts to short-term greed and maximising opportunities for genetic succession. ${ }^{65}$ This theory appears to be backed up by history, Ronald Wright (A Short History of Progress) and Jared Diamond (Collaspe) both give numerous examples of how short-term thinking can lead to environmental degradation and result in social collapse. ${ }^{66}$ Short-term thinking in modern society is both demonstrated and reinforced by short electoral cycles, media time horizons and quarterly profits reports. Short-term thinking doesn't only relate to time, it also relates to distance - the size and complexity of modern society makes it difficult for individuals to gauge the cause or effect of their actions. Accordingly, most individuals lack perspective about their situation in the world. ${ }^{67}$

Climate change is characterised by time lags and uncertainty. Because the dramatic impacts are perceived to happen in either remote geographical locations or at some time in the future, it remains a hypothetical risk for most people. This discrepancy is demonstrated by a research study ${ }^{68}$ that found that on average, Americans estimated annual deaths and injuries resulting from climate change to be in the hundreds - the World Health Organisation (WHO) have estimated that deaths attributed to climate change are currently around 150,000 per annum. ${ }^{69}$ In the same study, hardly any respondents made the association between climate change and human health in their community. George Monbiot asserts that the problem is further compounded by the improbable connection between cause and effect: "By turning on the lights, filling the kettle, taking the children to school, driving to the shops, we are condemning other people to death." ${ }^{70}$

\footnotetext{
${ }^{64}$ John McClure, “Guidelines for Encouraging Householders' Preparation for Earthquakes in New Zealand”, Building Research, Wellington, 2006, p. 9

${ }^{65}$ Richard Dawkins cited in Futerra, "The Rules of the Game: Principles of Climate Change Communications", London,

2005, Tim Jackson, "Models of Mammon", Centre for Environmental Strategy, University of Surrey, 2004

${ }^{66}$ Ronald Wright, A Short History of Progress, Text Publishing, Melbourne, 2004, James Lovelock, Revenge of Gaia, Allen

Lane, Victoria, 2005, Jared Diamond, Collapse, Allen Lane, Victoria, 2005

${ }^{67}$ Richard Docwra, "Why is it so Hard to Change People's Behaviour?", Changestar, November 2006

${ }^{68}$ Anthony Leiserowitz, "Communicating the Risks of Global Warming: American risk perceptions, affective images and interpretive communities", in S. Moser and L. Dilling (eds.), Communication and Social Change: Strategies for Dealing with the Climate Crisis, Cambridge University Press, 2007

${ }^{69}$ World Health Organisation, "Climate and health", July 2005 accessed at

http://www.who.int/globalchange/news/fsclimandhealth/en/index.html on 13th January 2007

${ }^{70}$ George Monbiot, op. cit., p. 22
} 


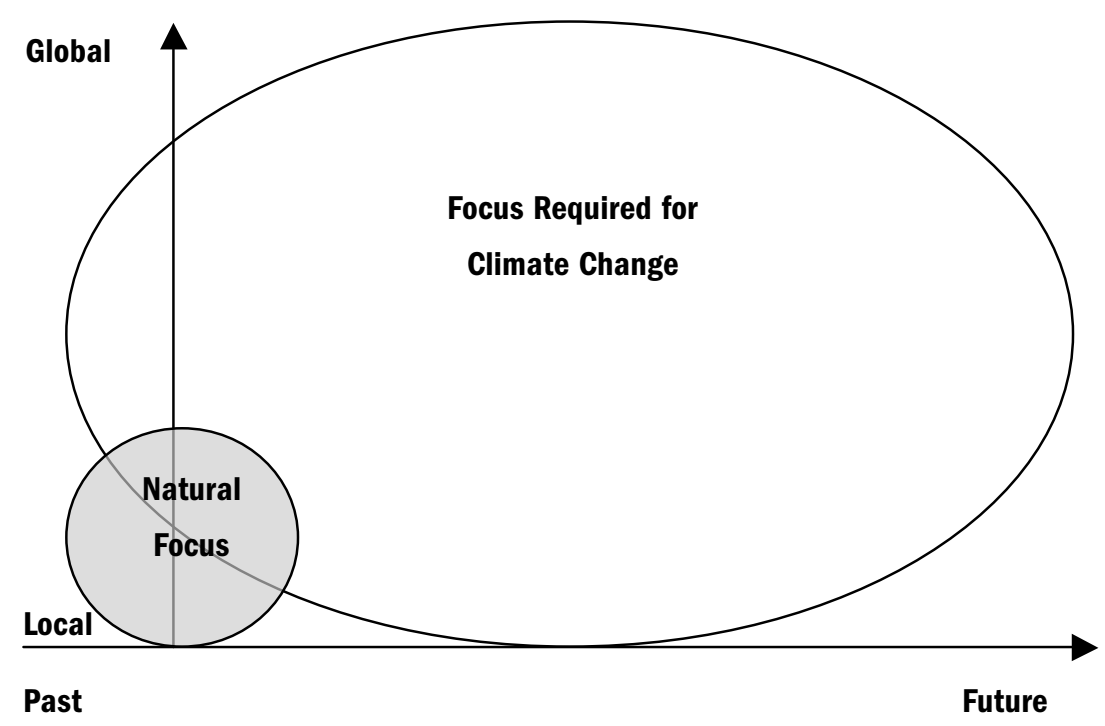

Figure 3.1 Mismatch between natural short-term focus and focus required for climate change

Even when there is tacit acceptance that climate change is happening, crafting communications that generate the social momentum to take the required action in the required time is a considerable challenge. As Tom Lowe from the Tyndall Centre for Climate Change Research sums up: "Communicating global risk to a global community is a challenge with limited historical precedent and one which shows no immediate signs of success on a scale great enough to have a significant impact. ${ }^{n 1}$ While we struggle to realise the significance of our current actions, the window for limiting emissions to a safe level maybe slipping out of our reach.

\subsection{Complexity and the scientific discourse}

Accepting that the earth's climate is not just a natural phenomenon that is experienced but a complex and sensitive system with which humankind interacts, demands either scientific training or a substantial leap of faith. Consequently, scientists who are acutely aware of the significance of their discoveries are confronted with a series of communication issues. Not only is climate science complex, the measurements incremental and the outcomes long term, but the discourse of science itself is not compatible with the discourse of clear public communications: ${ }^{72}$ "Science - as science always should be - is contradictory and confusing. There is no 'answer'; simply a story with many tellers, which changes every day. ${ }^{73}$ Accentuating this disconnect is the obscure language with which climate change is discussed, the preference for words and numbers over visual imagery and the use

\footnotetext{
${ }^{71}$ Tom Lowe, "Dangerous Claims: Is the Way We Perceive Climate Change Leading to a Precautionary Approach or an Irrational Response", Briefing Note 16, Tyndall Centre for Climate Change Research, November 2005, p. 4

${ }^{72}$ Weingart et al. "Risks of communication: Discourses on Climate Change in Science, Politics, and the Mass Media", Public Understanding of Science, 2000; 9, p. 262

${ }^{73}$ George Monbiot, op. cit., p. xviii
} 
of mind-boggling measurements and geological timescales. As a result, while scientists are trusted messengers, the scientific discourse has proved to be an ineffective medium for communicating the implications of climate change or offering meaningful engagement with it. While it has been necessary to simplify the science in order to develop a message that has resonance with the mainstream public, it is in this translation that the climate change story is open to distortion by messengers who construct new discourses to fit their worldview. ${ }^{74}$

\subsection{Information and disinformation}

Not withstanding the importance of climate change, there is a bottleneck in the flow of information from scientists to the public. Although trends are changing rapidly at the time of writing, prior to $\mathrm{Al}$ Gore's An Inconvenient Truth, popular culture had thrown up only two stories on climate change; the bizarre and far-fetched film The Day After Tomorrow and Michael Crichton's State of Fear, neither of which helped bring the reality of climate change into the public's front-of-mind consciousness in a constructive way. ${ }^{75}$

The mainstream media, and specifically television, provide the most common source of information about climate change. ${ }^{76}$ In New Zealand, this mainly means ad-hoc news items as other opportunities are limited by the competitive nature of commercial programming. Newspapers, magazines and radio can be more detailed in their coverage of climate change but remain fickle. This is an inevitable consequence of the way in which the media operate and is perpetuated by a range of structural issues including: perceived 'newsworthiness', lack of in-depth knowledge, time constraints, competition, issue lifecycle and the norm of reporting a balanced argument. ${ }^{77}$ Other than mainstream media coverage, information about climate change varies greatly in quality and message and in some cases may work at cross-purposes. To date, there is no consistent and cohesive message or vision as to what climate change is or means to the people of New Zealand.

Information attempting to raise awareness of climate change has to compete with information seeking to obscure the issue. The deliberate attempts by organisations and interest groups to confuse the issue are well documented. ${ }^{78}$ In his book Heat, George Monbiot dedicates a chapter to the 'denial industry'. He claims that public relations campaigns have been developed to deliberately confuse the public on the issue of climate change and protect economic interests. The reasoning

\footnotetext{
${ }^{74}$ Weingart et al. op. cit., p. 280

75 Bill McKibben, "Can you imagine? A Warming World Needs Art", Published on Open Democracy, 22 nd April 2005 accessed at http://www.opendemocracy.net/debates/article-6-129-2447.jsp on $2^{\text {nd }}$ September 2006

${ }^{76}$ Tony Pilalis and Associates, op. cit., DEFRA, op. cit.

${ }^{77}$ Summary of Key Points, "Panel on Communicating Climate Change", CIREO, COP, Nairobi, November 2006, Weingart et al. op. cit.,, Maxwell T. Boykoff and Jules M. Boykoffb, "Balance as bias: global warming and the US prestige press", Global Environmental Change 14, 2004, p.125-136, Daniel Abbasi, op. cit., Tom Lowe, op. cit.

${ }^{78}$ Kevin Trenberth, "The Politics of Climate Change", Sleeping Giants: Climate Change Science, Policy and Action, Airplane Studios, 2006, Ian Sample, "Scientists offered cash to dispute climate study", The Guardian, $2^{\text {nd }}$ February 2, 2007 accessed at http://www.guardian.co.uk/frontpage/story/0,,2004399,00.html on $17^{\text {th }}$ February 2007
} 
behind such campaigns is illustrated in a leaked memo from the influential US political consultant Frank Luntz: "Should the public come to believe that the scientific issues are settled, their views about climate change will change accordingly. Therefore, you need to continue to make the lack of scientific certainty a primary issue in the debate." ${ }^{79}$ This is a tactic that was originally developed by the tobacco industry to obscure the science that linked smoking with health risks. While it is difficult to say whether deliberate disinformation campaigns have taken place in New Zealand, it has to be said that the most voluble detractions of climate science are well organised, tactical and deliberately nuanced $^{80}$ and/or tend to come from lobbies and organisations that have vested interests in the status quo.

Political posturing also distorts the issue. Rhetorical language has been found to tune people out ${ }^{81}$ and partisan values have a strong influence on people's attitudes to climate change. This was demonstrated in 1997 when the Democratic Clinton Administration pushed for public agreement on the Kyoto protocol. Not only did the public relations campaign impact negatively on Republican voters' attitudes towards Kyoto, it also affected their attitudes towards the scientific basis of climate change itself. ${ }^{82}$ Based on this evidence, without a bi-partisan agreement on climate change there will always be a risk that the issue remains subject to traditional party values.

Beyond deliberate disinformation and politicking, other highly visible communications can confuse the issue. While it would be safe to say that an effective response to climate change would implicitly require more sustainable consumption patterns, this reality is continually at odds with advertising messages that promote resource hungry products and lifestyles. This is no better demonstrated than by the marketing of high performance motor vehicles. ${ }^{83}$ In the wake of diffuse and contrary information, the public are left to form their own opinions on a subject they know little about.

\subsection{How we understand what we don't know}

The Frameworks Institute specialises in analysing public discourse about social problems. The cognitive approach they use, 'framework analysis', states that human understanding is frame-based not fact-based. When people don't know much about a subject they look for shortcuts to understanding; this is achieved by applying existing frames of reference. Frames are made up from experiences, concepts and values and determine how a story is told, what counts, what can be ignored, what is inferred when information is missing and what action should be taken. The context, language, messengers, symbols and metaphors that accompany new information all influence which

\footnotetext{
${ }^{79}$ Frank Luntz, 'The Environment: A Cleaner, Safer, healthier America”, 2002 quoted in George Monbiot, op. cit., p. 27

${ }^{80}$ The New Zealand Climate Science Coalition, http://www.climatescience.org.nz/

${ }^{81}$ Frameworks Institute, op. cit.

82 Daniel Abbasi, op. cit., p. 75

${ }^{83}$ George Monbiot, op. cit., Kirsty Hamilton, “Opportunities for Business”, Sleeping Giants: Climate Change Science, Policy and Action, op. cit.
} 
frame is triggered and consequently how the information is understood. It is important to note that once a frame is established it can be difficult to change. ${ }^{84}$

Ideas come in hierarchies. The most dominant frames are value based and triggered by 'big ideas' such as progress, fairness and freedom. These high level frames trump 'issue types' such as education and the environment, and 'specific issues' such as NCEA and rainforest depletion. Accordingly, specific issues are positioned and understood depending on the high-level idea with which they are linked. The two dominant frames that have emerged and are perpetuated for climate change are the 'weather' frame and the 'economic' frame. ${ }^{85}$

\subsection{Climate change as 'weather'}

The 'weather' frame results from the anticipated impacts of unmitigated climate change being portrayed as catastrophic certainties. This happens because the media are required to turn the complex details of climate science into newsworthy stories: "The media are aware that the vagaries and uncertainty of scholarly hypotheses do not lend themselves to interesting 'news' [and therefore] tend to translate hypotheses into certainties." ${ }^{86}$ In a sample study, communications consultancy Futerra found that 59 percent of UK news stories referring to climate change were negative proffering doom and catastrophe. Negative stories were also more prevalent in the more widely distributed and read tabloid papers. ${ }^{87}$ In an extended discourse analysis of climate change in the UK, Gill Ereaut and Nat Segnit found that 'alarmism' was a dominant linguistic repertoire: "It is typified by an inflated or extreme lexicon, incorporating an urgent tone and cinematic codes. It employs a quasi-religious register of death and doom, and it uses language of acceleration and irreversibility. ${ }^{88}$ However, not only did they see 'alarmism' as the dominant media story but also as a common construct of government initiatives and environmental groups. ${ }^{89}$ In defence of allegations of sensationalism, or 'climate porn' ${ }^{90}$, Ian Birrell, editor of the Independent, argues that his paper has led the way on campaigning for climate change and has put the issue high on the political agenda. However, regardless of whether the motivation is to sell papers or stimulate public opinion (or both), communicating climate change through biblical imagery is likely to result in a fatalistic or, at best, an adaptive mindset.

In a report investigating how New Zealand households could be persuaded to increase their earthquake preparedness, ${ }^{91}$ John McClure synthesises the main psychological theories concerning

\footnotetext{
${ }^{84}$ Frameworks Institute, op. cit.

${ }^{85} \mathrm{Ibid}$

${ }^{86}$ Weingart et al. "op. cit., p. 274

${ }^{87}$ Futerra, "Climate Fear v Climate Hope", London, 2006

${ }^{88}$ Gill Ereut and Nat Segnit, "Warm Words", Institute of Public Policy Research, 2006, p. 7

${ }^{89} \mathrm{lbid}$

${ }^{90} \mathrm{lbid}$

${ }^{91}$ John McClure op. cit.
} 
risk perception and behaviour change. When presented with a high level of risk, two processes are at play - the perception of the ability to respond to the risk and perception of the risk itself. In terms of being motivated to take precautionary action against a risk, a crucial factor is the perceived locus of control. When individuals believe their actions can affect their circumstances they are more likely to act. When they perceive their circumstances to be uncontrollable, helplessness and fatalism are likely to take hold. Put simply, belief about the efficacy of an action is a better indicator of taking action than belief about the hazard. When climate change is communicated with 'alarmism' it seems beyond human control and impossible to change, as Stephan Kaplan asserts: "A situation in which people cannot act effectively, in which they cannot solve the problem they face or cannot implement the solutions they come up with, is likely to be extremely distasteful. In other words, people would be expected to avoid contexts that they consider conducive to helplessness." ${ }^{92}$

Risks that produce high levels of anxiety can also lead to denial. This has been demonstrated by a study investigating risk perception of earthquakes in Los Angeles. ${ }^{93}$ Students accommodated in a high-risk zone substantially downplayed the potential danger to which they were exposed compared to students accommodated in a low-risk zone. Ereaut and Segnit argue that denial of climate change manifests itself in the 'settlerdom' repertoire. 'Settlerdom' ignores the science of climate change and refuses to even engage in the debate. It dismisses climate change (and the 'doomsayers') in the name of commonsense. ${ }^{94}$

\subsection{A necessary evil}

The 'economic' frame works quite differently from the 'weather' frame and positions climate change as an unintended consequence of economic development: a necessary evil of having achieved the modern way of life. In this frame, action towards climate change is primarily discussed and evaluated in terms of cost and, in effect, positions climate change against self-interest. As a result, individual actions and policy measures are likely to be 'pragmatic' compromises at best. ${ }^{95}$ This view is echoed by John Ashton, The British Government's Climate Change Ambassador, who also argues that climate change is abstracted from everyday reality and put in the broad basket of environmental problems - trade-offs to economic growth and other desirable outcomes. ${ }^{96}$ While the media often induce the 'weather' frame when covering climate change science, they tend to use the 'economic' frame when reporting or discussing climate change policy. ${ }^{97}$

\footnotetext{
${ }^{92}$ Stephen Kaplan, “Human Nature and Environmentally Responsible Behavior”, Journal of Social Sciences, Vol. 56, No. 3, 2000, p. 491

${ }^{93}$ Lehman and Taylor, 1988, in John McClure, op. cit.,, p. 8

${ }^{94}$ Gill Ereut and Nat Segnit, op. cit.

${ }^{95}$ Frameworks Institute, op. cit.

${ }^{96}$ Tom Burke and John Ashton, "Climate Change: Changing the Frame“, London, February 2005

${ }^{97}$ Steve Hatfield-Dodds and Nigel Jollands, "Issues in Communicating the Impacts of Climate Change Policy Options", New Zealand Centre for Ecological Economics, 2006, p. 2
} 
The 'economic' response to climate change is one of feasibility not necessity. George Monbiot recalls a situation that arose at a conference in September 2005 when Sir David King, the British Government's Scientific Advisor, announced that 550 ppm was a reasonable target for stabilising $\mathrm{CO}_{2}$ emissions. When challenged that such a target would only give a 10-20 percent chance of preventing the global mean temperature from rising above the EU's ascribed 'non-dangerous' level of warming $\left(2^{\circ} \mathrm{C}\right.$ above pre-industrial levels), he replied that if he had set a lower level he would have lost credibility with the Government. ${ }^{98}$ In general, the 'economic' frame has created a disconnection between scientific reality and politically feasibility, while also creating a perception that action on climate change is too costly even when many studies, including the Stern Review, suggest otherwise. $^{99}$

The communications response facilitated by the 'economic' frame is what Ereaut and Segnit describe as the 'small actions' repertoire: "It involves asking a large number of people to do small things to counter climate change. The language is one of ease, convenience and effortless agency, as well as of domesticity, seen in reference to kettles and cars, ovens and light switches." ${ }^{100}$ While communications that push the 'small actions' narrative offer some semblance of a solution, the banality and limited impact of these actions seems at odds with the apocalyptic scenarios portrayed elsewhere. The clash between these two dominant narratives produces a sense of dissonance: "We use a loud rumbling voice to talk about the challenge, about melting ice and drought; yet we have a mouse-like voice when we talk about 'easy, cheap and simple' solutions, making them sound as tiny as possible because we think that's what makes them acceptable to the public." ${ }^{101}$ The contrast between the enormity of climate change and the diminutiveness of small individual actions makes them seem apologetic and futile.

\subsection{Small actions and good intentions}

When actions have clear benefits, information and communication can be effective ways to shift intentions and behaviours. ${ }^{102}$ Unfortunately, not only do most 'small actions' seem to be ineffectual they can also be inconvenient. These factors combine to make default behaviours resistant to information based messages. Even when people have ethical intentions it doesn't necessarily indicate that action will automatically follow. ${ }^{103}$ One study investigating ethical purchasing decisions found that as little as 10 percent of stated intentions were carried out when it come to the moment

\footnotetext{
${ }^{98}$ George Monbiot, op. cit., p. 41

99 Australian Business Roundtable on Climate Change, "The Business Case for Early Action", 2006 accessed at http://www.businessroundtable.com.au/html/documents.html on 2nd November 2006. Stern Review on the Economics of Climate Change, "The Economics of Climate Change: Executive Summary", HM Treasury, London, November 2006

${ }^{100}$ Gill Ereut and Nat Segnit, op. cit., p. 8

${ }^{101}$ Solitaire Townsend quoted in Richard Black, “Media Attacked for 'Climate Porn'”, BBC News Website, $2^{\text {nd }}$ August 2006

102 Joanna Collins et al., "Carrots, Sticks and Sermons: Influencing Public Behaviour for Environmental Goals", Green Alliance, Demos, 2003

${ }^{103}$ Futerra, "The Rules of the Game: Principles of Climate Change Communications", London, 2005, Joanna Collins et al., op. cit.
} 
of truth. ${ }^{104}$ The mismatch between intention and action is not necessarily because people are dishonest but because habitual behaviours are fundamentally difficult to change. The degree to which an action remains controlled or becomes automatic (habit) depends on the nature of the action itself. The three factors likely to influence whether an action becomes automatic are its perceived importance, its complexity and the cognitive processing capability available at the time of acting - the greater the pressure the more likely automatic processing will take control. ${ }^{105}$ Based on these criteria, it is easy to see why everyday behaviours associated with energy use, transport, consumption and waste management are likely to become subject to habit.

Regardless of the cause, a consequence of people failing to adopt climate friendly behaviours is that their enthusiasm may become blunted. In the 'Rules of the Game', one of Futerra's principles for communicating climate change outlines the danger of confronting people with the difference between their attitudes and actions. They cite Leon Festinger's Theory of Cognitive Dissonance (1957) which, simplistically put, argues that anxiety arises when there is conflict between an individual's attitudes and actions. To resolve this anxiety, an individual can either change their attitude or their behaviour. The majority of evidence suggests that attitudes are more likely to conform to behaviour than vice versa. ${ }^{106}$ A simple example of how perceptions can be twisted to justify behaviour is demonstrated in a UK study that found people exaggerate the length of a journey on public transport by 70 percent while overestimating the time efficiency of cars by 26 percent. ${ }^{107}$ Expanding on the principle of cognitive dissonance, Tim Jackson summarises a number of studies that explore the relationship between behaviour and attitude. Specifically, he cites Thogersen's work on 'spill-over effects' of environmental behaviour. A 'negative spill-over' refers to the process discussed above - harmful actions to the environment lead to indifferent or negative attitudes. However, 'positive spill-overs' can also happen, meaning that basic acts such as recycling can stimulate positive attitudes to other pro-environmental behaviours. While the strength of this effect is disputed, the principle has obvious significance for policy development. ${ }^{108}$

\subsection{Technology will save us}

A narrative that works well to reconcile the dissonance between self-interest and impending catastrophe is the idea that technology will save us. ${ }^{109}$ Ereaut and Segnit identify this repertoire as 'techno-optimism'. ${ }^{110}$ They argue that this takes two forms. One form is that current technology and business will evolve and solve the problem through convenient innovations such as 'green fossil fuels' and 'clean industry'. The other form is that solutions will come from invention. An example of

\footnotetext{
${ }^{104}$ Cowe, R. \& Williams, S. "Who are the ethical consumers?", The Co-operative Bank, 2001

${ }^{105}$ Tim Jackson, “Motivating Sustainable Consumption”, Sustainable Development Research Network, 2004

${ }^{106}$ Futerra, op. cit.

${ }^{107}$ Lynn Sloman, Car Sick: Solutions for Our Car-addicted Culture, Green Books, Devon, 2006

108 Tim Jackson, op. cit.

${ }^{109}$ George Monbiot, op. cit., p. 204-215

${ }^{110}$ Gill Ereut and Nat Segnit, op. cit.
} 
techno-optimism' can be found in a statement issued by Tony Blair in January 2007. The British Prime Minister defended the right of British citizens to keep flying for their holidays and validated his statement with the claim that technological advances in design and fuels will make jet-setting climate friendly. ${ }^{111}$ However, the argument that technological innovation will make action cheaper and more viable in the future is a dangerous and a pervasive misconception based on questionable assumptions. These include the notions that lower cost low-emissions technologies will become available in the future, that there is a 'comfortable' timeframe for reductions and that delayed action doesn't result in impacts that diminish our future capacity to respond. ${ }^{112}$

From a psychological viewpoint, 'unrealistic optimism' is a bias that makes people think they are less likely to experience misfortune than others. Drawing on a range of studies, John McClure summarises how unrealistic optimism can affect people's risk perception of hazards and disasters: "People know that unfortunate events happen, but they believe that they will not be among those suffering from these events. They think it will happen to someone else." ${ }^{113}$ A poignant example of this bias is demonstrated by a study that questioned individuals about the fall-out of an atomic bomb in their locality. While the aggregated estimated fatality rate was 97 percent, 90 percent of respondents also believed they would survive - only 2 percent believed they would be dead. Optimistic bias is only likely to be countered by directly experiencing or witnessing a salient event. This supports the view of some commentators that it won't be until climate change produces a substantial and significant shock that people will truly wake up to it. ${ }^{114}$

\subsection{Appealing to the greater good}

The flipside of future invention is conservation now. However, it would appear that direct attempts to stimulate action by invoking the need for precaution are relatively ineffectual. In The Rules of the Game, Futerra dispel the myth about the power of leveraging concern for future generations by citing studies that find that having children can even have a negative affect on attitudes towards climate change because parents become even more focused on survival here and now. ${ }^{115}$ The Frameworks Institute argue that invoking the need for environmental protection is ineffective because the idea of protection is already at play in the dominant 'economic' frame - 'I care about the environment but protecting my family and lifestyle come first'. ${ }^{116}$ Shellenburger and Nordaus argue that traditional environmental messages simply ask too much from people: "Most people wake up in the morning

\footnotetext{
111 Nicholas Watt, “Carry On Flying, Says Blair - Science Will Save the Planet”, The Guardian, Tuesday January 9, 2007 accessed at http://politics.guardian.co.uk/green/story/0,,1985981,00.html on $10^{\text {th }}$ January 2007

112 Steve Hatfield-Dodds, "Building Momentum for Climate Policy Through Improving Communication and Incentive Alignment”, CSIRO Integration Network, presented at 'Climate Change Policy Symposium', Victoria University of Wellington, $6^{\text {th }}$ October 2006, Ralph Chapman, “A Way Forward on Climate Change Policy for New Zealand”, in Boston, J. et al (eds.), Confronting Climate Change, Victoria University Press, Wellington, 2006, p. 307-321

113 John McClure, op. cit., p. 7

${ }^{114}$ Kirsty Hamilton, op. cit., Ronald Wright, op. cit., James Lovelock, Revenge of Gaia, Allen Lane, Victoria, 2005

115 Leaman, J. and Norton, A., 2004, in Futerra, op. cit., p. 10

${ }^{116}$ Frameworks Institute, op. cit.
} 
trying to reduce what they have to worry about. Environmentalists wake up trying to increase it. We want the public to care about and focus not only on global warming and rainforests but also species extinction, non-native plant invasives, agribusiness, overfishing, mercury, and toxic dumps." ${ }^{117}$ Although contested, Stephen Kaplan argues from an evolutionary psychological perspective that the idea that good intentions and self-sacrifice produce good social outcomes is a misguided assumption. He asserts that the traditional method of promoting environmentally friendly behaviour, relying on altruism and human goodwill, is inherently flawed. Promoting the idea that environmentally friendly behaviour is about self-sacrifice offers little in the way of benefit for the majority of people. Rather, it positions environmentally friendly behaviour as frugal and unattractive and can have the flip effect of reinforcing unfettered consumption as being more likely to bring happiness and satisfaction. ${ }^{118}$

Using a Maslow-based 'Value-Modes' mapping system, Chris Rose et al argue that climate change communications have to be more savvy about human motivation. They propose that society is divided into 'three broad psychological motivational groups' - 'settlers', 'prospectors' and 'pioneers'. ${ }^{119}$ 'Settlers' value security and belonging, they tend to be conservative and are resistant to change. 'Prospectors' are driven by outer directed needs and gaining the esteem of others, they live for the moment and seek explicit rewards in fashion, status and success. 'Pioneers' are driven by inner directed needs and ethics, they are more forward focused, are comfortable with change and welcome discovery. Rose et al assert that because 'pioneers' are more sensitive to environmental issues it is they who generally end up initiating communication campaigns for social change. The problem, however, is that they tend to develop communications that work for them and not the other social groups. For 'settlers' and 'prospectors' (who together form approximately 70 percent of society), value-based messages about future presenvation, bold change and ethical imperatives simply don't connect. In effect, 'pioneers' end up preaching to the converted. Frank Luntz, the same consultant who offered advice on how to confuse the issue of climate change also offers some pointed commentary on the environmental movement: "The problem the environmental community has is they don't listen to their opponents. When I do my research, I spend more time studying the opposition argument because that's what I need to respond to. The environmental community never listens." ${ }^{120}$

\subsection{Meaningful choices}

Developing his argument about what motivates environmentally responsible behaviour, Kaplan goes on to say that there may be more practical ways to get people on board than appealing to self-

\footnotetext{
${ }^{117}$ Michael Shellenburger and Ted Nordaus, “The Death of Environmentalism”, The Break Through Institute, 2004, p. 28

${ }^{118}$ Stephen Kaplan, op. cit.

${ }^{119}$ Chris Rose et al, "Climate Change Communications - Dipping a Toe into Public Motivation", May 2005 accessed at http://www.compassnetwork.org/resmat.php on 4th September 2006, p. 14

${ }^{120}$ Frank Luntz interviewed by Amanda Griscom Little, "And Now, a Word From Our Detractor", Grist, $31^{\text {st }}$ January 2007 accessed at http://grist.org/news/maindish/2007/01/31/luntz/ on $5^{\text {th }}$ February 2007
} 
sacrifice. Most people aren't selfless but neither are they totally gain oriented. Most of the time, people's actions depend as much on circumstance as predisposed psychological motivations. On this basis, environmentally responsible behaviour ultimately depends on real and meaningful opportunities to take action: "The observed environmental irresponsibility of many people cannot be interpreted as a simple example of disinterest or inappropriate attitude or sloth. Often there is a lack of appropriate infrastructure, or of multiple desirable choices, or of cultural support... When one adds to this the sense of inadequacy and helplessness as an individual tries to compensate for the inappropriate behaviour of huge corporations and governments, it is hardly surprising that the behaviour of ordinary people often falls short of being exemplary."

This begs the question of what can realistically be expected of any communication and engagement programme without the support of enabling and wide-reaching choices. Futerra underline this point by asserting that all climate change communications need to be backed up by policy and exemplified by government. ${ }^{122}$ Rose et al argue that given that the issue of climate change is already generally accepted, decision makers need to develop ways for people to take action rather than just continuing to highlight the issue. ${ }^{123}$ Given this focus on capability, it should also be recognised that disadvantaged social groups may be less able to engage and respond to climate change. Although research indicates people in low income groups express a similar amount of concern about the environment as those in more affluent groups, poverty, lack of education, lack of community support and lack of capital assets all inevitably undermine the ability to adopt new behaviours. ${ }^{124}$

\subsection{Conflicting incentives}

'Americans and Climate Change' is a synthesis of outcomes and insights from a workshop run by Yale University exploring why substantive action on climate change wasn't being taken in the US. The workshop involved representatives from eight different societal sectors: science, news media, religion and ethics, politics, entertainment and advertising, education, business and finance, and environmentalists and civil society. It was established that, in the absence of cohesive leadership, incentive structures within the different sectors were in many ways responsible for creating a diffusion of responsibility. ${ }^{125}$

The media's structural incentives have in part already been examined but a cursory look at some of the other sectors is revealing. Scientists are largely rewarded within their own community with reputation and funding but they do not get rewarded for bold public outreach (indeed, bold outreach can undermine credibility) and therefore often lack the skills to do so. Politicians are at the mercy of

\footnotetext{
${ }^{121}$ Stephen Kaplan, op. cit., p. 501

${ }^{122}$ Futerra, "The Rules of the Game: Principles of Climate Change Communications", London, 2005

${ }^{123}$ Chris Rose et al, op. cit., p. 14

124 Andrew Darnton, "The Impact of Sustainable Development on Public Behaviour", Centre of Information, UK, 2004, Andrew Darnton, “Driving Public Behaviours for Sustainable Lifestyles”, Centre of Information, UK, 2004

${ }^{125}$ Daniel Abbasi, op. cit.
} 
short electoral terms and influential sectors that may incur short-term penalties as a result of policies designed for the long-term collective benefit. Consequently there is a natural inclination to procrastinate over evidence and pass the buck to the next incumbent. Progressive action on climate change in the business sector is basically dependent on legislation and consumer preferences. Even if individuals within business have personal concerns regarding climate change (as recent New Zealand research demonstrates is the case ${ }^{126}$ ), they are unlikely to be able to shift the basic drivers upon which business operates. CEOs are beholden to quarterly earnings, traders and shareholders. This also extends to trade associations who have a vested interest in being seen to represent the majority view of business and to minimise regulatory impacts.

In the sectors where responding to climate change would appear to be more straightforward there are still barriers at play. Educators have a limited incentive to promote climate change unless the issue is locked into the curriculum. Environmental groups are often unable to respond to the diverse implications of climate change because an increasingly competitive civil society has forced them to become specialised. Chris Rose expands this point by arguing that environmental groups often feel compelled to spend much of their time on achieving specific policy wins at the expense of facilitating the social conditions that will make wider change inevitable. ${ }^{127}$

\subsection{Collective responsibility}

By looking at incentive structures, we find an answer to the seemingly confounding question of why anyone would wish to continue to contribute to the risk of considerable destruction and degradation by not taking responsible action on climate change. In a democratic and market system, although a large amount of power and influence comes down to individuals, it can often only be realised through collective action. The tragedy of the commons as it relates to climate change is higlighted on a global scale by the Stern Reveiw: "Each nation individually has an incentive to free-ride on the mitigation efforts of other nations, even though everyone could benefit from mitigation." ${ }^{128}$ What applies to nation states equally applies to businesses and individuals - the benefit of one's own cooperative action is dependent on the mutual cooperation of other parties.

In the absence of coherent leadership, a compelling vision and a level playing field, individual incentives will continue to drive choices: "Career has become arguably the most identity-defining feature of life in modern democratic capitalism, and career incentives almost universally argue against investing time in the climate change issue - whether understanding it, communicating it, or

\footnotetext{
${ }^{126}$ ShapeNZ, “Welcome Survey”, New Zealand Business Council for Sustainable Development, September 2006

${ }^{127}$ Chris Rose, "Commentary on the Death of the Environmentalism", 2004 accessed at http://www.campaignstrategy.org/ on $10^{\text {th }}$ January 2007

${ }^{128}$ Stern Review on the Economics of Climate Change, "What is the Economics of Climate Change", HM Treasury, London, $31^{\text {st }}$ January 2006, P. 27
} 
doing something about it." ${ }^{129}$ It is possible that 100 percent of society could be concerned about climate change and still do little or nothing about it. This is a classic example of the bystander effect where individuals subsume their responsibility into a collective responsibility and wait for something to magically happen. ${ }^{130}$

\subsection{Summary}

Climate change is an issue without precedent that presents a complex and inter-related range of obstacles to communications and engagement:

- People are naturally more focused on the immediate future than the long-term - this has implications for our ability to conceptualise and communicate climate change as a risk that requires urgent attention.

- The relationship between information, intent and action is not linear - what science discovers cannot be expected to naturally translate to action.

- Information about climate change is limited and diffuse. Clarity over the issue is also distorted by deliberate disinformation, advertising and political rhetoric.

- There is no one definition of the issue; it can "be assumed that the differences in perception are irreducible." ${ }^{131}$

- The way climate change is presented affects the way it is understood and responded to. Climate change is commonly presented as a looming catastrophe beyond human control. Feelings of helplessness are not conducive to motivating an effective response.

- The other dominant frame for thinking about climate change is one of feasibility and cost. This tends to result in a conservative mindset that is predisposed to pursue the minimum that can be done without disrupting lifestyles and the status quo.

- Everyday actions that tackle climate change are difficult to maintain because they seem at odds with the scale of the problem and also conflict with habitual behaviours - they are neither compelling nor convenient.

- If individuals are concerned about climate change but not doing anything about it (or able to do anything about it), their attitude is likely to move towards indifference or other compensatory positions such as an optimistic bias that technology will save us.

- Traditional environmental message framing doesn't work for the majority of society. This is not because people don't care but it does mean they need to be motivated in different ways.

\footnotetext{
${ }^{129}$ Daniel Abbasi, op. cit., p. 54

${ }_{130}$ Stanley Cohen citied in Penny Walker, "Different Planets: Belief, Denial and Courage", Greener Management International, Winter 2004/2005, 48, p. 67-81

${ }^{131}$ Weingart et al. op. cit., p. 280
} 
- Barriers to engaging with climate change are real as well as psychological - individuals have a limited ability to act on their own. Communications in the absence of meaningful options for action are likely to be underwhelming, counter productive and viewed as disingenuous.

- Inertia is systemic due to the conflicting incentive structures in society - although climate change is important it is never the priority.

- Responsibility for climate change is diffused by the need for collective action and free rider incentives (nationally and internationally). In the absence of cohesive leadership, individual motivations will take precedence regardless of stated attitudes.

Given all the obstacles to engaging with climate change it is reasonable to conclude that the problem may appear more overwhelming than it actually is. This is not to question the gravity of climate change but to speculate that our ability to take effective action might be underestimated. Gregg Easterbrook suggests that we are overly pessimistic about our ability to tackle climate change. ${ }^{132}$ He argues that if we understand climate change in the context of an air pollution problem we can feel empowered by an overwhelmingly successful track record. While he freely admits that climate change is bigger, more complex and more dangerous than previous challenges, he maintains that the problem is not insurmountable. This position is backed up by research that suggests that climate change can indeed be mitigated not only without degrading our quality of life but improving it. ${ }^{133}$ The challenge is to align ourselves to take advantage of this opportunity while it still exists.

132 Gregg Easterbrook, “Some Convenient Truths”, The Agenda, September 2006

${ }^{133}$ Steve Hatfield-Dodds, op. cit., Bert Metz, Detlef van Vuuren, "How, and at What Costs, can Low-Level Stabilisation be Achieved? - An Overview", in Schellnhuber, H.J. et al (eds.), Avoiding Dangerous Climate Change, Cambridge University Press, Cambridge, 2006 


\title{
Chapter 4
}

\section{Communications and behaviour change best practice and theory}

\author{
4.1 Scope \\ The primary objective of the Government's climate change communications and engagement \\ programme is to raise awareness, change attitudes and motivate behaviour change. ${ }^{134}$ Consequently \\ this synthesis draws primarily on theory and case studies with regard to communications and \\ behaviour change. This has specifically included research undertaken in the fields of social \\ psychology, social marketing, social change, strategic policy interventions, branding, climate change \\ communications and encouragement of pro-environmental behaviours.
}

Theories that seek to understand why people do what they do and models that attempt to harness this understanding are numerous. Certainly, the task of synthesising the vast array of literature on this subject into one succinct and unified strategy for climate change is near impossible: "The question of what shapes pro-environmental behaviours is such a complex one that no one model or framework can adequately express all the forces at work." ${ }^{135}$ Rather than develop an extensive list of theories, this chapter attempts to distil key insights from the literature and develop an overview that will add value to the core research objective.

\subsection{Awareness, attitudes and behaviour}

In Chapter 3 it was established that the link between information and action is non-linear. The relationship is complex and influenced by a range of interdependent and independent factors. Therefore, it can not be expected that there will be natural progression between raising awareness, attitude change and behaviour change. Influencing public behaviour is an inexact process and in many respects is more an art than a science. ${ }^{136}$ Nevertheless behaviours do change and indeed must change if New Zealand is to prepare itself effectively for the impacts of climate change and be part of a multi-lateral effort to reduce global GHG emissions.

\footnotetext{
${ }^{134}$ New Zealand Government, op. cit., p. 97

135 Kolmuss and Agyeman, 2002, quoted in Andrew Darnton, The Impact of Sustainable Development on Public Behaviour", op. cit., p. 9

${ }^{136}$ Joanna Collins et al., op. cit.
} 
Theories of behaviour change explore human behaviour from a range of perspectives including individual, interpersonal and community. ${ }^{137}$ Simplistically, these perspectives can be reduced to understanding behaviour as the result of internal processes - attitudes, values, habits - and external processes - incentives, constraints and social norms. ${ }^{138}$ Although by no means an authoritative model for behaviour change, Stern's Attitude-Behaviour-Context $(A B C)$ model presents an integrated and intuitive framework for exploring how pro-environmental behaviours might be influenced.

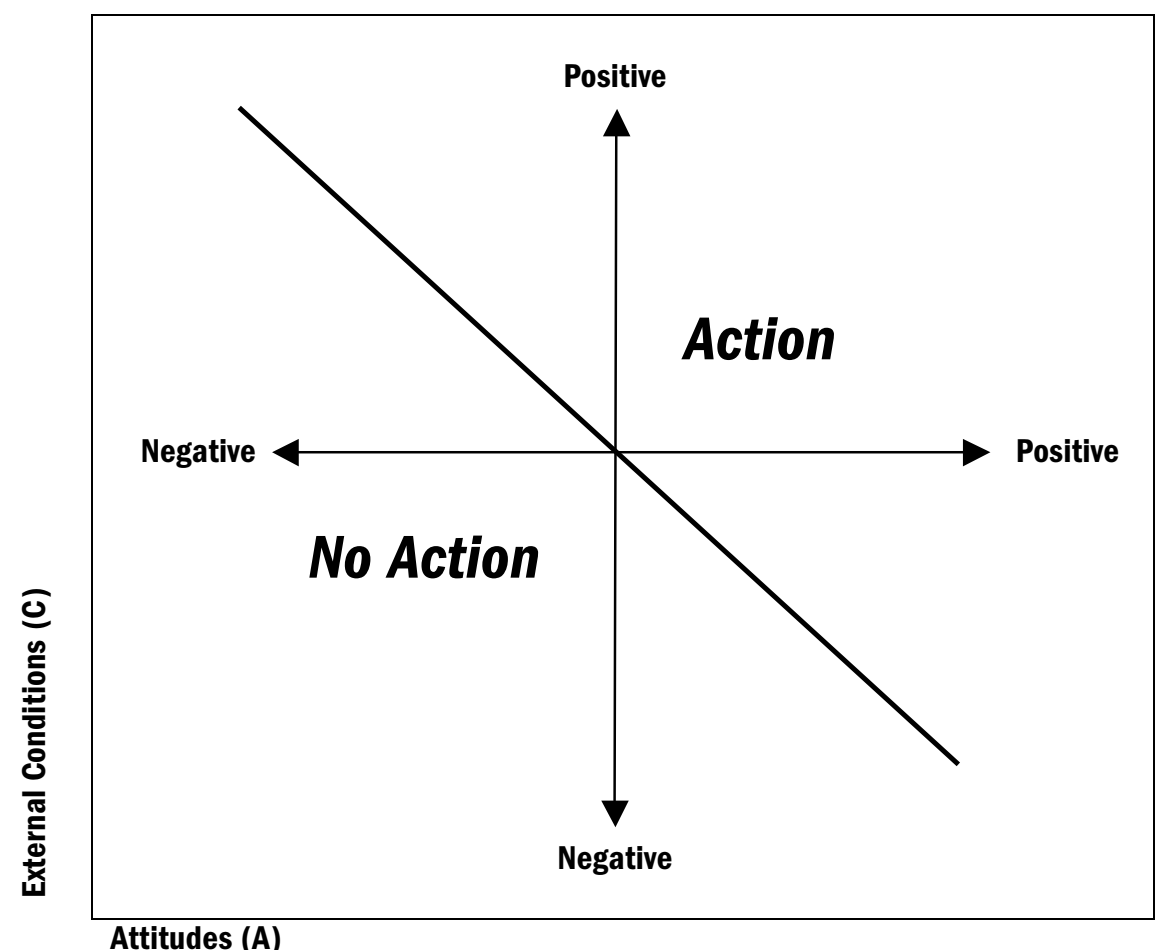

\section{Figure 4.1 Stern's Attitude-Behaviour-Context Model}

In Stern's $A B C$ model, behaviour is understood as a function of the individual and the environment. ${ }^{139}$ The attitudinal pre-disposition to act is measured up against contextual factors that may either encourage or inhibit an individual to act in a given way. The link between attitude and behaviour is strongest when contextual factors are weak and conversely, attitude has little influence on behaviour when contextual factors are strong. The relationship between attitude and context is further influenced by habit, which is significant because habit underlies much of the everyday behaviour that has environmental impacts. ${ }^{140}$

\footnotetext{
${ }^{137}$ David Halpern et al., "Personal Responsibility and Changing Behaviour: the State of Knowledge and its Implications for Public Policy”, Prime Minister's Strategy Unit, UK, February 2004

${ }^{138}$ Tim Jackson, “Motivating Sustainable Consumption”, Sustainable Development Research Network, 2004

${ }_{139}$ Paul Stern, "Toward a Coherent Theory of Environmentally Significant Behaviour", Journal of Social Issues 56, Autumn 2000, p. 407-424

${ }^{140}$ Tim Jackson, op. cit.
} 
The influences on everyday life are dynamic and numerous and, accordingly, interventions that seek to promote specific behaviours have to be equally diverse and personalised. Doug McKenzie-Mohr's Community-Based Social Marketing approach holds that behaviour change is most effectively achieved through specific and structured initiatives delivered at a community level. ${ }^{141}$ This involves four progressive steps:

1. identifying the barriers and benefits to an activity.

2. developing a strategy that utilizes 'tools' that have been shown to be effective in changing behaviour.

3. piloting the strategy.

4. evaluating the strategy once it has been implemented across a community.

This targeted and thorough approach underlines how potentially difficult and resource hungry effective behaviour change programmes can be. Ultimately, orchestrated behaviour change is a matter of implementing an integrated package of interventions that change the social logic that people actually live under. This means not only considering the psychological impact of communications but also facilitating an environment that is supportive of change. This is not beyond a government's ability to realise but it does mean looking beyond the traditional policy interventions of regulation and information. ${ }^{142}$

The literature in this area consistently calls for a mix of interventions that responds to all stages of the life cycle of social and individual behaviour change. In this chapter, elements of this life cycle are explored through an overarching structure for promoting sustainable behaviours developed by a unit within DEFRA for the British Government. ${ }^{143}$ The model contains four categories of intervention engage, enable, encourage and exemplify. While the elements discussed in this chapter differ from the elements and their categorisation in the original model, it serves to provide an accessible framework for the key elements that need to be considered.

\footnotetext{
${ }^{141}$ Doug McKenzie-Mohr and William Smith, Fostering Sustainable Behaviour: An Introduction to Community-Based Social Marketing, New Society, British Columbia, 1999

${ }^{142}$ Tim Jackson, op. cit., David Halpern et al., op. cit.

${ }^{143} \mathrm{http}: / /$ www.sustainable-development.gov.uk/index.asp
} 


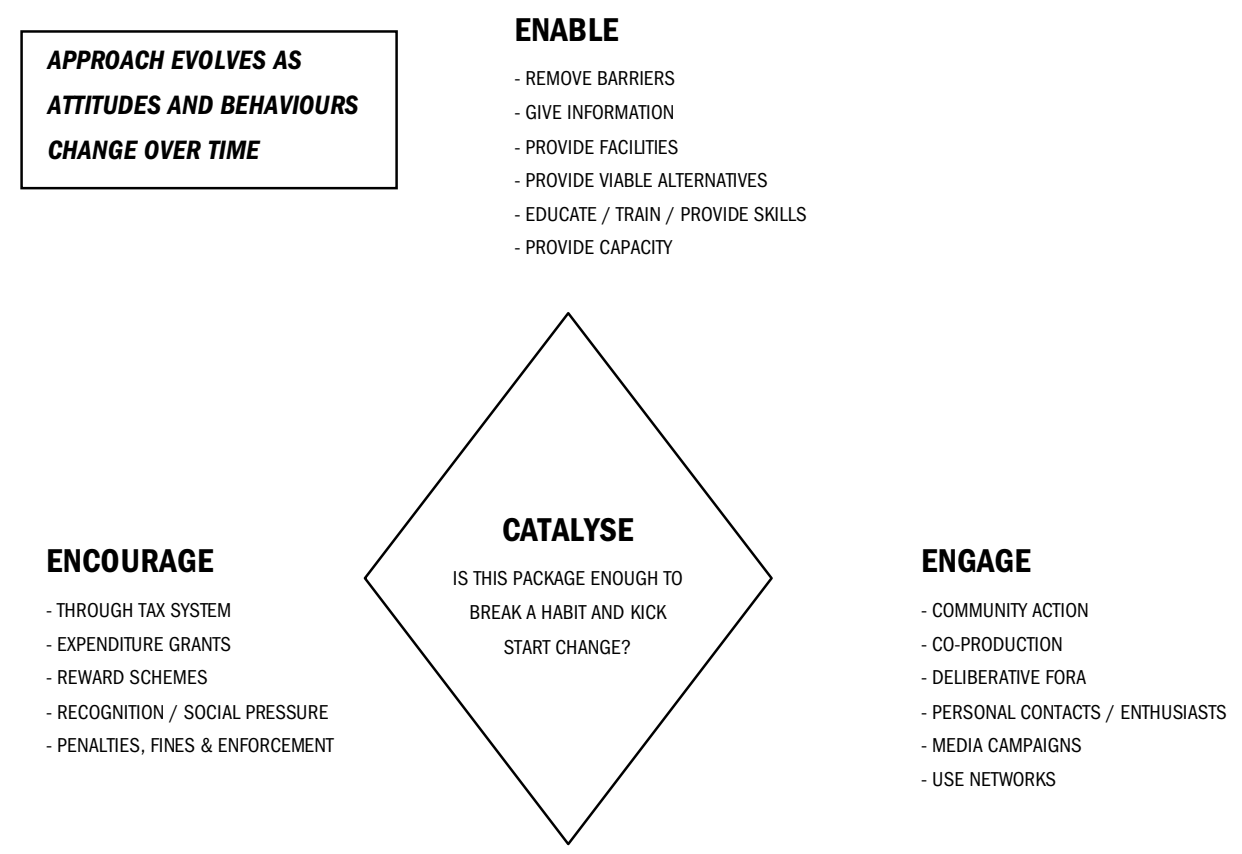

\section{EXEMPLIFY}

- LEADING BY EXAMPLE

- ACHIEVING CONSISTENCY IN

POLICIES

Figure 4.2 Evidence-based model of behaviour change ${ }^{144}$

\subsection{Engage - getting people involved}

\subsubsection{Information and communication}

There is a key difference between information that educates and directed communications that lay the basis for action: "Education... is a broadening exercise. It uses examples to reveal layers of complexity, leading to lower certainty but higher understanding. Campaigning maximises the motivation of the audience, not their knowledge. Try using education to campaign, and you will end up circling and exploring your issue but not changing it." ${ }^{145}$ While education plays an important role in evolving social consciousness, building a mandate for policy makers and sending signals to the market, it is unlikely to result in immediate behaviour change.

For a more direct response, information can't be passive. It has to be actively communicated in ways that are mindful of how information is actually received and purposeful in what is trying to be achieved. An indication of how active communications might work is outlined by John McClure in his

\footnotetext{
144 http://www.sustainable-development.gov.uk/what/priority/changing-behaviour.htm

${ }^{145}$ Campaign Strategy, "12 basic guidelines: Motivation not education”, accessed at

http://www.campaignstrategy.org/cr12 1.html on 3rd November 2006
} 
work on communicating risk: "People are more likely to prepare when the information they receive has several features: It provides specific details on how to prepare, and where to get further information; it comes from many different sources that are trusted; it is disseminated through different media, is disseminated frequently and the information across different sources is consistent." ${ }^{146}$ Communications that aim to change behaviour should primarily provide the target audience with information that will help them adopt the new behaviour. ${ }^{147}$ More information is not a substitution for good communication - large amounts of information may lead to higher levels of concern but is also likely to lead to higher levels of confusion and helplessness if it is presented without direction. ${ }^{148}$

\subsubsection{Relevance}

If public opinion was ever homogenous, it isn't in the modern world. Diverse forms of communications, information transfer, information overload, freedom of speech and plurality of social norms makes society today more diverse, fragmented and complex than it has ever been. ${ }^{149}$ Messages that seek to be persuasive have to be personalised: "In order to be seen as real, something must first attract our attention." ${ }^{150}$ This can only be achieved by connecting the message to everyday perceptions and experiences. As Frameworks assert, when the story doesn't fit the required policy, the story needs to change. ${ }^{151}$

The Elaboration Likelihood Model (ELM) holds that the relevance of the message effects the way we process it. The model makes the distinction between two types of cognitive processing - central and peripheral. When a message or action is perceived to be relevant it is prioritised and time is taken to elaborate on its implications. When a message is considered less relevant it is instead processed on the basis of associated cues. While elaborated central processing is more likely to lead to lasting attitude change, peripheral processing still offers opportunities for influence. One of the key cues associated with peripheral processing is 'source attractiveness' or the potential reward from the new behaviour. This reward can be either material or aspirational. From an ELM perspective, the association between a number of celebrities and the Toyota Prius helps to explain their rampant popularity. The suggestion that peripheral processing can lead to attitudinal change comes with the caveat that it has to be consistently reinforced if it is to be enduring. ${ }^{152}$

In The Activation Point, Kristen Grimm reinforces the importance of relevancy by arguing that while the public can often be sceptical of statistics, illustrating them in a manner that is personalised can

\footnotetext{
${ }^{146}$ John McClure, op. cit., p. 17

${ }^{147}$ Andrew Darnton, "Driving Public Behaviours for Sustainable Lifestyles", op. cit., p. 51

${ }^{148}$ Kristen Grimm, "The Activation Point", Spitfire Strategies, December 2006

${ }_{149}$ James Ogilvy, "What Strategists Can Learn From Sartre", 2003 accessed at http://www.strategybusiness.com/press/article/03405?pg=all on $9^{\text {th }}$ December 2006, Joanna Collins et al., op. cit.

150 Jeanne Liedtka on William James, "Is Your Strategy a Duck?", Journal of Business Strategy, Vol. 27, No. 5, 2006, p. 33

${ }^{151}$ Frameworks Institute, op. cit.

${ }^{152}$ Tim Jackson, op. cit.
} 
be effective. The examples she gives include how many trees might be saved if 1,000 people stopped receiving junk mail and how much household energy bills can be reduced by lowering the thermostat by a couple of degrees. ${ }^{153}$ Communicating climate change from an angle of what needs to be done to protect and enhance local interests is an effective way to engage the public with the broader issue and sets the scene for more progressive action. People don't need the technical details about climate change any more than they need to know about how an aeroplane works to get on one. To be persuaded to act, they need to know what the issue means in the context of their lifestyle and how they can manage it. ${ }^{154}$

\subsubsection{Message framing}

As discussed in Chapter 3, people respond to information differently because they are driven by different motivational needs. Add in other demographic factors such as age, gender, culture and wealth and it becomes easy to understand why everyday marketing practice carefully selects and targets its audience. Selling an idea is the same as selling a new product or a service, it has to be targeted: "The most successful communications campaigns are the ones which tightly define their target audiences and develop messages appropriate to them." ${ }^{155}$ While some products and services naturally lend themselves to certain markets and vice versa, the challenge of selling climate change is that it needs to reach nearly the whole market to ensure cohesive and comprehensive action. Given the diversity of motivational wants and needs, climate change has to become a number of different ideas that are sold in different ways.

The objective of framing is to package your message into an existing frame that evokes the desired emotion, attitude or action. This means delivering the message with triggers and cues that already have established meaning. According to Lupia and McCubbins, these cues can be incredibly subtle: "People choose to disregard most of the information they could acquire and base virtually all of their decisions on remarkably little information. ${ }^{156}$ A good example of how powerful framing can be is demonstrated by a litter reduction campaign in Texas that was primarily targeted at young males. The campaign avoided discussing environmental impacts and focused solely on emotive triggers that would resonate with the target group such as belonging and state pride. The tag line of the campaign was 'Don't mess with Texas'. The campaign was effective - littering decreased by 29 percent in 12 months. ${ }^{157}$

The emotive relationship between values and action is more powerful than the rational link between fact and action. After extensive audience testing, the Frameworks Institute concluded that the important values to invoke in climate change communications are 'big ideas' like management,

\footnotetext{
${ }^{153}$ Kristen Grimm, op. cit.

${ }^{154}$ John McClure, op. cit., p. 7

${ }^{155}$ Futerra, "Communicating Sustainability", UNEP, 2005, p. 14

${ }^{156}$ Arthur Lupia, Matthew D. McCubbins, The Democratic Dilemma, Cambridge University Press, Cambridge, 1998, p. 2

${ }^{157}$ Joanna Collins et al., op. cit., p. 26
} 
planning, responsibility, initiative and progress. ${ }^{158}$ Frank Luntz argues that ideas like efficiency, energy independence and energy diversity are also effective. ${ }^{159}$ These words have a meta-narrative of being solutions orientated and are both intuitive and psychologically affirming to a modern capitalist society. They are frames that are compatible with the dominant 'economic' frame, not in conflict with it.

In The Achieving Society, behavioural psychologist David C. McClelland explores the human needs that drive economic development. ${ }^{160} \mathrm{He}$ identifies three main human motivations over and beyond basic needs - the need for affiliation, the need for power and the need for achievement. 'Affiliation' is an approval-seeking motive; it is also defined by concern for what others are doing and trust in friends over experts. 'Power' is defined by controlling situations and dominance activities. This means 'avoiding weakness' and 'taking pleasure in winning'. 'Achievement' equates to greater participation in community activity, having resilience to social pressure and a preference to work with experts over friends. The 'achievement' motive responds to 'task orientated' challenges and seeks to test and improve personal performance. McClelland's early work on establishing these three core motivational drivers can be traced through to Rose et al's recent work on motivational groupings - 'settlers', 'prospectors' and 'pioneers'. ${ }^{161}$ 'Settlers' value belonging and dislike anything that threatens identity (predominantly affiliation). 'Prospectors' have external directed needs and require the esteem of others. It follows that they seek material success and recognition for it (predominantly power). 'Pioneers' are driven by inner-directed needs and value new challenges and discovering new meaning (predominantly achievement).

By targeting the emotions that are at the heart of these core human motivations, communications can position climate friendly actions as both salient and compelling: "Advocates do not have to manufacture new feelings; they simply need to tap them." ${ }^{162}$ Rose et al suggest how the three groups might receive climate change messages differently and how inducements might be framed to connect with their core motivations. ${ }^{163}$

\footnotetext{
${ }^{158}$ Frameworks Institute, op. cit.

${ }^{159}$ Frank Luntz interviewed by Amanda Griscom Little, op. cit.

${ }^{160}$ David C. McClelland, The Achieving Society, D. Von Nostrand Company, Princeton, 1961

${ }^{161}$ Chris Rose et al, "Climate Change Communications - Dipping a Toe into Public Motivation", op. cit.

162 Kristen Grimm, op. cit.

${ }^{163}$ Chris Rose et al, "Climate Change Communications - Dipping a Toe into Public Motivation”, op. cit., p. 3-4
} 


\begin{tabular}{|c|c|c|c|}
\hline & Settlers & Prospectors & Pioneers \\
\hline $\begin{array}{l}\text { Climate change is a long } \\
\text { term global problem }\end{array}$ & $\begin{array}{l}\text { It's not a problem unless } \\
\text { it affects my family, my } \\
\text { locality, my identity and } \\
\text { traditions }\end{array}$ & $\begin{array}{l}\text { It's not a problem unless } \\
\text { it affects my prospects } \\
\text { for success }\end{array}$ & It's a problem \\
\hline $\begin{array}{l}\text { Climate change is worthy } \\
\text { of action }\end{array}$ & $\begin{array}{l}\text { Someone should do } \\
\text { something about it but } \\
\text { not me }\end{array}$ & $\begin{array}{l}\text { Society should organsise } \\
\text { preferably under a high } \\
\text { status brand in the } \\
\text { system }\end{array}$ & $\begin{array}{l}\text { I'll do it myself and } \\
\text { change the system if I } \\
\text { have to }\end{array}$ \\
\hline $\begin{array}{l}\text { We're offering you a } \\
\text { solution }\end{array}$ & $\begin{array}{l}\text { I'd rather not change but } \\
\text { if everyone else is doing } \\
\text { it I will }\end{array}$ & $\begin{array}{l}\text { I'm not taking up causes } \\
\text { or things that may not } \\
\text { work but if its cool and } \\
\text { advantageous to me then } \\
\text { I'm on board }\end{array}$ & $\begin{array}{l}\text { If it's ethical and for the } \\
\text { good of the planet we } \\
\text { must do it }\end{array}$ \\
\hline $\begin{array}{l}\text { Inducement to act - for } \\
\text { example, fit solar panels }\end{array}$ & $\begin{array}{l}\text { Leading figureheads have } \\
\text { them on their roofs, the } \\
\text { council supplies them, } \\
\text { my neighbour has one - } \\
\text { they're normal }\end{array}$ & $\begin{array}{l}\text { It's added value to my } \\
\text { home, they're the latest } \\
\text { thing, made by a high } \\
\text { quality brand with } \\
\text { options for up-grade }\end{array}$ & $\begin{array}{l}\text { I'm in a network of } \\
\text { interesting people, } \\
\text { achieving something for } \\
\text { a good cause }\end{array}$ \\
\hline
\end{tabular}

Table 4.1 Sample responses of settlers, prospectors and pioneers to climate change issues

Rose et al readily admit that these broad groupings are gross simplifications and argue that a far richer picture emerges when the groups are broken out in more detail. Looking specifically at the New Zealand context, it would be interesting to draw on the work of Jill Caldwell and Christopher Brown's 8 Tribes - The Hidden Classes of New Zealand. ${ }^{164}$ This categorisation of contemporary New Zealand society may provide valuable insights into the core values and emotions that can be tapped to engage the New Zealand public with climate change.

\subsubsection{Credibility}

Persuasion isn't just about the message; the messenger also needs to be credible and trustworthy. Lupia and McCubbins argue that the most trustworthy messengers are individuals who are perceived to either make significant investments in their claims or who stand to pay a penalty if they are found to be disingenuous. ${ }^{165}$ Scientists are trustworthy because their reputations and, indeed, careers depend on the validity of their assertions. A poll conducted by Yale University in 2005 found that 83 percent of Americans trusted university scientists compared to 62 percent who trusted industry scientists and 56 percent who trusted their state governor. ${ }^{166}$ On the issue of climate change, business people have been found to be more credible than environmentalists seemingly because

\footnotetext{
${ }^{164}$ Jill Caldwell and Christopher Brown, 8 Tribes - The Hidden Classes of New Zealand, Wicked Little Books, 2007

${ }^{165}$ Arthur Lupia, Matthew D. McCubbins, op. cit., p. 9

${ }^{166}$ Daniel Abbasi, op. cit., p. 56
} 
they are perceived to have more to lose. ${ }^{167}$ Frank Luntz argues that with regard to climate change the most effective messengers are the ones who initially came from a contrary position: "The most effective voice would be a convert, someone you least expect to speak out." ${ }^{168}$ This underlines the importance of encouraging business figureheads, unexpected role models and even previous climate change detractors to speak out in public about the importance of acting on climate change.

As environmental issues are dogged by uncertainty, trust becomes a pivotal issue. Trust in governments on environmental issues tends to be low. One UK study suggests that only one quarter to one third of the population believe that the government is acting in the public interest. ${ }^{169}$ The Global Environmental Change Programme of the Economic and Social Research Council (ESRC) has made some recommendations about how governments should deal with low public confidence on environmental issues. Firstly, they argue for better institutions built on scientific knowledge with openness about risk and uncertainty. Secondly, they call for more deliberative policy development emphasising legitimacy, transparency and public ownership. To do this they suggest:

- ensuring that input comes from a wide range of expert and non-expert sources.

- interactive research; encouraging and supporting people to re-explore their opinions.

- new ways to make decisions - interactive research is allowed to evolve into action. ${ }^{170}$

Given that action on climate change requires majority buy-in, it is crucially important that the issue remains credible. This means honesty about its implications and the necessary courses of action: "This is important for ethical reasons but is also strategically sound: people have been shown, in laboratory experiments, and in real life, to be adept at detecting when they are being manipulated, even subtly. They discount scripted events or speakers and the reliability of the information being conveyed." ${ }^{n 11}$ Advocates for climate change need to be knowledgeable, sincere and capable of emotive spontaneity. The individuals who lead the engagement process need to be free from institutional constraints and enabled to speak authentically about the difficult trade-offs inherent in the issue.

\subsubsection{Consensus}

A 2005 poll conducted by the University of Maryland found that the 51 percent of people who believed there is a scientific consensus on climate change also believed that high cost steps were both necessary and acceptable to mitigate climate change. Where people believed that scientists were divided, only 17 percent favoured high cost steps. ${ }^{172}$ While this finding indicates that

\footnotetext{
167 Ibid

${ }^{168}$ Frank Luntz interviewed by Amanda Griscom Little, op. cit.

${ }^{169}$ MORI poll referred to in Joanna Collins et al., op. cit., p. 9

170 Ibid

171 Daniel Abbasi, op. cit., p. 44

172 Daniel Abbasi, op. cit., p. 32
} 
establishing certainty about climate change is a fruitful communications objective, a number of commentators have been quick to emphasise that consensus isn't necessarily achieved by rejoining the debate as to whether climate change is happening or not with climate change detractors. ${ }^{173}$

Using quantitative surveys and values segmentation, Rose et al. not only provide insight into what people believe about climate change but also why they do so. As previously cited, they found that the majority of people in the UK already believe that climate change is happening and that it is manmade. Looking at the minority of people who do not believe climate change is manmade they found that the group is disproportionately made up of 'settlers' - individuals who favour the status quo, believe mostly in what they experience and are disinclined to listen to 'experts'. A communications campaign that seeks to raise certainty amongst this minority group is not only likely to be unsuccessful but it also risks re-opening an argument that the majority of people had thought settled: "The battle for the public's acceptance of climate change has been won. Continuing to focus our efforts on detractors, however noisy or annoying they may be, is a red herring." ${ }^{174}$ The strongest way to establish consensus is to assume it. That climate change is happening should be treated as simple scientific fact - like the rotation of the earth or the water cycle. ${ }^{175}$

\subsubsection{Consequences}

While there is much in climate change communications literature about not inducing fatalism by portraying catastrophic future images, it is interesting to note that health campaigns often find that emphasising the consequences of an action i.e. lung cancer as a result of smoking, has a stronger effect than emphasising benefits i.e. fitness and saving money. ${ }^{176}$ The use of negative imagery in drink-driving campaigns also suggests that consequence is a powerful means of changing behaviour. These communications demonstrate the principle of loss aversion, a theory that describes how humans subjectively value a loss more than the equivalent gain. ${ }^{177}$ Accordingly, people respond more actively when they are told what they stand to lose than when they are told what they stand to gain or save.

The potency of employing loss aversion as a communications technique relies on the extent of control that the target audience has over the outcome, for example using harsh consequences in a drink-driving campaign is appropriate because a driver has the choice not to drive. Consequently, while using apocalyptic images is a fruitless way to motivate people to act on climate change per se, loss aversion can still be very effective in targeted behaviour changes campaigns. Wa\$ted!, a TV3

\footnotetext{
${ }^{173}$ Gill Ereut and Nat Segnit, "op. cit. and Chris Rose et al, "Climate Change Communications - Dipping a Toe into Public Motivation", op. cit.

${ }^{174}$ Futerra, "The Rules of the Game: Principles of Climate Change Communications", op. cit., p. 16

${ }^{175}$ Gill Ereut and Nat Segnit, "op. cit.

176 John McClure, op. cit., David Halpern et al., op. cit.

${ }^{177}$ Daniel Kahneman and Amos Tversky, “Loss Aversion in Riskless Choice: A Reference Dependent Model”, Quarterly Journal of Economics 106, 1991, p. 1039-1061
} 
series starting in February 2007 that audits household waste and energy usage stands to demonstrate this point effectively.

\subsubsection{Scenarios}

While presenting the potential consequences of climate change without qualifying what can be done to prevent them is likely to induce alarmism and result in apathy, contrasting scenarios can draw attention to the choices that society and individuals have in the present. Scenarios are detailed constructions of possible futures. They allow people to explore how complex interrelated factors might play out - such as how climate change necessitating energy conservation leads to increased communal activity and results in less crime ${ }^{178}$ - in a manner that is visible, digestible and revealing: “Scenarios are the most powerful vehicles I know for challenging our 'mental models' about the world, and lifting the 'blinders' that limit our creativity and resourcefulness." ${ }^{179}$ Scenarios strengthen the tie between circumstance and action. This connection can reveal alarming future impacts without being debilitating because the warnings come hand-in-hand with insights into feasible courses of action that can mitigate them. Hence, they can be powerful motivators for disrupting the status quo and initiating action. While scenario planning is a tool primarily used by decision makers, it is also a means to capture the collective imagination - especially when in the hands of society's storytellers.

\subsubsection{Storytelling}

Storytelling is the oldest means of transferring knowledge and remains central to modern-day communications: "It is our chief means of looking into the future, of predicting, of planning, and of explaining... most of our experience, our knowledge and our thinking is organised as stories." ${ }^{180}$ If the technical aspects of communications framing such as language, message framing and structure refer to composition, storytelling relates to how the melody sounds. It is through storytelling that reframing actually takes place.

Branding is a modern incarnation of storytelling used synonymously with marketing and corporate identity. Branding is a critical concept to employ in climate change communications because it provides a vehicle to make climate-friendly behaviour desirable rather than dutiful or obedient. ${ }^{181}$ Futerra describe brand as the 'glue' that can hold a climate change communications strategy together. A well-managed brand not only reinforces itself through consistency of use and message, it becomes a dynamic and integrated cue for identity, personality and behaviour. Brand should neither be used nor dismissed flippantly in the context of climate change. A cautionary tale about branding comes from the German climate change communications campaign that enlisted comical penguins as a main graphic. While it may have conveyed a certain aspect of climate change, it proved to be a

\footnotetext{
${ }^{178}$ Dr Kevin L. Anderson, “UK SCE Scenarios”, Tyndall Centre for Climate Change Research, UMIST, UK, $16^{\text {th }}$ February 2000

179 Peter Schwartz, The Art of the Long View, Currency Doubleday, New York, 1996, p. xiii

${ }^{180}$ Mark Turner, The Literary Mind: The Origins of Thought and Language, Oxford University Press, 1996, p. 4

${ }^{181}$ Gill Ereut and Nat Segnit, op. cit., p. 27
} 
weak vehicle after extensive flooding occurred in 2002. The comic illustrations were incompatible with the destructive reality of events linked to climate change. ${ }^{182}$ At best, brand becomes a totem for the overall purpose, a touchstone for the vision or "compelling alternative future" ${ }^{183}$ that is being strived for.

Science tells us what is happening to the climate but not what society needs to do and become. To prepare a foundation for cohesive action, visionary outcomes are required to let everyone know where they need to be and why ${ }^{184}$ The emotive, simple and cohesive messages that were developed to mobilise action in the World Wars provide an apt illustration for this point. The Break Through Institute gives a specific vision for action on climate change. Rather than simply target "carbon neutrality', they place climate change within the context of other social aspirations and thereby demonstrate the interconnectivity of issues. Their main objectives are:

- slow and reverse global warming.

- create millions of new jobs in the clean energy economy.

- create a "race to the top" in social and environmental performance by corporations and governments.

- create poison-free products made from materials that can be continuously recycled.

- $\quad$ reduce crime and increase the quality of life for people living in cities. ${ }^{185}$

As outlined in the strategic thinking model in Chapter 2, the use of vision is a powerful means of highlighting the gap between intent and reality: “A positive, transformative vision doesn't just inspire, it also creates the cognitive space for assumptions to be challenged and new ideas to surface." 186 Climate change commentators often invoke the need for vision by citing the 'man on the moon' analogy ${ }^{187}$ It is within this gap that the creativity and expertise of storytelling comes to the fore as a motivating and galvanizing force: "Myth (which can reconcile seemingly irreconcilable cultural truths) can be used to inject the discourse with the energy it currently lacks." ${ }^{188}$ While small individual actions may seem meaningless in isolation they can become inspiring when depicted en masse. Once a meaningful vision has been established, artists, filmmakers, musicians, writers, actors, orators, designers, architects and marketers need to be enlisted to embed the challenge of climate change into society's imagination. With regard to climate change, storytelling isn't about changing people; it's about creating a cause.

\footnotetext{
182 Jessica Cederberg Wodmar, op. cit.

${ }^{183}$ Futerra, "Recommendations: UK Communications Strategy on Climate Change", London, 2005, p. 23

${ }^{184}$ Michael Shellenburger and Ted Nordaus, "The Death of Environmentalism", The Break Through Institute, 2004, p. 34

${ }^{185}$ Accessed at http://www.thebreakthrough.org/strategy.php on 10th January 2007

${ }^{186}$ Michael Shellenburger and Ted Nordaus, op. cit., p. 31

${ }^{187}$ Tom Burke and John Ashton, "Climate Change: Changing the Frame“, London, February 2005

${ }^{188}$ Gill Ereut and Nat Segnit, op. cit., p. 8
} 


\subsubsection{Coordination and penetration}

In both the UK and Sweden, climate change communications strategies have included a detailed audit of organisations and agencies actively working on issues related to climate change. ${ }^{189}$ The purpose was twofold - to link activities and to avoid diffusion. In a noisy world of information and advertising it is important that your message has a critical mass. In both countries, once a brand had been centrally developed, other organisations were invited to adopt the platform.

Given that climate change is here for the long-term and social-marketing campaigns may take a long time to work, it is inevitable that other issues will eclipse climate change on a regular basis. Communications about climate change have to work around the competition. In a recommendation to DEFRA, Futerra emphasise the need for ' $360^{\circ}$ communications' that embed climate change messages in the everyday environment. ${ }^{190}$ The Apollo Energy strategy in the USA raises the profile of climate change by integrating it with energy security, an issue that is already high up on the public radar. ${ }^{191}$ The Swedish campaign - 'The Greenhouse effect affects you, how do you affect it?' - was dynamic in how it used media channels. When war broke out in Iraq in 2003, it pulled out of national media anticipating that its message would be swamped, and transferred its resources to local channels where it wasn't competing. ${ }^{192}$

\subsubsection{Networks}

The UK think-tank Demos argue that people are increasingly turning away from centralised authorities and traditional media channels to find out what to think and how to act. ${ }^{193}$ Extended peer networks, enhanced by global communications, are becoming the "anchors of identity and behaviour. ${ }^{194}$ This places constraints on some traditional forms of mass communication but opens up new opportunities.

Rather than seeing persuasion as a dominant influence on attitudes and behaviour, Social Learning Theory suggests that the most potent stimulus for new behaviours is experience. Experience can also be inferred from people around us and particularly from the ones with whom we identify. Indeed, observed experience can influence our behaviour as much as our own. ${ }^{195}$ Social Proof is a related theory that argues that we moderate our situational behaviour based on the behaviour of those around us even when we don't know them. The common behaviour denotes the accepted social norm. Examples of this include the way we drive on a motorway and our complicit response to

\footnotetext{
189 Jessica Cederberg Wodmar, op. cit., Futerra, "Recommendations: UK Communications Strategy on Climate Change”, op. cit.

${ }^{190}$ Futerra, "Climate Change: Large-Scale National Activities”, 2005

191 http://www.apolloalliance.org/

192 Jessica Cederberg Wodmar, op. cit.

193 Joanna Collins et al., op. cit., David Halpern et al., op. cit.

194 Joanna Collins et al., op. cit., p. 6

${ }^{195}$ Tim Jackson, op. cit.
} 
canned laughter on a comedy show. ${ }^{196}$ The potential benefits of considering both Social Learning and Social Proof in policy interventions is highlighted by research that has demonstrated that people who are active in community and neighbourhood networks are significantly more prepared for natural hazards than those who are not. ${ }^{197}$ Health research in the UK has demonstrated that our perceptions of other peoples' attitudes to precautionary health practices are more influential than factors such as increased awareness of the health risk or its severity. ${ }^{198}$

Direct interpersonal approaches to behaviour change are also effective. In a study comparing the affect of leaflets, telephone calls and face-to-face reminders on voter turnout, it was found that faceto-face reminders boosted turnout by 15 percent. Leaflets produced a marginal 2 percent increase while telephone calls were found to have a negative effect. ${ }^{199}$ Another example of the power of interpersonal communication is how the installation of a dedicated donor liaison nurse at the Royal Bolton Hospital has increased organ donations by 700 percent. ${ }^{200}$ Given that peer education programmes are increasingly employed by NGOs to broach difficult issues such as sex education and drug use it is easy to see why Daniel Abbasi asserts: "The most persuasive and trusted channel for propagating information on controversial issues like climate change is peer-to-peer dialogue." ${ }^{201}$ If this is the case, the climate change communications and engagement strategy not only needs to think about direct means of influencing the public but also managing and cultivating the social energy already at play. ${ }^{202}$

In The Tipping Point, Malcolm Gladwell studies a range of modern social epidemics and analyses what caused them. ${ }^{203} \mathrm{He}$ holds that big changes often result from small changes at the margins. Furthermore, when things change they can do so very quickly. Just as there are potential tipping points in the climate system, Gladwell's theory would suggest that with the right momentum and leverage there could also be tipping points in the social response. According to Gladwell, the spread of a social epidemic depends on three elements - 'the law of the few', 'the stickiness factor' and 'the power of context'. 'The law of the few' is about three types of people - mavens, connectors and salesmen. In short, mavens are people who create/gather knowledge and are socially motivated to share it. Connectors are individuals who are at the hub of social groups and are also able to bring diverse groups of individuals together. Salesmen are charismatic, optimistic individuals who are able to persuade others of their worldview. The 'stickiness factor' relates to the impact and power of the message. The 'power of context' refers to the actual environment that people operate in - their circumstances and their physical locality. He holds that intelligent action can spark a social epidemic by concentrating on these elements - finding the right messengers, creating a powerful message and

\footnotetext{
${ }^{196}$ David Halpern et al., op. cit.

${ }^{197}$ John McClure, op. cit., p. 22

${ }^{198}$ David Halpern et al., op. cit.

${ }^{199} \mathrm{Ibid}$

$200 \mathrm{lbid}$

${ }^{201}$ Daniel Abbasi, “op. cit., p. 44

202 Joanna Collins et al., op. cit., p. 17

${ }^{203}$ Malcolm Gladwell, "The Tipping Point”, Abacus, 2000, p. 7
} 
delivering it in an amenable context. Relating Gladwell's theory to climate change, there are already substantial numbers of scientists, economists and policy experts playing the role of mavens. We now need connectors and salesmen at all levels of society who can deliver a 'sticky' message and make the action on climate change contagious.

\subsubsection{Dialogue and participation}

The above discussion outlines the importance of communication not only as a means of raising awareness but also as a means of creating new social norms and meaning: "Dialogue has the potential to alter the meaning each individual holds and, by doing so, is capable of transforming the group, organization, and society." ${ }^{204}$ It follows that genuine engagement necessarily needs to result in a flexible two-way process.

According to Stephen Kaplan, the key to promoting environmentally friendly behaviour relies on "a coherent conception of human nature." ${ }^{205}$ From an evolutionary perspective, the human capability to process information has been our adaptive advantage. As a result, circumstances where we are able to employ this capability are naturally attractive to us and circumstances where we were unable to do so were not. From Kaplan's perspective, human motivation to engage with a problem is directly linked with the opportunity to solve it. If people don't have the ability to actively participate in solving a problem they instinctively avoid it: "Helplessness is not only an important issue in the context of environmentally friendly behaviour, it is perhaps the pivotal issue." ${ }^{206}$ Kaplan argues that programmes that seek to change behaviour need to be designed around three principles:

- $\quad$ people are motivated to know, to understand what is going on; they hate being confused or disorientated.

- $\quad$ people are also motivated to learn, to discover, to explore; they prefer acquiring information at their own pace and in answer to their own questions.

- $\quad$ people want to participate, to play a role, in what is going on around them; they hate being incompetent or helpless. ${ }^{207}$

People become engaged when they are allowed to explore a subject for themselves. Kaplan asserts that while people don't like being dictated to, they do enjoy being guided. This support allows people to discover, test and reaffirm their own understandings and solutions as they go. In a presentation delivered by a local authority's Climate Change Advisor in October 2006, it was recognised that

\footnotetext{
${ }^{204}$ Nancy Dixon quoted in Jeanne Liedtka, “Strategic Thinking: Can it be Taught?”, op. cit. p. 125

${ }^{205}$ Stephen Kaplan, op. cit., p. 498

${ }^{206} \mathrm{Ibid}$

${ }^{207} \mathrm{Ibid}$
} 
dialogue was one of the crucial factors in building constituency and initiating community action on climate change. ${ }^{208}$

\subsection{Enable - creating opportunties for action}

Many aspects of enabling people to adopt new behaviours lie squarely with the removal of structural barriers and the provision of infrastructure, products and senvices. However, other aspects of enabling people such as the accessibility and functionality of policies, products and services rely on the process of their design. As this research project is concerned with communications and engagement, it is this interpersonal aspect of enabling people that is explored.

\subsubsection{Participatory problem-solving and co-production}

Where engagement stops and enabling begins is a moot point. In the same way that engagement is a critical part of strategy development (as discussed in Chapter 2), so too is it a critical aspect of strategy implementation and policy development. Involving people in the problem-solving process not only connects them to the issue, it leads to the development of better solutions. In this sense, involving people in the development of policy is a critical aspect in enabling society to adopt new behaviours.

Kaplan's proposed participatory problem-solving approach has the advantage of blending specific expertise with local knowledge. Effective participatory problem-solving recognises that people are fully capable of changing their behaviour when given the opportunity to participate in a meaningful way - i.e. guided with information, allowed to come to their own decisions and empowered to act. While local programmes need to be coordinated with regional and national objectives, individual and local groups are given ownership over finding solutions that are "both satisfying and responsible" 209 . He asserts that a participatory problem-solving approach should:

1. be sensitive to going with the grain, to recognising and working with the motivations and inclinations characteristic of this species.

2. treat the human cognitive capacity as a resource.

3. engage the powerful motivations for competence, being needed, making a difference, and forging a better life. ${ }^{210}$

Kaplan's participatory problem-solving approach is echoed by the UK Prime Minister's Strategy Unit's co-production approach to policy development. Like Kaplan, the Strategy Unit cite the need to

\footnotetext{
208 Waverley Parsons, “Climate Change and Local Government”, presented at 'Climate Change: The Policy Challenges', Wellington, $6^{\text {th }}$ October 2006

${ }^{209}$ Stephen Kaplan op. cit., p. 500

${ }^{210}$ Stephen Kaplan, op. cit., p. 505
} 
supplement the traditional methods of policy intervention with "a more realistic understanding of how people really do make choices and engage in society" but also "twinned with a sustained dialogue over the implications for the citizen's and state's responsibilities." ${ }^{211}$ They argue that the coproduction of policy not only leads to more effective policy but that it implicitly leads to a better society where citizens are able to take more responsibility for their actions and more control of their lives.

While participatory problem solving and co-production may be effective forms of enabling social change it is not to say that engaging and empowering communities to develop their own solutions is a means of abdicating responsibility for achieving outcomes. Supporting and facilitating the conditions that allow communities to explore, establish and implement climate change initiatives is likely to take much creativity, commitment and coordination.

\subsubsection{Resourcing 'co-produced'212 programmes}

The principle of co-production presents an effective method of enabling communities and organisations to respond to climate change and offers the following benefits:

- scale - many devolved programmes can operate independently and simultaneously.

- functionality - solutions are developed to fit local requirements.

- divergence - ability to compare and contrast the effectiveness of different approaches.

- participation - individuals become committed to realising target behaviours and outcomes.

However, unless governance goes hand-in-hand with engagement and provides the infrastructure and resources for co-produced programmes to be realised, the process is both disingenuous and useless. In Sweden, the Government's climate investment programme, 'Klimp', has been true to its stated intent and has invested US\$640.1 million into local government, private sector and community programmes since 2003. Programmes have included smart heating, anaerobic digestion of waste to produce bio-gas, transition to bio-fuels, energy efficiency and public education programmes. The programmes have saved an estimated 785,000 MWh of energy a year and resulted in emissions reductions that would have cost considerably more to offset by purchasing the equivalent carbon credits. ${ }^{213}$ While managing devolved programmes is notoriously difficult due to issues of contestability, accountability and monitoring, this research project explores one model of how partnerships between government, business and community might be effectively run.

\footnotetext{
${ }^{211}$ David Halpern et al., "op. cit., p. 68

${ }^{212}$ The common principles of participatory problem solving and co-production will now be referred to under the one term 'co-production'. This does not represent a preference for one approach over the other but rather a preference for brevity. It is acknowledged that there are key differences between the two approaches but for the sake of this discussion they are not substantially relevant.

${ }_{213}^{21}$ Jessica Cederberg Wodmar, op. cit.
} 
Action on climate change is an area in which New Zealand is currently impoverished - the gaps between what the state and the private sector are providing results in uninformed and unsustainable practice. Where the divide between what is being done and what needs to be done is significant, there is room for innovative models that can bridge the gap. Social entrepreneurship combines private sector efficiencies with citizen sector sensibilities to work in the gaps between what the state and private sector provide. The model has evolved prolifically in developing countries over the last 25 years to provide innovative and purposeful programmes to improve health, education, private enterprise, environmental sustainability and social support. A seminal example of social entrepreneurship is the Grameen Bank that runs a banking system for the poor based on participation and mutual trust. Started in 1983, the bank currently has 6.91 million borrowers and covers more than 89 percent of villages in Bangladesh. ${ }^{214}$ The founder Muhammad Yunus was awarded the Nobel Peace Prize in 2006.

For Mair and Seelos the assumption behind social entrepreneurship is: "Poverty is not a normal state but a symptom of a lack of social structures that:

- organize people around economic opportunities.

- empower individuals to look after themselves.

- $\quad$ build communities that look after individuals who fail to do so.

- formalise norms of behaviour that create effective societies and capabilities for learning, growth and development." 215

This statement can be re-written to provide a basis for climate entrepreneurship: 'climate change is not a normal state but a symptom of a lack of social structures that':

- organise people around sustainable practices.

- enable individuals to adopt sustainable practice.

- build communities that encourage individuals to act sustainability.

- formalise norms of behaviour that create sustainable societies and capabilities for learning, growth and development.

Mair and Seelos have identified three models for social entrepreneurship - Complementary, Integrated and Symbiotic. An example of the Complementary Model that specifically relates to climate entrepreneurship is a project run by Bengali NGO, WasteConcern, which has transformed the problem of urban waste into a business opportunity. In Dhaka, a city of 11 million people, WasteConcern intervened to tackle a problem that the city government neither had the labour nor the

\footnotetext{
214 http://www.grameen-info.org/index.html accessed on 14th February 2007

215 Johanna Mair and Christian Seelos, "Social Entrepreneurs as Competitors and Partners in Global Markets", presented at EABIS, Barcelona, $19^{\text {th }}$ September 2005
} 
capital to deal with. WasteConcern collects organic waste, produces compost and sells it. It allows communities to run independent plants and links them with commercial partners who are willing to purchase the product and distribute it to rural areas. The programme has reduced methane emissions, reduced health risks, created 16,000 new jobs, brought about a reduction in the use of chemical fertilisers and achieved government savings: "WasteConcern's complementary model is tied to a profit loop in which everybody is a winner: the public sector, the private sector, the local community, and the NGO itself." ${ }^{216}$ The NGO is improving public health, reducing methane emissions and is also feeding into the private sector - the processes are complementary.

The Integrated and Symbiotic Models are also applicable to climate entrepreneurship. The Integrated Model is where the private sector works hand-in-hand with the public sector to achieve social outcomes. A simple example of this model would be the Government contracting a company to develop and install solar-heating systems to the maximum number of households. Rather than setting prices at the full market rate, the company would work in partnership with the state to find 'value innovation' - keeping a margin that is profitable while making the service widely accessible. Economies of scale, split-pricing models, increased efficiencies and reduced costs all allow the project to be viable. This model has been used to provide mass optical healthcare in India. Aurolab and the Avarind Eye Hospital carry out over 220,000 operations a year to individuals who would otherwise never be able to afford them. While the market price for intraocular lenses is US $\$ 100$, they are sold through the programme at $\$ 4.50$. The venture still makes $\$ 1.60$ profit for every $\$ 1$ spent and is growing on an annual basis. This form of compassionate capitalism focuses on outcomes and affordability rather than profit and achieves both at a spectacular rate. ${ }^{217}$

The 'symbiotic model' is where a company works hand-in-hand with a not-for-profit programme to create a market. This could involve a bio-fuel company involved in a programme to convert conventional vehicles to be bio-fuel compatible (at low cost) in order to develop a market for their product. The company might be given a grant for the seed programme that is relative to downstream emissions reductions. Seed funding could come from a levy on carbon trading/carbon tax or through direct relationships with private sector organisations needing to offset their emissions.

\subsubsection{Linking action through technology}

Modern technology provides an unprecedented communications infrastructure. This provides the ability to coordinate national programmes and leverage existing networks and programmes. An example of how modern technology can be used to enable a coordinated response to climate change is the Science to Action Collaboration run by Yale University. ${ }^{218}$ The Science to Action

\footnotetext{
${ }^{216}$ Johanna Mair and Christian Seelos, "Executive Summary: What Can Companies Learn From Social Entrepreneurs?" IESE, September 2005

${ }^{217}$ Johanna Mair and Christian Seelos, "Social Entrepreneurs as Competitors and Partners in Global Markets", op. cit.

218 http://www. environment.yale.edu/climate/
} 
Collaboration recognises that climate change solutions require leadership from all sectors of society. After an initial conference where representatives from different social sectors came together to identify the sector incentives structures and barriers to action, 39 specific and nationwide action points were established. These action points are coordinated and monitored principally through a web portal managed by Yale. The portal also became a hub for tools and resources on climate change that helps the programmes within interdependent sectors evolve together. Once a functioning network is established, it also becomes easier to identify programmes that are performing and to provide targeted support with substantially less risk and bureaucracy.

\subsubsection{Individual carbon trading schemes}

When the New Zealand Government released its energy strategy for discussion in December 2006, business commentator Rod Oram stated: "The comprehensive architecture and many good ideas make this second framework for energy and climate change much better than the first... [but] there is very little in the framework that will engage and excite the public, let alone many businesses. This will make it hard to sell to voters, thus drastically diminishing its effectiveness." ${ }^{219}$ Echoing this point, George Monbiot argues: "Complex ideas seldom do well in politics, as most people do not have the time or patience required to understand them." ${ }^{220}$ The majority of people are unable to take part in the debate around climate change policy simply because it is too complex to readily understand. The Government's acknowledgement of the confusion over the Kyoto Protocol and the carbon tax are testament to this. ${ }^{221}$ In contrast, individual carbon trading schemes offer an idea that is, at a conceptual level, both attractive and simple. ${ }^{222}$

Individual carbon trading schemes offer a means of enabling individuals to manage their emissions while also becoming more in tune with the link between their lifestyle choices and climate change. ${ }^{223}$ Simplistically, such schemes operate by annually allocating carbon credits to individuals. The allocations are linked to an overall emissions target. The individual then uses their carbon credits every time they purchase a service or product that has a carbon footprint. Carbon credits, in effect, become a second currency that the individuals can save and spend as they see fit. If they do not use all of the carbon allocation they can sell their surplus. If they need more credits than their allocation allows they have to purchase them at a market rate.

While there are many complexities regarding the implementation of such schemes including the feasibility and cost of administration, allocation rights, equity issues, inclusion/exclusion of products

\footnotetext{
${ }^{219}$ Rod Oram, "The Politics of Energy”, Sunday Star Times, Sunday, 17 December 2006

${ }^{220}$ George Monbiot, op. cit., p. 44

${ }^{221}$ New Zealand Government, op. cit.

${ }^{222}$ Simon Roberts and Joshua Thumim, "A Rough Guide to Individual Carbon Trading”, Centre for Sustainable Energy, November 2006

${ }^{223}$ Jonathon Boston, "The Public Interest, Climate Change and the Future of the Planet: Reducing the Sins of Emissions", Institute of Policy Studies, Victoria University of Wellington, 2006, David Miliband, "The great stink: towards an environmental contract", speech at the Audit Commission annual lecture, $19^{\text {th }}$ July 2006
} 
and services and market caps and boundaries, giving people a personal carbon quota can be effective in a number of ways:

- $\quad$ it positions the carbon cost of a product or service at the point of sale allowing individuals to differentiate the impact of specific actions.

- $\quad$ it empowers individuals to take responsibility for their own choices and reinforces actions that are aligned with the public interest.

- $\quad$ because entitlement is provided up front, loss aversion becomes linked with behaviours that have a carbon footprint rather than with mitigating actions.

- it allows consumers to financially realise the value of products and services provided by companies who have built sustainability into their business practice - making them an economic choice as well as an ethical one. This will drive the market to create more lowcarbon choices for the consumer.

- $\quad$ it provides the basis for competition between households, friends and colleagues and raises the status of low-carbon choices.

- it is likely to stimulate interest about climate change and how further efficiencies can be maximised.

- it increases the likelihood of stimulating the 'positive spill-over' of pro-environmental behaviours.

- $\quad$ it provides a comprehensive platform of participation and shifts social consciousness with regard to sustainability.

\subsection{Encourage - motivating behaviour}

\subsubsection{Carrots and sticks}

Incentives can play a significant role in disrupting or "unfreezing'224 habitual behaviours and encouraging new ones to be adopted. While carrots and sticks can take many forms - social, economic or physical - finding a mix of incentives appropriate to the circumstance is fundamental to achieving an outcome. An example of how sticks and carrots can have markedly different outcomes is presented in a case study undertaken by the Green Alliance and Demos. ${ }^{225}$ The study compares two initiatives undertaken by the Irish and Australian Governments that were designed to reduce the use of plastic shopping bags and/or encourage their recycling. The Australian campaign was information based and supported by carrots such as plastic bag free lanes in supermarkets and a swap scheme where people could trade in plastic bags for a calico bag in return. While the campaign achieved short-term increases in recycling, the long-term outcomes were negligible. In contrast, the Irish 'PlasTax' campaign was based squarely on a point-of-sale levy on plastic bags. The

\footnotetext{
${ }^{222}$ Lewin in Tim Jackson, “Motivating Sustainable Consumption”, op. cit.

${ }^{225}$ Joanna Collins et al op. cit.
} 
levy was supported by a public education campaign outlining why the levy was being introduced and how it could be avoided. The revenue from the levy was recycled into an environmental initiatives fund. The campaign has been successful leading to a 90 percent reduction in the consumption of plastic bags. Furthermore, the campaign has been immensely popular with the public.

Getting a balanced interplay between the use of carrots and sticks is complex and depends on a number of factors. Doug McKenzie-Mohr identifies some key elements that make incentives work. Incentives need to be visible and closely positioned to target behaviour. They also need to be managed to mitigate people's attempt to beat the incentive (which is inevitable if the incentive is strong) and carefully weighted to the inconvenience/difficulty of the behaviour. He suggests caution is required when removing an incentive because conditioning can undermine people's internal motivations and the previous behaviour can be reverted to when the incentive disappears. Andrew Darnton picks up this point when he asserts the importance of making the distinction between proenvironment intent and pro-environment impacts - behavioural reinforcement should ideally persist until the new behaviour has become habit. ${ }^{226}$

The relative advantages of sticks versus carrots are disputed. While Doug McKenzie-Mohr, amongst others, argues that incentives are best employed to reinforce positive behaviours, ${ }^{227}$ the principle of loss aversion supported by the results of Ireland's 'PlasTax' campaign and London's congestion charge would indicate this isn't always the case. Identifying the appropriate incentives for any given behaviour will depend on research and experimentation.

\subsubsection{Prompts}

The 'PlasTax' campaign suggests that a price signal is an effective means of changing behaviour. However, it is important to recognise that the levy also represents a means of bringing the issue of recycling to the front of peoples' minds. The charge acts as a prompt that reminds people of a commonsense action that they're already latently inclined to pursue. George Monbiot illustrates how prompts can act as powerful incentives by revealing that household appliances fitted with energy meters have the effect of reducing energy usage by around 15 percent. ${ }^{228}$ He goes on to argue that considerable efficiency gains can be made by fitting households with 'smart meters' that are positioned in a prominent place and indicate the cost of energy being used at any given time. In Canada, the state government of Ontario has ruled that 'smart meters' will be fitted into every household by 2010. ${ }^{229}$ Doug McKenzie-Mohr argues that prompts are most effective when they are highly visible, self-explanatory and in close proximity to where the target action is being taken. ${ }^{230}$

\footnotetext{
${ }^{226}$ Andrew Darnton, “Driving Public Behaviours for Sustainable Lifestyles”, op. cit.

${ }^{227}$ Doug McKenzie-Mohr and William Smith, op. cit.

${ }^{228}$ George Monbiot, op. cit., p. 76

${ }^{229} \mathrm{http}: / /$ www.oeb.gov.on.ca/html/en/industryrelations/ongoingprojects_smartmeters.htm

230 Doug McKenzie-Mohr and William Smith, op. cit.
} 


\subsubsection{Specific actions}

Having synthesised a range of psychological theories specifically relevant to motivating disaster preparedness, John McClure identifies the following key points:

1. Focus on specific actions rather than broad classes of action.

2. Develop specific implementation plans as to how, when and what.

3. Focus on actions that solve the problem rather managing the associated emotional responses.

4. Foster the recognition that people have at least some of the resources to respond to the risk. $^{231}$

The Communities for Climate Protection (CCP) programme facilitated by the International Council for Local Environmental Initiatives (ICLEI) in partnership with over 650 local authorities worldwide, provides a powerful example of incorporating these principles. The programme focuses on identifying activities that generate or influence GHG emissions (energy, waste, transport, land use planning), quantifying a baseline and then developing a reduction framework. Its governance approach combines monitoring and reporting with communication and education. In Australia, the city of Melbourne began with a reduction goal of 20 percent below baseline by 2010 and has now adopted a zero net emissions goal by 2020 . The programme is underpinned by focusing on specific actions and exactly how, when and where actions will be carried out. ${ }^{232}$

In Driving Public Behaviours for Sustainable Lifestyles, Andrew Darnton proposes 'an exploratory framework for a sustainable lifestyle' that includes 13 groups of behaviour. A similar framework could be used to identify targets and structure specific actions that New Zealanders can take to respond to climate change. It follows that the actions would be developed in a manner consistent with the best practice previously discussed.

\begin{tabular}{|c|c|c|}
\hline 1. Energy Use - Domestic & 7. Housing & 11. Participation \\
\hline 2. Energy Use - Transport & 8. Tourism & 12. Volunteering \\
\hline 3. Water Use & 9. Leisure & 13. Neighbourliness \\
\hline 4. Household Consumption - Food & 10. Banking & \\
\hline 5. Household Consumption - General & & \\
\hline 6. Waste & & \\
\hline
\end{tabular}

Table 4.2 An exploratory framework for a sustainable lifestyle $e^{233}$

\footnotetext{
231 John McClure, op. cit., p. 5

232 Diana Shand, "Mitigation and adaptation within local government", presented at 'Climate Change: The Policy Challenges', Wellington, $6^{\text {th }}$ October 2006

${ }^{233}$ Andrew Darnton, “Driving Public Behaviours for Sustainable Lifestyles”, op. cit., p. 9
} 


\subsubsection{Low hanging fruit and acknowledgement}

It has been established how important the perceived efficacy of an action is. It has also been discussed how actions can produce a 'positive spill-over' effect and lead to related types of action. Both these arguments point to the value of encouraging easy wins before tackling more difficult behaviour changes. John McClure suggests that target behaviours might be ranked on a cost/benefit ratio therefore ensuring that the most effective and efficient actions are prioritised. Behaviour can be further encouraged when actions are communicated to serve multiple purposes or have multiple benefits. $^{234}$

A way to reinforce the efficacy of action is to measure and acknowledge achievement. The CCP programme again exemplifies this point through a process of monitoring the progress on specific actions points and recognising 'milestone' achievements at public events. The motivational qualities of tangible measurement also further illustrate the inherent value of individual carbon-trading schemes.

\subsubsection{Commitments}

Obtaining public commitment to specific actions has been found to be an effective way of encouraging individuals to follow through on their intentions. This technique utilises the principles of Cognitive Dissonance and works because people seek to act in a manner consistent with their expressed intention. While it has previously been suggested that the power of cognitive dissonance tends to bend attitudes towards behaviours, an explicit commitment can reverse this process because publicly expressed intentions are not as easy to rationalise away. 'Acceptable Behaviour Contracts' have been used to great effect in the UK between landlords, young people and the police. Although the contracts aren't legally binding (and provide no threat of sanction) they have been effective in improving tenant behaviour and reducing associated maintenance and management costs. ${ }^{235}$ Public commitments are already employed in a number of environmental campaigns including an initiative run by the UK Royal Geographical Society - 'Changing Climate; Changing Lives?' The programme asks individuals to make a pledge to reduce their personal GHG emissions by 20 percent by $2010 .^{236}$

\subsubsection{Competition}

In a UK-based 'Action at Home' programme that supported households in shifting to more proenvironmental behaviours, it was found that one of the main reasons that people decided to participate was to measure their lives against the ways other people lived. ${ }^{237}$ Social Identity Theory

\footnotetext{
234 John McClure. op. cit.

${ }^{235}$ David Halpern et al., op. cit.

${ }^{236}$ http://www.climatechallenge.gov.uk/whats_being_done/projects/rgsibg/default.aspx

${ }^{237}$ Kersty Hobson in Andrew Darnton, "The Impact of Sustainable Development on Public Behaviour”, op. cit., p. 9
} 
argues that competitive inter-group behaviour is common to all human societies. Humans naturally organise themselves into any number of simultaneous 'in-groups', often without reason and even when there is no obvious goal or scarce resource. The very fact of being in a group automatically forms discrimination to those outside it. Where there is a strong reason for a group to form (for instance locality, ethnicity or common purpose), group identity and discrimination to the outside are likely to be stronger. Once in a group, it is important for individuals to gain a sense of 'group esteem': "We are motivated as human beings to feel good about the group we perceive ourselves as belonging to." ${ }^{238}$ It naturally follows that positive identity is often achieved by distinction from other groups. On this basis there are opportunities for encouraging pro-environmental behaviours when outcomes can be measured and compared: "Though inter-group bias may underpin conflict, it may also serve desirable ends if channelled into competition in desirable activity." ${ }^{239}$ Stimulating and publishing emissions reduction competitions between towns, organisations and schools, for example, could be an effective means of motivating behaviour change.

\subsection{Exemplify - leading and sustaining change}

\subsubsection{State leadership}

Tim Jackson argues that the insights we gain from social psychology reinforce how important it is that government is committed to the practices that it expects the public to adopt. The influence of the state isn't confined to transactional interventions; it also sets the context for ethical conduct and cultural identity. Within this social logic, consistency between policy and action is vital: "People mistrust and ignore pro-environmental exhortation if it appears inconsistent with policy messages coming from elsewhere in Government, or is seen to be at odds with the behaviour of central government, local authorities, private companies and the behaviours of other key social actors." ${ }^{240}$ The power of setting a meaningful and unifying tone cannot be underestimated. As Henry Mintzberg asserts: "Pride, dignity, and corresponding confidence... cannot be measured. But they figure prominently in just about every story of success. How people feel about themselves, personally and collectively, influences the energy with which they develop themselves." ${ }^{241}$ Referring back to the discussion in Chapter 2, responsibility for achieving strategic objectives must be taken by the leading body. Leadership is not only developing and communicating a vision, it is embodying the vision in culture and practice.

However, it is not only for reasons of integrity and credibility that exemplifying best practice is important. Jackson gives two other arguments as to why government leadership is important. The first point is one of simple practicality - in the UK, public sector expenditure contributes to almost 40

\footnotetext{
${ }^{238}$ Tim Jackson, “Motivating Sustainable Consumption”, op. cit., p. 71

${ }^{239}$ David Halpern et al., op. cit., p. 27

${ }^{240}$ Tim Jackson, "Motivating Sustainable Consumption", op. cit., p. 118

${ }^{241}$ Henry Mintzberg, "Developing Leaders? Developing Countries? Learning from another place", Development in Practice, February 2006, Appendix 1, accessed at http://www.mintzberg.org/ on $20^{\text {th }}$ September 2006, P. 9
} 
percent of national income. ${ }^{242}$ It follows that if the public sector is able to exemplify climate-friendly practice it will make a significant impact on the country's overall GHG emissions. Secondly, Social Learning Theory holds that new behaviours are learnt not only from our own trial and error but also from the examples of others, especially those in leadership roles. Many of the practices that will increasingly need to be adopted by organisations and individuals will be novel - if Government is able to demonstrate how these new practices can be made to work it provides an important 'learning ground' about what is possible in the private and citizen sectors. ${ }^{243}$

\subsubsection{Individual leadership}

Individual influence is perhaps too easily overlooked in the technical process of policy development despite the fact that it is often the indomitability of individuals that enable institutions to realise their objectives. Between 1980 and 1995, James P. Grant revolutionised UNICEF, and through his vision, intent and determination to mobilise networks and resources, saved the lives of approximately 25 million children. ${ }^{244}$ Being aware of what it took to realise his objectives, Grant insisted on employing entrepreneurial talent over seniority and giving his staff the autonomy to respond to the needs of the programme they were working on as they saw fit. ${ }^{245}$

Ashoka is a pioneering organisation in social entrepreneurship that was founded by Bill Drayton in 1980. The principle aims of the organisation are empowerment, efficiency and effectiveness. They focus on putting people in charge; enlisting grassroots professionals (while allowing experts to focus on necessities); creating new legal frameworks; helping small groups to do more; linking economic development and environmental protection; unleashing resources in the community; and linking sectors for comprehensive solutions. ${ }^{246}$ Ashoka realises these objectives by focusing on individuals: "Ashoka invests in people. We search the world for leading social entrepreneurs and at the launch stage, provide these entrepreneurs - Ashoka Fellows - a living stipend for an average of three years, allowing them to focus full-time on building their institutions and spreading their ideas. We also provide our Fellows with a global support network of their peers and partnerships with professional consultants." ${ }^{247}$ By actively identifying and championing the people who have the capability to create social change, Ashoka has been able to facilitate many measurable and significant achievements since its inception. The organisation now supports over 1800 social entrepreneurs in 63 countries. While Ashoka's recruitment approach is pro-active, it is also rigorous. It is based on four qualities:

1. creativity - the vision to see over the horizon and the creativity to solve unforeseen problems.

\footnotetext{
${ }^{242}$ Tim Jackson, “Motivating Sustainable Consumption”, op. cit.

${ }^{243} \mathrm{Ibid}$

${ }^{244}$ UN estimate in David Bornstein, op. cit., p. 242

${ }^{245}$ Ibid, p. 242-255

${ }^{246}$ Ibid, p. $146-158$

${ }^{247}$ Ashoka website, accessed at http://www.ashoka.org/support on $11^{\text {th }}$ February 2007
} 
2. entrepreneurial quality - possessed by an idea and relentless in carrying it out until it has spread across all society.

3. social impact - is the idea practical, feasible and repeatable?

4. ethical fibre - integrity and ability to gain credibility and be persuasive. ${ }^{248}$

Given the challenge that climate change presents to our civilisation and planet, there is a compelling argument as to why the most capable and passionate individuals must be recruited to lead advocacy and engagement on climate change: "If ideas are to take root and spread... they need champions obsessive people who have the skill, motivation, energy, and bullheadedness to do whatever is necessary to move them forward: to persuade, inspire, seduce, cajole, enlighten, touch hearts, alleviate fears, shift perceptions, articulate meanings and artfully manoeuvre them through systems." ${ }^{249}$ If the Government is genuine in its conviction to the put "climate change policy on the centre stage nationally and internationally in terms of its vision and innovative approach', 250 it will need individuals who have vision and the licence to innovate.

\subsection{Summary}

This chapter has highlighted a number of insights that are relevant to the development of the Government's communications and engagement strategy:

- The primary objective of the climate change communications and engagement programme is to raise awareness, change attitudes and motivate behaviour change. The other stated objectives - to demonstrate leadership, promote national interest and inform good policy decisions are all implicit in successfully realising this primary objective.

- Furthermore, the relationship between awareness, attitude change and behaviour change is not progressive. In many circumstances, changes in behaviour precede those in knowledge and opinion. If the eventual aim is to change behaviour then that should be its intent from the beginning. ${ }^{251}$

- A clear sense of purpose or vision has to be built to direct the national response to climate change. This has to be authentic and include broader social aims than simply mitigating the threat of long-term climate impacts.

- Communications need to focus on 'how' specific actions can be taken then supported with 'why'. Messages need to be personalised, credible and made relevant. Understanding the audience's values and harnessing core human motivations will be key to engaging New Zealanders with the issue.

\footnotetext{
${ }^{248}$ David Bornstein, op. cit., p. 117-125

${ }^{249}$ Ibid, p. 92.

${ }^{250}$ New Zealand Government, op. cit., p. 97 ,

${ }^{251}$ Andrew Darnton, "Driving Public Behaviours for Sustainable Lifestyles", op. cit.
} 
- Communications campaigns need to use multiple channels and have both identity (logo, tagline, voice, labelling, style guide) and experience (resources, targeted advertising, media management, events). The brand should be well managed and evolve over time. It should be creative and surprising, looking beyond the traditional and congested media channels. Society's storytellers can help embed climate change and 'compelling alternative futures' in the imagination of the nation.

- Interpersonal networks and influence could provide the best opportunity for stimulating lasting social change. Enlisting and supporting local and national opinion leaders to champion the response to climate change and raise the status of climate friendly actions can cultivate this process.

- Influencing behaviour does not necessarily create the conditions to enable behaviour change to happen. An intervention strategy that seeks to change behaviour will have to consider the external context of behaviour change as well as internal attitudes and habits. Within these parameters, it will also have to accept that different target behaviours may require different interventions

- Setting specific, measurable and achievable targets and ensuring that new behaviours are reinforced at the point of action will help encourage new behaviours. Behaviour can further be encouraged by rigorously demonstrating that outcomes are effective and serve multiple benefits. Individual carbon trading schemes provide an unprecedented opportunity to link personal action with climate change.

- If the Government is to stimulate communities and sectors to take action and be involved in the co-production of climate change policy it needs to be pro-active in finding and supporting the exceptional individuals that have the will and ability to drive the process from both sides.

- New governance models should be explored in order to facilitate and support localised initiatives. Social entrepreneurship models have been proven to be effective in seeding grassroots innovations in market areas where there is a gap between what the state and the private sector are able to provide. Communications technology provides an invaluable means to link and coordinate extensive and distributed programmes.

- Building the service capability to deliver an effective communications and engagement strategy will be a substantial challenge. While central Government has the necessary resources and reach, issues concerning structure and credibility may undermine its ability to be the dynamic and persuasive advocate that is required.

- Central Government and public sector must exemplify climate-friendly practice. 


\section{Chapter 5}

\section{Research surveys: public attitudes and behaviours relevant to climate change}

\subsection{Scope}

Given the rapidly moving debate on climate change, it was important that primary consideration be given to research surveys conducted within the last two years. In this section, research surveys that explicitly investigated attitudes towards climate change in New Zealand are complemented by studies on consumer trends and social values. A large-scale UK survey on attitudes towards climate change is also reviewed to provide a comparison. The research surveys considered are:

- $\quad$ UMR Research Limited, “Omnibus Results”, New Zealand Climate Change Office, May 2006

- Tony Pilalis and Associates, "Perceptions and Opinions About Climate Change", Joule and the British Council, Wellington, May 2006

- Steve Hatfield-Dodds and Nigel Jollands, "Issues in Communicating the Impacts of Climate Change Policy Options", New Zealand Centre for Ecological Economics, 2006

- ShapeNZ, "Welcome Survey", New Zealand Business Council for Sustainable Development, September 2006

- Sally Casswell et al., "Economic Values: A Report from the New Zealand Values Study", Centre for Social and Health Outcomes Research and Evaluation \& Te Ropu Whariki, Massey University, 2005

- Moxie Design, "Solution Seekers: A New Market Opportunity", 2005

- Department of Environment, Food and Rural Affairs, "Topline Summary Attitudes to Climate Change - Wave 1-3”, Centre of Information, UK, March 2005-2006.

\subsection{What do New Zealanders think about climate change?}

The 'Omnibus' research survey is a nationwide study that was conducted by UMR Research on behalf of the New Zealand Climate Change Office (now disbanded) and the Ministry for the Environment (MFE) in May 2006. The sample was 750 New Zealanders aged 18 years and over. ${ }^{252}$

The main finding was that climate change is becoming a more 'top of mind' environmental concern. This was demonstrated by a significant increase in unprompted mentions of the issue. However, only 69 percent of respondents felt climate change was a 'serious problem', down from 74 percent

\footnotetext{
252 UMR Research Limited, “Omnibus Results”, New Zealand Climate Change Office, May 2006
} 
recorded in the previous survey (carried out in January 2006). The study suggested that this dip was a result of a publicity initiative in April 2006 conducted by Augie Auer, a popular weather broadcaster and climate change detractor. 18 percent felt it wasn't a serious problem. When given a choice of options, 67 percent of respondents indicated that they thought climate change was a result of human activity, 24 percent thought it was a result of natural changes. Pollution remained the most nominated environmental problem with 84 percent of respondents citing it.

In contrast to the 69 percent of respondents that thought climate change was a serious problem, only 47 percent had thought about taking action to help reduce the effects of climate change. A subsequent UMR poll released in January 2007 indicated that this figure had risen to 58 percent. ${ }^{253}$ Anecdotal evidence from Honda New Zealand suggests that the trend of consumers purchasing smaller cars was more related to fuel prices than environmental concerns such as climate change. ${ }^{254}$

\subsection{Perceptions about climate change and communication preferences amongst 18-35 year-olds}

Joule and the British Council commissioned this small research study to better understand the attitudes of 18-35 year-olds towards climate change and how this demographic might be effectively engaged with the issue. ${ }^{255}$ The survey covered a range of community sectors mostly around the greater Wellington region.

70 percent of respondents felt that the issue of climate change was very important. 63 percent believed it impacted on their lives. 82 percent believed that New Zealand, as a nation, should make changes to address climate change and 100 percent supported the provision of better information in the public domain as to why action on climate change was needed. Interest in the issue was high with 82 percent of respondents claiming to read/listen/watch media about climate change. The primary reasons for being interested in climate change were split between those seeking to understand how it would affect them directly and those seeking greater understanding and knowledge. Countries identified as showing leadership on climate change included New Zealand, Australia, the UK, Switzerland, Germany, Japan, Norway and Iceland. The USA and China were identified as being guilty of bad practice.

While the majority of the respondents expressed a reasonable interest in science and technology, very few had attended a related event in the last two years. The most commonly used medium for finding out about science and technology was television, followed by newspapers and the internet. When asked about their preferred means of actively engaging with science and technology there was

\footnotetext{
253 Irene Chapple, “Kiwis warm fast to saving planet", Sunday Star Times, $7^{\text {th }}$ January

${ }^{254}$ Errol Kiong, "As the World Warms, Kiwis are Reducing Their Energy Use", New Zealand Herald, $4^{\text {th }}$ January 2007

255 Tony Pilalis and Associates, op. cit.
} 
strong support for discrete mediums - documentaries and interactive exhibitions were preferred to formal lectures. The chance to discuss climate change with an expert was definitely not an attractive option for some groups. None of the respondents could give specific details of a science and technology communication initiative held in the last two years. 60 percent of respondents felt that science and technology is not well-promoted or promoted at all.

\subsection{The effect of framing}

Steve Hatfield-Dodds (CSIRO) and Nigel Jollands (NZCEE) prepared 'Issues in Communicating the Impacts of Climate Change Policy Options' for MFE in June $2006^{256}$. The study sought to investigate the affect of communications framing on people's attitudes towards potential government action on climate change. The background of this study was informed by a recent Australian case study that ran two policy scenarios to measure the impact of emissions abatement on economic growth. In the first scenario, no mitigating action is taken and emissions increase significantly by 2050 . In the other scenario, early action is taken and emissions are cut by 65 percent. The model indicates that the difference in economic growth between the two scenarios is marginal and in both cases 'real' average income increases - early action neither leads to a reduction in GDP nor a decline in the standard of living (this point is proved in practice in Sweden - GHGs are being reduced while GDP continues to grow $\left.^{257}\right)$. Given the premise that action on climate change is widely perceived to be 'costly', the study sought to find out how more comprehensive information might influence public support for government action on climate change.

Establishing a baseline, the survey found that 65 percent of New Zealanders reported having at least some knowledge of climate change. On average, the older and wealthier respondents claimed to know more. Asked whether they supported government action on climate change when action was framed as a 'cost' (e.g. $\$ 11$ a week), 57 percent said yes. Asked the same question when action was framed as a 'forgone gain' (e.g. your income will rise by $\$ 350$ a year rather than $\$ 400$ ) and agreement increased to 73 percent. Depending on framing, expressed support swung by 15 percent. The effect of framing was even stronger when the respondent had little knowledge of climate change. Farm owners claimed to have the highest levels of knowledge but expressed the lowest levels of support for government action. A comparative study undertaken in Australia indicated that general support for government action on climate change was 15 percent higher than it was in New Zealand.

In the report's executive summary the authors assert: "Common economic shorthand is likely to miscommunicate the impact of taking action to reduce greenhouse emissions, and mislead a significant portion of the general public by conflating ideas of 'cost' and 'opportunity cost'. In particular, this

\footnotetext{
${ }^{256}$ Steve Hatfield-Dodds and Nigel Jollands, “Issues in Communicating the Impacts of Climate Change Policy Options”, New Zealand Centre for Ecological Economics, 2006

257 Jessica Cederberg Wodmar, op. cit.
} 
language may be understood as implying that climate policies will reduce economic living standards relative to current levels - which is not true of any emissions reductions target under consideration." ${ }^{258}$ This research appears to reinforce arguments about the pervasive affect of the 'economic' frame as discussed in Chapter 2.

\subsection{What does business think?}

The ShapeNZ 'Welcome Survey' is an online questionnaire run by the New Zealand Business Council for Sustainable Development. ${ }^{259}$ It questions decision makers in the business community about their opinions on a range of issues including climate change, energy security, government performance and the role of business. A summary report published in September 2006 found that 83 percent of respondents thought that climate change was a problem, 45 percent felt it was an urgent and immediate problem. Only 7 percent felt that it wasn't a problem at all.

The majority of respondents expressed support for a comprehensive range of policy measures (from home insulation programmes to a price on carbon) and all bar one initiative received expressed support at around 90 percent. Only 6 percent of respondents supported a status quo position on government climate change policy. 82 percent of respondents felt the government's current performance on climate change was 'average' to 'poor'. 85 percent of respondents felt their life quality in New Zealand to be 'good' or 'excellent'. No one felt life quality in New Zealand to be 'poor'.

\subsection{What do New Zealanders value?}

The 'New Zealand Values Study' was undertaken in $2005 .{ }^{260}$ It provides a comprehensive window to what New Zealanders currently value and therefore how they might engage with climate change.

When asked about key goals for New Zealand's development, the number one choice was "seeing people have more say about how things are done at their workplaces and in their communities". This was ranked slightly higher than economic growth. 63 percent thought less emphasis on money and material possessions would be a progressive change. 64 percent agreed with the statement: "protecting the environment should be given priority, even if it causes slower economic growth and some loss of jobs." Older age groups were less likely to agree with this statement meaning younger respondents supported it more.

\footnotetext{
${ }^{258}$ Steve Hatfield-Dodds and Nigel Jollands, op. cit., p. 4

${ }^{259}$ ShapeNZ, “Welcome Survey”, New Zealand Business Council for Sustainable Development, September 2006

${ }^{260}$ Sally Casswell et al., "Economic Values: A Report from the New Zealand Values Study", Centre for Social and Health Outcomes Research and Evaluation \& Te Ropu Whariki, Massey University, 2005
} 
In response to a separate statement: "Economic growth and development should only occur if it does not cause lasting damage to the environment", 90 percent of respondents agreed or strongly agreed. The education level of the respondent strongly affected agreement with this statement - the higher the level of education, the higher the level of agreement. 97 percent of respondents agreed or strongly agreed with the statement: "Business should be financially responsible for environmental damage caused by their activities." Likewise, 97 percent of respondents agreed or strongly agreed "Individuals should take responsibility to minimise any environmental harm they may cause". 78 percent of respondents indicated that they saw their long-term future in New Zealand with 95 percent of this group stating that a high-quality natural environment was a key determinant in this decision.

60 percent of respondents agreed or strongly agreed with giving part of their income to causes they were certain would be used to prevent environmental pollution. However, in response to a similar proposition, only 52 percent of respondents agreed or strongly agreed with an increase in taxes to prevent environmental pollution. Younger respondents were more willing to sacrifice their income than their older counterparts, as were respondents with higher education levels.

The majority of respondents felt that people should take more responsibility for themselves rather than rely on government. Priorities in choosing employment were, in order of preference, 'accomplishment', 'income', 'workmates' and 'security'. Being recognised at work came out as a priority above other factors such as reasonable hours and reduced work-related stress.

\section{7 'Solution Seekers'}

The 'Solution Seekers' research programme was undertaken by Moxie Design to identify and understand the attitudes and preferences of a growing segment of society who are actively seeking to promote environmental and social responsibility through their choice of products and services. ${ }^{261}$ 'Solution seekers' are not activists or 'greenies'; they want to maintain their modern lifestyles and financial security but are willing to take responsibility for their actions. 'Solution seekers' are discriminating and prepared to compare / validate the information they receive - authenticity and integrity are important to them. 'Solution seekers' are not just looking for 'greener' products; they are looking for new solutions to what the product or senvice ultimately delivers.

26 percent of New Zealanders can be classified as 'Solution Seekers' and Moxie believes this proportion is growing and will eventually become the dominant market. This trend is driven by the unsustainable consequences of current lifestyles (e.g. environmental degradation), the expansion of choices in products and services and the rise of 'sustainability' as an aspirational brand. 'Solution

${ }^{261}$ Moxie Design, “Solution Seekers: A New Market Opportunity”, 2005 
Seekers' are a diverse group spanning age, locality, political persuasion and other socio-economic factors. They are technologically literate and easy to reach with information. They want enduring relationships with organisations that share their values and provide them with opportunities to make ethical decisions. Their convictions become stronger the more they are able to exercise values-based consumption choices (echoing the point made about the implications of 'positive spill-over' discussed in Chapter 2). This growing sector of society wants authenticity, innovation and empowerment.

\subsection{Trends in the UK}

DEFRA commissioned three extensive surveys between March 2005 and March 2006. ${ }^{262}$ The results from these UK surveys provide a comparison on attitudes towards climate change and an indication of where current trends may be heading within New Zealand. A national communications campaign on climate change was initiated in the UK on 1 December 2005.

In March 2005, 95 percent of respondents had heard of global warming. From this sample, around 90 percent anticipated that the effect of global warming would be to change the global climate and induce ice-cap melt. 85 percent demonstrated some confusion over the issue by also relating global warming to a hole in the ozone layer. 94 percent agreed or strongly agreed with the statement that the world's climate is changing. 71 percent indicated that the change was to some degree manmade although they were generally unaware of $\mathrm{CO}_{2}$ specifically. Respondents were able to connect their individual contribution to some causes of climate change including transport, 'pollution' and fossil fuels but took less responsibility for industry, deforestation and aviation.

60 percent of respondents believed that climate change was already affecting the world and a similar amount indicated that the UK was already being affected. However, only 36 percent believed they were personally being affected. Although 79 percent were concerned about climate change, the majority of respondents were unsure about both scale and the nature of likely impacts.

Communities and individuals were seen as being able to only have a small influence on climate change, while the majority of respondents saw governments and industry as having a large influence on climate change. Around 50 percent of respondents claimed to be taking actions that reduce GHG emissions. Government officials or politicians were most remembered for speaking about climate change recently. Television followed by newsprint and radio were the most common channels of information delivery. Women were less likely to know about climate change than men but men were less likely to be concerned about it.

${ }^{262}$ DEFRA, “Top line Summary Attitudes to Climate Change - Wave 1-3”, op. cit. 
Over the course of the year there were some small shifts in attitudes. Most respondents were still concerned about climate change and the proportion of respondents who were 'fairly concerned' rose steadily. Respondents also appeared to have become more negative about the issue with the proportion of people claiming to be 'fearful' and 'frustrated' increasing. Ways in which respondents had heard about climate change had diversified to include leaflets and the internet. The proportion of respondents that had heard climate change being discussed by celebrities, families and friends had also increased although it was not a discussion held frequently. A third of respondents were familiar with the phrase 'carbon offsetting', only a very small percentage claimed to do it.

\subsection{Summary}

Climate change is becoming a more visible issue in New Zealand and there are strong indications that influential sectors of society are becoming focused on what needs to be done. However, while the majority of people feel it is a serious problem, there is still a significant proportion of the population who regard climate change as either not serious or not man-made. Immediacy is also an issue - the majority of New Zealanders don't see climate change as a 'now' problem and only half the population feel inclined to take individual action (there is little indication of what action is actually taken). Making an inference from the UK-based evidence, awareness of and concern for climate change will continue to increase organically. However, this will not necessarily increase the proportion of individuals prepared to take action. Indeed, without effective communications in place, further awareness and concern for climate change could lead to higher levels of negativity and apathy.

Although New Zealanders don't need or want to become experts on the subject, they do want to be more connected with what climate change means to them and understand why action needs to be taken. Resources and support that allow individuals and communities to explore the issue on their own and specific efforts to reach women (who may know less but care more) should be considered. The term 'pollution' seems to be a touchstone for environmental degradation. This is important because pollution is something that humans create and can therefore control. Positioning climate change as a direct affect of man-made GHG pollution might be an accessible and effective way to frame the issue. As politicians and celebrities are highly visible messengers of information about climate change it is important, where possible, that they be engaged to deliver consistent (apolitical) messages and exemplify climate friendly behaviours.

Complete information and communications framing can significantly influence public support for action on climate change. The current framing of 'cost' is constraining government action and policy development. This inertia is compounded by a lack of confidence in the Government's handling of climate change to date. It is interesting to note that support for government action is 15 percent 
higher in Australia (where the dedicated Australian Greenhouse Office ${ }^{263}$ leads action on climate change).

While New Zealanders' stated values are perhaps leading to an overestimation of the country's current activity on climate change, they nonetheless offer a huge opportunity for future cohesion. The 'New Zealand Values Study' indicates that New Zealanders believe in individual responsibility and like to be challenged. New Zealanders also value fairness, recognition for achievement, strong communities and express a willingness to participate in social change. The vast majority of New Zealanders are committed to staying in New Zealand and cite the quality of the natural environment as a central motivation. Indeed, the importance of the environment is perceived to be paramount to economic growth and on a par with education and health. This value set provides a strong base for climate change communications and engagement if:

- the affects of climate change can be clearly linked to the immediate environment.

- climate change is seen as a result of individual and business actions.

- climate change is seen as a threat to our communities and quality of life.

- inertia is seen as undermining national reputation and pride.

- individuals can have a real influence on the national response.

- investment is transparent and directed towards protecting the environment.

- individual efforts are recognised and rewarded.

There is a growing section of society that will actively support organisations, agencies and authorities that provide them with the choices that enable them to live their lives responsibly. This group needs to be nurtured, grown and rewarded. Developing a community base of individuals strongly committed to individual social and environmental responsibility is likely to develop its own momentum and influence parts of society that even the most sophisticated social marketing or education campaign would struggle to reach.

${ }^{263}$ http://www.greenhouse.gov.au/ 


\section{Chapter 6}

\section{Interview highlights}

\subsection{Scope}

The purpose of conducting research interviews was to broaden the discussion around the Government's climate change communication and engagement objectives and to test ideas and assumptions. The exercise was not intended to bring about specific solutions but rather to create new insights into the primary task of engaging New Zealanders with climate change.

The interview participants were deliberately selected to represent a diverse but relevant range of backgrounds that included: strategy development, economics, design, communications, climate science, psychology, peer education and network development. While the structure of the interviews was prompted by a number of consistent questions, the aim was to facilitate a conversation that allowed the participants to explore the objectives from their personal area of expertise and interest. The results of the interviews are presented via bullet points under leading themes in an aggregated and non-attributed manner.

\subsection{Interview participants}

A list of interview participants accompanied by a short biography can be found in Appendix 2 Inteniew process.

\subsection{Leading themes}

\subsubsection{Thoughts on how the objectives might be achieved}

- The important thing is connecting with communities and thinking about how we connect with communities. This means looking at local government initiatives rather than central government ones. This would mean central government working in partnership with local government, NGOs and communities, which is not a model usually followed.

- We need to communicate the trends of social change and show business where the money is. The Ministry of Economic Development (MED), New Zealand Trade and Enterprise (NZTE) and MFE need to get together to form a business advisory unit for ethical marketing opportunities. This would include information about how the market is changing, how they can adapt their brand and advice on what new products and services to develop. 
- Peer education is a means of practically employing a range of social psychology theorems to influence social norms, attitudes and behaviours within a community. It is particularly effective in passing messages through hard to reach demographics.

- Sustainable innovation is not about designing a green car but designing a better way for someone to get their groceries choices - it's about creating products and services that are meaningful for the consumer. The government should be supporting business to develop these opportunities. Making design convenient at every stage of the process, easy to produce, easy to market, easy to use, easy to recycle.

- Technology will play a role in helping us to reduce emissions. If you look at Auckland you have thousands of people struggling to get into work everyday to sit at a computer. Part of this is to be in an office environment but much of it is also about having access to the specific network. If there is better network technology they can start doing a lot of this work from home. Good video conferencing facilities will reduce the regular need for medium and long distance travel. There will always be a role for pressing the flesh but a lot of the regular interaction could move to the network if the system was good enough. You basically have to pay for the bandwidth of human emotion. These systems are very nearly there and while the costs seem prohibitive they need to be balanced against the true costs of travel.

- There's no need to raise awareness of climate change, people already know about it. They just need real choices and opportunities to make an impact.

- There needs to be good Maori analysis of policy interventions at the beginning of the process rather than at the end when the threat of a Treaty claim comes up.

- Influencing the school curriculum with environmental behaviours could be a powerful way of moving them into households. Parents are often willing to indulge their children's activities and as a result end up learning through them. Children are also less set in their behaviours and easier to influence.

- The power of forum is undervalued. We could do with quarterly public forums on climate change driven by the Crown and delivered through existing groups. We do it for business but not for the public - it's a job for people in business, it's the public that need to be activated.

- The first priority is getting rid of the disinformation and self-interested lobbying from climate change deniers, industries that want to be exempt and agriculture that wants to hide its 
head in the sand. There is inertia in developing a consensus because Ministers are scared to act and officials want to protect their careers. New Zealanders will understand that 'climate change is here' when they hear an authoritative voice speaking.

- Every individual has a different mix of motivations. To engage with a huge range of individuals you would need substantial funding. The first thing you would need is an institution within Government that is independent and could provide the Government with self-awareness on the issue. However, the current structure of the bureaucracy is unlikely to allow such an institution to be formed.

- Urban living has disconnected us from reality and as individuals we don't have a deep understanding of the biological nature of our economy. As a result climate change is an issue that happens out there and people don't get it. We don't understand how we run our economy or how fragile it is. We are quite insulated from the leading thinking around the world. We like to think of ourselves as innovative and 'world class' but our economy is still fundamentally linked to the biological economy as it always has been. Communications isn't a case of delivering climate change 101 but biological economy 101 linked to climate change. From here it's a case of what needs to change and what is possible. Al Gore and Richard Attenborough's work is very interesting but we need something that puts the issue in New Zealand terms - our own 'An Inconvenient Truth'.

- In a democracy things can change in two ways. Through public pressure, and this will happen as New Zealanders realise that we're increasingly out of step with the world - 15 years from now New Zealanders will go overseas and get laughed at for coming from a destructive, red-neck country. People will get frustrated about why we've missed the boat and then people who know why we've missed the boat will get elected into Parliament. The other way that democracies can change is from the top, when a leader can galvanize the nation behind a cause but that isn't evident in either this Government or the National Party.

- Central Government can provide a brand and local government has indicated they would like a brand along with the resources that go with it. The arts, design and architecture could also be hugely influential.

- Behaviour change isn't just a matter of changing what people think and understand, its changing how the system behaves and the New Zealand system behaves more pathologically on the environment than any other country I know.

- People can't just look to the Government for change and it may not be central Government that is the best organisation to lead change. Communities have an important role and 
responsibility to effect change. Communities are not bound by the political constraints of the Government.

- People don't need to know a lot about climate change but they do need to know what they can do. Determining which events have the most consequences is crucial for developing robust policy outcome statements. There needs to be a focus on specific actions.

- An advantage of modern communications technology is that it feeds on itself - if you can do something smart it spreads itself very quickly. The downside is that there is so much information and noise. However, quality attracts numbers and search engines like Google are democratic in that respect - they put the most popular sites at the top of the list. Government can play a proactive role in making sure that the most popular sites up on the internet are also the most authoritative and directive.

- We are a very small country and we know what the critical sectors are for GHG emissions. Rather than developing policy, why can't we start a dialogue with the key players and the best experts in the world to work out the best solutions for the country? We seem to go down a policy route that is then countered by business and everything moves incrementally. We need to move fast; climate change threatens our national brand as well as our infrastructure.

- Make actions measurable wherever possible - fuel meters in cars, smart metres for household electricity. Measurements act as a front of mind reinforcement of behaviour.

- The most important things in driving social change are the idea, the champions that can communicate the idea and continually asking the question: 'Is there a better way of doing this?'

\subsubsection{Messages, vision and values}

- There is a strong outside perception that New Zealand is a green country but we are complacent about our brand. NZTE has developed the brand of 'New Thinking' but there's room for a greater emphasis on sustainability in that brand that incorporates tourism.

- The $100 \%$ pure campaign has been getting a lot of feedback from tourists that it isn't true. Some of these images have become quite tarnished. The tourism industry is keen to explore a 'promote and live sustainably' campaign and because providers in the tourism industry are also members of the community they could become powerful advocates. 
- Messages about risk work best when they focus on specific actions. The target actions should be the ones that offer the biggest gains relative to cost. For example, water cylinders use 40 percent of household energy, replacing them all would lead to a huge efficiency gain.

- High anxiety is counterproductive but no anxiety results in indifference. A moderate amount of concern framed in the context of actions that can be taken is effective.

- Message is just one part of behaviour change. Other factors include legislation, incentives and social motivations including peer pressure and reward. Messages should highlight the incentives and get rid of false dichotomies - i.e. being green costs.

- A lot of issues around climate change are conceptual; we can't necessarily see them so it becomes important to question how we portray them visually. Academic mindsets find it easy to work with expert information but it isn't the trigger point for most people. Unless you can place an issue amongst a value set it is very hard to internalise what the issue means and climate change hasn't made that leap into social values yet.

- New Zealanders inherently have a feeling for the environment and a whole generation sees the 'non-nuclear' stance as putting us on the map. I feel positive that given that this has proven to be a unifying force before that it could be again but it isn't working at the moment. Although 'carbon neutrality' isn't the way to engage the nation with climate change there is an opportunity to sit down and talk with the nation about the issue. Yes, people are concerned about how something will hit them in their pocket but they will subscribe to meaningful action if they are enabled to make changes.

- Climate change should be linked our spiritual connection to the outdoors and what Maori want to protect - whakapapa, manaakitanga and taonga. More broadly we need to target inward values like health and wellbeing.

- The vision has to be aspirational but achievable as well, if people don't believe in it, or even if they do but it appears too difficult, it will tune them out. Different communities have different aspirations. 


\subsubsection{Obstacles to engagement}

- There is no easy way to solve the communications confusion because in a democracy money will buy you the way onto talkback shows, into school education packs and fund conferences that perpetuate the debate. Where it is a straight-out contest of the pocketbook the climate change deniers will win.

- In the early days of the internet the discussion was caught up in the technical aspects rather than the potential applications. We can see this happening with climate change now; the discussion centres around the science not the popular application or required actions.

- The new business opportunities with regard to climate change are blocked because big corporate interests are protecting their established ones.

- People can't engage with climate friendly behaviour if the options aren't supported transport in Auckland for example. There is a lot of talk in Wellington of sustainability and bio-fuels but I don't see where people are changing their behaviour.

- The failure of individuals to follow through on their ethical intentions (as demonstrated by the $30 \%$ ethical intention to $3 \%$ action $^{264}$ ) is a relative statistic. Ethical consumption is relative to the choice provided to people. That fact that only $3 \%$ out of $30 \%$ follow through on their intentions represents the poor choice of ethical products and services available to consumers.

- Our problem isn't the science or needing to know what needs to be done, our problem is the way in which the political economy plays out in this country. New Zealand has gone from being ahead of the world on climate change to the back of the OECD. We need some honesty about how we've squandered this but the canvas is too confused to speak plainly about the issue.

- Ordinary people can do a few things: buy a smaller car, downsize their house, lower their standard of living but all of these require sacrifice. There are very few things people can do to transform the economy in a sustainable direction. This is one of the realities of being a small market place with a weak government. In Australia you can have a net metering

${ }^{264}$ Cowe, R. and Williams, S, 2000, in Futerra, "The Rules of the Games", op. cit. 
arrangement where you can sell electricity back to the power company. Everywhere in New Zealand you can see business interests blocking customers from making sensible adjustments. The Government has failed to understand and act on this.

- Maori were upset with the climate change policy documents that were released in December 2006 because they threatened the continued erosion of Maori property rights, forestry and farming. MFE hadn't done a lot of rigorous analysis of impacts outside of the business sector; this lack of consultation turns climate change into a political issue and makes getting public buy-in difficult as a result.

- Climate change is difficult because of all the different agencies involved - MFE, Department of Conservation (DOC), Ministry of Agriculture and Forestry (MAF), Treasury - all have conflicting incentives. The issue needs to be driven by the best leadership and minds in the public service.

- Since 1980 there has been a rampant ideology of individualism in New Zealand and this trend runs counter to community identity. If New Zealand is to respond to climate change it has to engage locally and in the geography that people live in, this is hard if community ties have been broken down.

- There is a feeling that policymakers look at this issue as a technical problem and not as a human one, it is vitally important that we come at this problem understanding humans as they actually are. When people come at the issue with institutional leanings it is distorting and confusing.

\subsubsection{The role of leadership}

- The goal of a climate change strategy is simple - reduce GHGs at least cost to the economy. Regardless of what's going on elsewhere, New Zealand has to get its house in order and show leadership.

- New Zealand can lead the world when there is an obvious objective, the Government is prepared to commit serious funding to achieving it and the public and private sectors pull in the same direction.

- Government leadership is very important because if Government can't exemplify behaviour it can't expect others to follow its lead. Role modelling is important, sincerity is important and 
proving that it can be done is important. The Government owns the greenest and the least green energy provider, what kind of messages does this put out?

- We don't just need one figurehead leader, we need different leaders in the different sectors. Individuals can do a lot, we need to educate and engage with our smart business people, not just ask them to 'come to a meeting' but take time to explain the issues properly to them as individuals.

- Society is tribal and we have tribal leaders that different sections of society identify with. We need different champions for climate change that work for these different social groupings. Someone like Peter Jackson deciding his next film would be zero waste would grab my attention far more than David Parker.

- The Government hasn't fulfilled any of these objectives itself. If you can't lead by example and you are not prepared to do the analysis yourself or have Ministers that can compel others to act, how can the people of New Zealand engage with the issue?

- Leadership in government is lacking on climate change. There is no vision - where are we going? We need a 'moonshot'. There is a huge opportunity with climate change and the whole sustainable consumption debate to improve our quality of life but it needs investment.

- The Government has to be credited for taking climate change on but the reality is that New Zealanders currently live their lives in ways that aren't compatible with what needs to happen. There is a need for stronger leadership and for someone to start making some hard calls.

- The movement is already underway internationally. The market is being redesigned to work better and the first ones in will be the ones that influence where the market goes. We need national leadership to take this opportunity.

\subsubsection{Institutional structures}

- Some of the Ministers don't necessarily have a good understanding of what will work and what will not work, so it is important that they are connected with good information and advice about what is happening out there. 
- Trying to influence climate change policy has become an exercise in futility. The political system has to remake itself before any substantive progress can be made. This may happen if politicians stand up and show leadership but there has to be a genuine will from the top to make an effective change. At the moment the intent is to be seen to be doing something not to actually make things better.

- Strategy needs to start with what actually needs to happen, then what people need to do to achieve that outcome and then the Government capability that is needed to effect those actions. Forget the institutional context at the beginning and concentrate on the outcomes.

- The governance behind the model is very important - how do you set the mark and how do you fund initiatives? Governance structures need to be set for the long term and not be at risk of being dismissed by successive governments. They also need to have a mandate to ensure intergenerational equity and therefore not simply acting for now. We can't just replicate another ministry; the organisation in question will have to have the governance that allows it to operate in the most effective way. It would employ the best people with passion for the issue. If the organisation is able to become a recognised leader it will attract the best young people from here and overseas.

- l'd hate to see another layer of bureaucracy and another set of guidelines but we need an organisation that can champion climate change and lead the process. It can't champion all sustainability issues; it needs to focus on specific outcomes for climate change.

- The Greenhouse Office in Australia would be a good model to replicate. It has a dedicated mission, offers career paths for talent and creates meaningful and consistent work. We need an office that has statutory independence and can push back on politicians. Unfortunately, it would be difficult to operate in this space while the MFE exists as it does.

- There is a divide between policy design, policy implementation and the communications that go around that implementation. A lot of policy people see policy as the way forward and generally speaking many of them may never have worked on the ground. Because they haven't been part of that environment it may be difficult for them to see how that policy will actually work. So part of this comes down to whom you actually put into the Government positions to effect changes, both in policy development and communication. This may mean identifying people who have a more practical background and having outreach capacity. 
- Management style is critically important in behaviour change campaigns - individual presence, determination, integrity and embodying the vision of the organisation are all essential elements of developing trust and implementing a successful programme.

- Investment in the environment has to be seen in terms of its true costs and benefits. Agencies and organisations should be encouraged to think across silos and superficial budget lines.

\subsubsection{Community initiatives}

- You have to be able to show what you're doing and you have to be able to measure it. Projects need tangible achievements, intermediate outcomes and milestones. Measures for climate change could be based around households.

- Peer education has to work within the natural dynamics of the community and can't be forced. Potential peer educators are selected on the basis of their confidence and interest extroverts that have a knack of influencing others.

- The aim of peer educators is to set the right conditions for the social group or community. The target behaviours become subject to peer pressure - compliance is approved and noncompliance becomes taboo.

- Development initiatives can be dysfunctional on both sides. Donors put unreasonable expectations on application processes and reporting and many recipients either waste funds or have no intention of using them for the stated reasons. Good practitioners and individuals that are best suited to facilitating social change can often be too engaged with their work to negotiate lengthy bureaucratic processes.

- Peer education is not a low-intensity resource. Successful peer education programmes need to be consistently reinvigorated with training and support.

- Liability, accountability etc is always going to complicate funding initiatives. Monitoring is labour intensive and the Government carries the responsibility of distributing public money. Maybe it should be run like a business in so much as you start with what's manageable, do it well and then start to filter it out.

- If money is devolved to other organisations they are likely to want to manage it in a manner consistent with their practice and structure and central Government might be uncomfortable 
with this. Government is essentially conservative and the chances of getting radical ideas to fly are small.

- Contestable funds are suited to specialist 'rent-seekers' that spend an endless amount of time writing carefully crafted reports to bureaucrats and twisting people's arms.

\subsubsection{Insights from other areas}

- An example of a successful campaign is 'Total 2020 conservation management'. It was successful because there is an alignment between community values and project objectives. The communication strategy has an emphasis on strong leadership and governance. Ongoing public forums are held to discuss progress regardless of attendance there is a commitment to maintaining open communications. The leaders of the programme are committed to the programme and the people. The leaders are the right people - there are too many wrong people out there leading initiatives they're not committed to.

- A good example of rapid political action in New Zealand is the state housing project instigated by John A Lee in Michael Joseph Savage's Government in the 1930s. The state housing programme responded to an urgent problem of public health. The first thing he did was to recruit big business - the project was the making of Fletcher's building empire - and get the Government funding to go out and make bulk purchases (i.e. timber, brick and tiles). The economies of scale made it worthwhile for industry to make substantial investments into their infrastructure. From a standing start the whole programme was up and running within 18 months. New Zealand can move very quickly when everyone wants to pull in the same direction.

- In his book Language Death, David Crystal looks at how languages die out and how threatened languages survive. Looking at the Welsh language, he identifies two important agents for its resurgence - pop stars and young women. The pop stars were important because they were visible and influenced the teenagers. The young women, who were influenced by pop stars, were important because they brought up the next generation of children.

- The model of how the internet has spread is an example of a viral social change. The internet started in New Zealand about 18 years ago when a few people at a few organisations at a grassroots level recognised the need to get on board. At that stage the idea seemed obscure and primitive, it would have been laughable to think it would be part of everyday life 15 years later. But people took the idea, started working on it and made it 
easier for others to think about and adopt it. In a few years it had spread across the country.

- While the growth curve for the internet was exponential it took a few things to make it grow it. Firstly, it required people who were passionate about it and told other people about it - a social network. Secondly, it required Tim Berners-Lee to invent the World Wide Web protocol. This was crucial because it gave people a common framework to work in. It allowed the web to be commercialised and for local providers and innovators to spring up. It provided a structure without constraints. Thirdly, it took people pushing each other saying 'can we make this happen' and a willingness to make it happen - both competition and cooperation between parties.

\subsubsection{What we need to know more about}

- We need to bring people together to find out what works in the New Zealand context - find out what people want, what is meaningful to them, then incentivise it and make it easy.

- Health programmes are the mainstay of social marketing campaigns in New Zealand but they're different to environmental campaigns - they're not as holistic as the environment. For example, it's hard for people to believe that by recycling plastic rubbish that they're doing anything to stop climate change. Only 55 percent of people recycle, what's stopping the other 45 percent?

- The issue is so multi-dimensional. It would be good to get a range of people who want to make this work around a table and work it out.

- We need to know more about what motivates people and what barriers are stopping them from acting in environmentally friendly ways. We have to understand people rather than assuming that a broad-brush communications campaign will work for everyone. Al Gore has single-handedly brought about a huge attitudinal change but it's not behaviour change.

- We're very focused on adaptation; it would be great to get some excellent research done on what the actual impacts are going to be from all perspectives - from the household to the nation. We don't have a good understanding of this yet.

\subsubsection{Other thoughts}


- Ethical consumers are not a static market group - they are the early adopters of a major social trend. The majority of people adopt ethical behaviours partly in self-interest but once they start adopting ethical behaviours and they become more engaged with the thinking behind the actions their attitudes change to one of altruism.

- The response to climate change also requires the Government to follow through on an ambitious ICT strategy. Ideally we need a fibre network. The costs may seem prohibitive in New Zealand compared to highly populated countries like Japan but their speed is 100 times faster and their potential value is vast.

- Technology may make things smaller and faster but that isn't where the main innovations will come from. Technology responds to what people want. Innovations like 'Access Grid' - a very high quality video conferencing facility that makes the virtual communication intimate will be the major drivers of new technology. Companies in the private sector aren't necessarily aware of what is currently possible and how it could benefit their business.

- A climate change communications and engagement strategy might need a time horizon of around 20 years.

- $\quad$ Our bureaucracies and ministries have a size and scale that equals the private sector. When people in the ministries talk about business they talk about it as if it has a depth that it just doesn't have. The two need to come together in dialogue with a more creative approach to problem solving.

- $\quad$ The IPCC is providing a consensual information base. Information doesn't lead to behaviour change in the short run but it does in the long term. Behaviour change takes decades unless in war or in response to significant shocks. There will be another five years before there is a world consensus on climate change and New Zealand will be behind the world. It will probably be a decade from now before we get a genuine consensus here. If we are lucky the two major parties and the Greens might form a united policy base before the next election and we'll have a working system by 2012 .

\subsection{Summary}

The strongest themes to emerge from the interviews were as follows:

- New Zealand's response to climate change is way behind our perceived peers. Responding quickly and comprehensively to climate change is critical for both New Zealand's national image and long-term social and economic prosperity. 
- A transformational international movement is already on its way and it would be better to be in the leading pack rather than behind it. New Zealand is well positioned to respond to climate change if it can align its internal incentives.

- Specific and transparent outcomes need to be set. Specific actions that produce the most gain at the least cost then need to be determined and undertaken.

- Public, private and citizen sectors need to take a cooperative approach to problem solving to enable New Zealand to start a meaningful dialogue about how action can be taken on climate change.

- Committed leadership at all levels of society is required to build momentum on a national response to climate change. This is especially true of central Government where a bipartisan agreement is of fundamental importance.

- A dedicated and well-resourced agency with an independent governance structure should lead the national response on climate change.

- Expansive analysis should be conducted to identify the barriers that stop people from taking action on climate change. Concentrated action then needs to be taken to remove these barriers.

- A vision that speaks to New Zealanders as New Zealanders with sensitivity of heritage needs to be delivered through a comprehensive, compelling and long-term communications campaign.

- Communities should be empowered to take action on climate change within their localities. However, finding ways to support local level initiatives is notoriously difficult.

- Business needs to be supported to adopt transparent practices and develop products and services that will allow consumers to make climate friendly choices.

- Communications technology can play a major role in making climate-friendly behaviours straightforward and desirable. Government and private sector cooperation will be needed to realise this potential.

- A culture of honesty, inquiry and improvement should underpin the collective response to climate change. 


\section{Chapter 7}

\section{Leading principles}

\subsection{Scope}

These leading principles are based on the research outcomes. They reflect the complex nature of fulfilling the Government's communications and engagement objectives and achieving the target outcome of: "Well informed and well motivated sectors positively and effectively contributing to the progression of climate change policy and its implementation., ${ }^{265}$ The principles are not expressed in order of importance; they are interconnected and interdependent (and in some cases overlapping). Each principle has a core focus, a summary of key points and a concise commentary. As stated in Chapter 2, these principles are not intended as precise solutions; they represent elemental components of an effective communications and engagement programme and serve to inform thinking for the next stage of the strategy process.

\subsection{Introduction}

This research paper recommends that the following leading principles should drive the development of the New Zealand Government's climate change communications and engagement strategy:

- Specific targets, objectives and actions

- Research and learning

- Build a vision

- Dedication, coordination and autonomy

- Establish a culture

- Sector support

- Develop brand and resource centre

- Recruit champions

- Co-produce and investment in innovation

- Align policy with intention

${ }^{265}$ New Zealand Government, op. cit., p. 97 


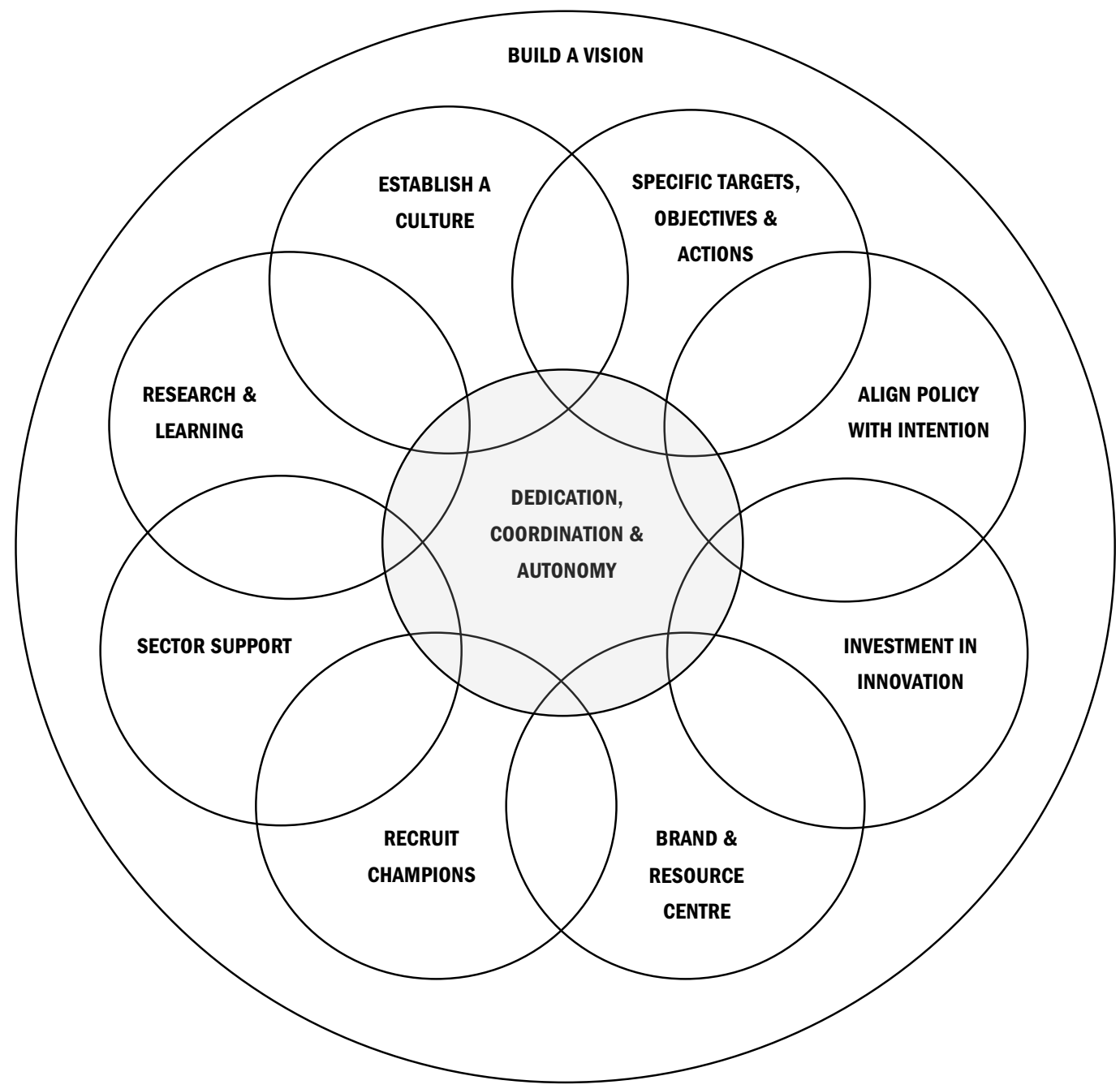

Figure 7.1 Leading Principles for the New Zealand Government's climate change communications and engagement strategy 


\subsubsection{Specific targets, objectives and actions}

- Behaviour change should become the focus of the Government's communications and engagement strategy.

- Communications and engagement objectives should be linked to specific adaptation and mitigation outcomes.

- Effective and specific actions should form the basis of a 'how to' communications and engagement programme.

- A selection of core actions that offer easy wins and multiple benefits should be implemented nationally and supported with powerful incentives.

Changes in behaviour at all levels of society will underpin much of the national response to climate change. Accordingly, behaviour change should become the focus of the communications and engagement strategy. This will mean working to change behaviours directly while also facilitating and supporting localised programmes, business innovation and national policy interventions.

The objectives of the national communications and engagement strategy need to be directly aligned to specific targets and timelines. What New Zealanders need to achieve must be made clear. These targets should be held up as explicit challenges and linked to practice at all levels of society - the public sector, industry sectors, communities, households and individuals. The country's current position should be made transparent both in terms of internal accountability and comparisons to international practice. This will be facilitated by a culture of transparent disclosure.

Once targets for both mitigation and adaptation have been established, actions that provide the most tangible and achievable gains should be identified and communicated to the relevant audiences. These solutions will provide the focus of a 'how to' communications and engagement programme. These solutions will not be directives but rather a toolbox of action opportunities that can be adapted and incentivised to suit specific circumstances and communities. Action opportunities will be communicated hand-in-hand with the benefits of action and be supported with information that allows further initiatives to be easily pursued. Communications will debunk the myth that being 'green' costs and reveal the true costs of environmental externalities and current wasteful behaviours. Specific action plans will be 'co-produced' and facilitated through active engagement and sector support. Frameworks, such as Andrew Darnton's ‘exploratory framework for a sustainable lifestyle,266 (Chapter 4: 4.5.3), can provide comprehensive models to develop action plans around.

To champion 'how to' action opportunities, a selection of core activities that are highly effective, acceptable and offer multiple benefits (for example installing smart meters, radically reducing the

${ }^{266}$ Andrew Darnton, “Driving Public Behaviours for Sustainable Lifestyles”, op. cit., p. 9 
use of plastic bags, insulating water boilers, expanding recycling opportunities) should be aggressively implemented through nationwide initiatives. The aim of these campaigns, beyond their implicit benefits, will be to disrupt inertia, stimulate behaviour 'spill-overs' and provide momentum for further engagement. These core activities will be easily measurable and strongly encouraged by a range of social, physical and economic incentives. 


\subsubsection{Research and learning}

- Promote and maintain evidence-based practice and a culture of learning.

- Better understand the barriers that constrain people from adopting target actions and behaviours.

- Employ participatory research methods.

- Initiate a national research programme in collaboration with a university institute.

- Collate case studies from international peers and programmes.

- Continue to monitor, review and share the outcomes of localised programmes to enhance the effectiveness of the national programme.

The Government's communications and engagement programme will be built on an evidence-based approach that continually strives for a better understanding of the target audience and the social logic that we live under. Employing social science methodologies, collecting comparable case studies from around the world and maintaining a practice of double loop learning will help achieve this.

Behaviour change programmes must know and understand both the internal and external constraints influencing the target audience. Research is a way of understanding these influences and surfacing the barriers that inhibit the adoption of new behaviours. Participatory research processes are twoway processes that provide insights and enable the participants to develop a better understanding of their own circumstances.

A richer understanding of how social science can be employed in policy interventions and behaviour change programmes will strengthen the communications and engagement programme. This will begin with auditing and refining the relevant literature and continue in collaboration with a university research programme. A working group comprising Climate Ambassadors, social scientists, market researchers, social marketers and communications specialists will oversee the research agenda. The research programme will actively encourage students to pursue research in this area through scholarships. The evidence base will also be expanded through cooperation with peer programmes from around the world and a compilation of relevant case studies.

The principles of climate change communications and engagement will be pro-actively shared with individuals and organisations involved in developing a response to climate change. This may include conferences and workshops that discuss research, practical applications and opportunities for collaboration. The centralised evidence base will be made available and accessible to localised initiatives through sector support. 
The design and implementation of local programmes will be piloted, monitored and reviewed. This principle is central to a learning culture and maintains the spirit of good design. This process will continually enhance the capability of practitioners and the effectiveness of the communications and engagement programme. 


\subsubsection{Build a vision}

Build a vision that makes the national response to climate change purposeful and relevant.

Set specific outcomes and incorporate broader social indicators.

- Avoid rhetoric, maintain honesty about New Zealand's current position and embed outcomes in established values.

- Emphasise the means of achieving outcomes as well as the result.

The majority of New Zealanders already know that climate change is here. However, because there is a lack of clear purpose as to where the country needs to go and why, climate change remains divorced from peoples' everyday lives. To provide the foundation for a national response, an authentic and purposeful vision needs to be established to connect New Zealanders with the reality of climate change.

The vision will set the clear expectations of 'what', 'how' and 'why', will be linked to international targets and receive multi-party support. It should be ambitious but based on specific and achievable outcomes. It should also include indicators other than reducing emissions and adapting to the impacts of climate change. Social indicators such as healthier homes, stronger communities, better public services and increased energy security should be highlighted as interdependent and mutually important goals. It will emphasise transformation rather than adjustment.

The vision should be honest. It will clearly indicate New Zealand's current position and what needs to change. It should avoid the predictable rhetoric of New Zealand becoming 'world beaters' and concentrate on more pragmatic and local incentives. It should reinforce New Zealanders' intimate connection with the environment as both a resource that needs to be managed to ensure future prosperity (agriculture, forestry, tourism) and also as an integral part of national identity and spiritual heritage. It should incorporate and promote other areas of national expertise, and potential competitive advantage, such as biotechnology and land management. From a motivational point of view myth is as important as the reality - the response to climate change should be bound with heartfelt values and national pride.

The vision will also emphasise the means of achieving outcomes as well as the result. Again, this should be based on what New Zealanders have actually indicated they value: the ability to participate, influence decisions, responding to challenges and have their work recognised. The response to climate change has to be understood as a joint process. Sustainability needs to be cultivated as a practice as instinctive as transparency and accountability, and understood as the essence of self-managed and strategic growth - inclusive of externalities and designed for long-term security. 


\subsubsection{Dedication, coordination and autonomy}

- Form a specialised, well-resourced and dedicated agency that is capable of managing the unique challenge of climate change.

- $\quad$ Retain statutory independence from, and provide self-awareness to, central Government.

- Have a governance structure that supports a dynamic, holistic and service-orientated approach.

- $\quad$ Recruit and retain the best talent.

Climate change poses an unprecedented challenge both in terms of its complexity and its potential impacts. To manage this unique and critical problem the response and service capability will need to be immediate, dynamic, long-term, comprehensive and integrated. This will be best delivered through a specialised and dedicated agency that is well resourced and expertly governed.

A Commission for Climate Response (CCR) will be given a dedicated mandate to bring about the social transformation articulated in the national vision for climate change and to realise the target outcomes. The CCR will retain independence from central Government and will be empowered to openly advocate for action on climate change. The CCR will work with and across Government to ensure that issues are highlighted and related policies and practice are cohesive and informed. The CCR will also be responsible for coordinating and publishing research, managing public communications, sector support, facilitating localised programmes and leading the implementation of nationwide activities.

Effectively engaging New Zealand to respond to climate change will demand an emergent and dynamic approach. The CCR must have the ability to respond to problems, new opportunities and changing market conditions as they happen. Close linkages with international peers and sectors on the ground will enable this. The CCR will set high internal expectations and aggressively recruit and retain the best individuals in the field. The CCR will aim to support climate change initiatives where they exist and develop them where they don't. Co-production and partnership will underpin the CCR's ethos and approach. 


\subsubsection{Establish a culture}

- Individuals committed to achieving and enhancing the goals of the strategy.

- The vision embodied in the organisational culture.

- Target attitudes and behaviours to become high status and contagious.

- Encourage experimentation and creative thinking.

The success of the communications and engagement strategy will be dependent on the individuals and organisations charged with its implementation. This relates to both the attitude, integrity and ability of the individuals themselves and the culture of the organisation they work within. To facilitate a culture that allows individuals to fulfil their potential, the strategic intent for social transformation should remain at the forefront of the programme's implementation. This means the vision must drive every decision, process and behaviour.

The CCR will recruit passionate individuals who are committed to realising the objectives of the communications and engagement strategy. They will be well managed and have progressive career paths opened to them. Underpinning their work will be an organisational culture that characterises the national vision, namely dedicated to achieving specific and transformational outcomes and value-based practice. The culture will stress pursuing the most effective interventions, allowing staff to follow their entrepreneurial instincts, enabling people on the ground to take control and maintaining open and honest communications.

By embodying these principles of competence, cooperation and improvement, the individuals responsible for implementing the communications and engagement strategy will become ambassadors for climate change in every sense of the word. Their conduct and attitude will make responding to climate change more accessible, credible and compelling. Their aim will be to make climate friendly behaviours high status and synonymous with the modern way of living. Given that integrity will be a key element of the organisational culture, sustainable practice will be rigorously pursued and demonstrated. This will include adopting the latest innovations in communications technology. This approach will also underpin the design of the brand and communications resources.

The CCR will become a hub where practice and evidence from different social sectors and geographical regions is interchanged. This will provide a fertile ground for reflection and innovation. This process will be actively encouraged and fed back into the research programme. The organisational culture will encourage experimentation and creative thinking. 


\subsubsection{Sector support}

- Support social sectors to align them with the national vision.

Audit sector needs and explore opportunities for cooperation.

- Assign specialised Climate Ambassadors for individual sectors and adapt resources to fit the context.

- Recruit motivated organisations to form clusters and support existing programmes.

- Manage a 'hub and spoke' network that avoids duplication, disseminates best practice and provides the opportunity for cross-sector collaboration.

The focus of the communications and engagement programme will be dedicated to sustainable innovation and New Zealand's long-term best interests. Within these parameters, Climate Ambassadors, employed within the CCR, will support and advocate for the sectors they work with. This will include tasks that range from communicating basic issues about climate change to providing market intelligence, highlighting risks, facilitating linkages, lobbying on the sector's behalf (nationally and internationally), helping organisations with disclosure audits, showcasing best practice, co-producing programmes and supporting innovation.

The process would begin with a collaborative national auditing process to map key players, their needs and opportunities for cooperation. Bringing sector representatives together to identify incentives structures and barriers in a forum similar to Yale University's Science to Action Collaboration could facilitate this. Distinct sectors will include central government, local government, community groups, NGOs, business and finance, agriculture, media, education, Maori and youth. Climate Ambassadors will be appointed for each major social sector and will have an excellent understanding of the field they are working in. Climate Ambassadors will be senice orientated and able to adapt core messages, resources and programmes to fit the context they work in.

Climate Ambassadors will not be able to directly support all organisations in any sector. Priority service will be given to organisations that are motivated to align themselves with the target outcomes of the national vision. Having achieved successful outcomes, these organisations will be encouraged to become local champions, form clusters and pass on best practice (in the education sector this may mean schools partnering on a geographical basis; in business it might mean companies partnering within the supply chain; in youth groups it could mean initiating discussion through a virtual community). Where support and umbrella organisations are already achieving successful outcomes, such as Enviroschools and Communities for Climate Protection, the Commission for Climate Response (CCR) will work through them.

This hub and spoke system will allow the CCR to have a grounded understanding of all relevant activities in progress in all sectors at any given time. This will help prevent duplication of effort and 
provide the basis for coherence between inter-sector and cross-sector activities. Best practice from each sector will be fed back into the CCR and disseminated back out to the sectors where appropriate. 


\subsubsection{Develop brand and a resource centre}

Audit existing organisations and campaigns communicating climate change.

- Develop and manage a high-quality brand that expresses the national vision.

- Communications will have a 'how to' focus and demonstrate climate friendly activities as bringing utility, satisfaction and high status.

- Develop an open access and high quality resource centre.

Initiate broader activities including television programmes, new media, point of sale prompts and scholarships for journalists, artists and creative professionals.

The process of creating a brand and a communications platform will begin with an audit of existing New Zealand communications campaigns that refer to climate change. This will include researching their aims, usage, message and audience. The audit process will also provide the opportunity to develop relationships with the organisations involved in climate change communications and build constituency around an integrated national brand and resource centre.

The brand will express the identity of the national vision and the culture of the CCR. The experience of the brand (resources, advertising, media management and events) will focus on 'how to' and be supported by 'why'. Climate friendly behaviours will be positioned and demonstrated to bring utility, satisfaction and high status. Demonstrating their efficacy and the power of collective impacts will help encourage individual actions. While the brand will be closely managed and protected, it will also be pro-actively made available to other organisations and adapted to meet their specific purposes. All public sector communications and programmes will use the one core brand.

The resource centre will be an open access web portal that provides varied and expert resources on climate change. This will include presentations, films, educational resources, marketing collateral and interactive forums. The resource centre will be developed through ongoing communication with sectors and regularly updated. The development of resources will be informed by the best scientific research and executed by the best creative talent in New Zealand. The website will be intelligently designed to ensure usability, popularity and predominance in search-engine rankings. The resource centre will become the authoritative source for information about climate change by dint of active promotion and natural selection. Resources will be made readily available to grassroots initiatives and campaigns.

Communications will also include a regular primetime television slot (made to be entertaining), point of sale prompts, new media (such as blogging and virtual communities), a network of experts available for media liaison and public events, a variety of local and national events and creative ways of connecting with the public. The balance of communications will be carefully managed to work with different 'values groupings'. The communications and engagement programme will also 
provide scholarships, grants and education workshops for journalists, artists and creative professionals. Resources could further be channelled through NGOs and the New Zealand Agency for International Development (NZAID) to support climate change communications in developing countries. 


\subsubsection{Recruit champions}

- Pro-actively recruit champions at all levels of society.

- Initiate and support a network approach at a local level.

- $\quad$ Promote the best practice of individuals and organisations.

Enlist highly visible trendsetters to support the national brand and communications campaign.

Use the profiles of champions appropriately and authentically.

Climate change champions should be recruited at four basic levels:

1. Exceptional individuals working within the process (facilitated by creating a dedicated agency with an enabling culture).

2. Local opinion leaders working locally within sectors and communities.

3. Ordinary people doing innovative and spectacular things

4. Highly visible trendsetters capable of influencing public opinion and creating an agenda for social change.

Local champions will already be working within established social networks. They will be recruited carefully on the basis of their ability to initiate and coordinate local programmes and will identify with the culture and purpose of the programme. They will be provided with resources, given access to a network of expert speakers, supported with communications training and invited to take part in both regional and national workshops. Local champions will also supply ongoing feedback about to what is happening on the ground and provide new insights into opportunities for action. The aim will be to build a self-expanding network where: the climate change message is widely but intimately distributed; individuals can contribute to the development of the programme; experiences and best practice are exchanged and individuals are recognised for what they achieve.

Throughout New Zealand there are already numerous individuals and organisations doing innovative and spectacular things to respond to climate change. These individuals and organisations should be identified and profiled through sector specific and nationwide communications. This will provide social learning, reward individual leadership and add momentum to the shift in social consciousness.

High-visibility champions and trendsetters will be recruited on the basis of their personal and proven commitment to taking action on climate change and their ability to connect with target social groups. Champions will come from diverse backgrounds and could include media celebrities, business leaders, sporting icons, community figureheads and popular artists. The profiles of champions will be used with integrity and in the appropriate context. Champion profiles that provide 'how l've changed 
my thinking' and 'what I do now' messages will play a key role in the delivery of the national communications strategy. 


\subsubsection{Co-produce and invest in innovation}

- Pro-actively identify the individuals and opportunities that are capable of creating social change. Use co-production models to get people involved and create multiple intervention options.

- Use the co-production process as a means to assess investment suitability.

- Enhance devolved intervention management by employing social entrepreneurship best practice and theory.

- Identify and support innovations occurring outside the co-production process.

- Target innovation in specific areas by establishing clusters and incubators.

The individuals that are best suited to facilitating social change can often be too engaged with their own work to negotiate lengthy and bureaucratic funding processes. If the Government wants to stimulate action across sectors and develop innovative ways of responding to climate change, it needs to be pro-active in engaging and enabling the exceptional individuals that will allow it to do so.

Co-production acts as a model to develop effective local interventions within readymade sector infrastructures. Not only does this distribute and magnify the ability to influence behaviour change, it also provides the incentives of solidarity and competition - a race to the top in climate innovation. This approach has the potential to work well in New Zealand due to contextual factors such as our self-contained geography, small population, relative social harmony, good communications infrastructure, innate resourcefulness, stated desire to strengthen communities and a willingness to participate in social change. Using co-production models in sector support programmes will create many alternative options for action. Given the spectrum of sectors involved, co-production models could be used for everything from community recycling programmes to the development of fuel cells.

The process of co-production can ameliorate the difficult issues associated with devolved funding. The approach provides close engagement, ensures the design of the innovation is refined and allows the capability and commitment of the innovators to be properly gauged. By working pro-actively through co-produced processes, Climate Ambassadors will be able to identify and support the initiatives that are most likely to produce effective outcomes as they are developed. Applying social entrepreneurship best practice and theory from organisations like Ashoka ${ }^{267}$ and The European Academy of Business in Society (EABIS) ${ }^{268}$ will richly enhance the effectiveness of devolved intervention models. Where copyright allows, successful programmes should be blueprinted and disseminated to other groups and organisations via the resource centre and Climate Ambassadors.

\footnotetext{
${ }^{267} \mathrm{http}: / /$ www.ashoka.org/

${ }^{268} \mathrm{http}: / /$ www.eabis.org/default.aspx
} 
Other innovations will naturally occur outside the co-production process. Targeted innovations in specific areas such as bio-fuels, renewable energy and biotechnology may also be facilitated through the inception of dedicated clusters and incubators. The CCR should be responsive to these projects and adopt a service approach to enabling the organisations and individuals behind the innovations to implement their programmes and/or take their product/senvice to market. 


\subsubsection{Align policy with intention}

Prioritise and resource the communications and engagement programme so it is able to achieve its objectives.

- $\quad$ Ensure policy across government is consistent with the stated intentions of the communications and engagement programme.

"Manmade global warming cannot be restrained unless we persuade the government to force us to change the way we live."269

In a democracy the relationship between policy development and public opinion is necessarily interdependent. To implement bold policy a government requires the backing of the public and to receive the backing of the public, a policy generally has to be perceived to be effective and beneficial. Generating a policy environment that responds to climate change, therefore, is dependent on the public believing that the Government's actions meet both these criteria.

Communications and engagement with regard to climate change is not only an element of building a successful response to climate change, it is possibly the most important element. Society is a human creation and if it can be engaged to align behind a common purpose everything else follows. The communications and engagement strategy as a means to create this alignment should accordingly be given the priority and resources it deserves and needs to be successful.

A crucial part of the communications and engagement programme will be to identify the barriers that constrain individuals and organisations from adopting new behaviours. It essential that once these barriers have been identified, policy is developed and implemented across government to ensure the regulatory environment is consistent with the stated vision and supports 'how to' communications. This may include allowing households to supply energy, providing accessible public transport, implementing stricter building and product standards, demanding compulsory emissions disclosure, setting a comprehensive price on carbon that reveals the true cost of externalities and setting up a personal carbon-trading scheme to help New Zealanders align their individual actions with climate change. While the political issues surrounding climate change are complex and 'are not amenable to simple fixes', ${ }^{270}$ bold policy initiatives like the state housing programme in the 1930 s prove that radical action can be effective and benefit all sectors of society.

\footnotetext{
${ }^{269}$ George Monbiot, op. cit., p. xv

${ }^{270}$ Stern Review on the Economics of Climate Change, "What is the Economics of Climate Change”, op. cit., p. 15
} 


\section{Chapter 8}

\section{Conclusion}

\subsection{Scope}

The conclusions of this research project are presented in Chapter 7. This chapter specifically concludes on the research and does so by reflecting on the extent to which the project has measured up to the original aims. This final chapter is broken down into succinct evaluations of the research process, the research output and the research project as a whole.

\subsection{Evaluation of research process}

The research process employed in this programme was based on the strategic thinking model described in Chapter 2. It was intended to be ambitious with regard to appraising the scope of the problem and the potential solutions; thorough in the collection of evidence; collaborative and creative. At a base level, the process was faithful to this intent. Certainly, it succeeded in generating an evidence base balanced between theory, case studies, market research and free-flowing interviews. This in turn allowed the design of leading principles that were well informed, provocative, specific to the issue and tailored to the New Zealand context. However, on reflection the process could be improved by taking the following actions:

- A richer diagnosis of New Zealand society. Desk research with regard to what New Zealander's think and value fails to capture the principle of engagement. Primary qualitative research with a range of demographic groups would provide a valuable input into the evidence base.

- More evidence of successful behaviour changes programmes through an expanded collection and examination of case studies. As the literature has demonstrated, outcomes resulting from behaviour change programmes can be subtly nuanced. By examining case studies in a more detailed and comparative manner it might be possible to tease out a better understanding of critical success factors.

- An expanded interview programme. One of the most insightful parts of the whole research process was to realise how people (as represented by the interviewees) not only had different opinions about engaging the New Zealand with climate change but fundamentally different conceptual perspectives of the issue. Achieving a better understanding of how differently people perceive this issue would contribute to the design of an inclusive and effective strategy. 
- Carry out the process with an expanded research team. This would enable an expanded interviews programme, a more thorough analysis of evidence and also enrich the process of developing recommendations and possible solutions. As is identified in the literature and demonstrated by the interview process, much of the strategic thinking process manifests itself through interaction and conversation.

- A second round of interviews or focus groups where the leading principles / recommendations could be reality tested. This process would bring attention to the most compelling and acceptable aspects of the recommendations and allow weaknesses to be either re-worked or discarded.

\subsection{Evaluation of research output}

To appraise a strategy development process and policy options, the UK Prime Minister's Strategy Unit suggest three criteria - suitability, acceptability and feasibility. ${ }^{271}$ Suitability refers to whether the option addresses the key issue and is able to deliver the desired outcomes. Acceptability refers to whether the option is supported by those with authority and influence to legitimise action. Feasibility refers to whether the option is realistic and a practical possibility.

When evaluating for suitability, the research output does well to define the complex nature of the problem and identify that to achieve the desired outcome of behaviour change, a multilayered set of interventions are required. To this end, the leading principles are thorough and multidimensional.

When evaluating for acceptability, the research output demonstrates a clear focus on the need to generate buy-in from stakeholders and the people of New Zealand. This is reflected in the emphasis on promoting engagement with, and ownership of, both the issue of climate change and the strategy itself through sector support and co-production of policy. Undeniably, there is a synergy between the elements that make a sound strategy and those that will drive an effective response to climate change: "Good design succeeds by persuading, great design succeeds by inspiring". ${ }^{272}$

However, assessing the research output with regard to feasibility is more problematic. When reflecting on the recommendations of this research it is easy to feel that many of the leading principles such as the establishment of a dedicated commission, the recruitment of a team of skilled and passionate professionals and the implementation of a nationwide sector engagement programme fall outside what can currently be categorised as feasible or realistic. That said, the pervasive view of what is currently feasible is also at odds with the scale of the problem that we face and the timeframe we have to act in. As Al Gore asserts: "If we acknowledge candidly that what we need to do is beyond the limits of our current political capacities, that really is just another way of

\footnotetext{
${ }^{271}$ Prime Minister's Strategy Unit, “Strategy Survival Guide”, op. cit., p. 9

272 Jeanne Liedtka, "Strategy as design", op. cit., p. 15
} 
saying that we have to urgently expand the limits of what is politically possible."273 The metaprinciple of this research output is that the communications and engagement programme is resourced and supported in a manner consistent with the significance of the task. While the New Zealand Government's stated objectives are achievable they are manifestly complex and will come at a cost. While aspects of this research output may not currently seem feasible, if we are serious and sincere about fulfilling the stated objectives we will need to redefine what is possible.

\subsection{Evaluation of research project}

The author's note at the beginning of this research paper stated that this project was specifically intended to increase my personal capability to advocate for better communication of and engagement with this issue. To this end, the research project has been successful - this statement can be qualified by the following measures:

- On the 11 April 2007 I ran a half-day conference on the theme of climate change communications and engagement (see Appendix 3). This event was hosted in association with Victoria University of Wellington, the British Council and the Ministry for the Environment. The event was a direct output of the research project and featured presentations from many of the sources cited in this paper. Approximately 150 representatives attended the event from a broad range of organisations and social sectors. Feedback was positive and a web user-group has been formed to continue discussion and plan future events and initiatives on the theme of climate change communications and engagement. ${ }^{274}$

- As a result of the conference an abridged version of this research study has been requested by, and issued to, interested parties including both the Ministry for the Environment and the Department of the Prime Minister and Cabinet.

- As of April 2007 I am continuing to work with the British Council, Futerra, the consultancy behind the development of the UK's climate change communications strategy, Moxie Design and Nick Jones and Associates to scope and develop a programme of nationwide workshops on the subject of climate change communications and engagement.

On this basis, while there is much to refine and explore on this issue, I believe this project has been a valuable piece of research and catalyst for some degree of action.

\footnotetext{
${ }^{273}$ Al Gore, "Solving the Climate Crisis", speech delivered at New York University Law School on 18 September 2006

${ }^{274} \mathrm{http}: / /$ groups.google.com/group/making-change?hl=en
} 


\subsection{Final comment}

In the last 100 years mankind's power to dominate the natural environment has increased without precedent. Without a relative increase in our sense of responsibility and perspective it is perhaps inevitable that we would find ourselves on a collision course with the basic systems that support us. Climate change has to be seen within this context, it is not a phenomenon to be addressed in isolation but a symptom of an imbalanced system that can only be resolved by integrating a greater sense of forbearance, responsibility and compassion into our social norms and values. In this respect, a genuine response to climate change cannot be separated from comprehensively addressing poverty, inequality and injustice.

It is in this sense that communications and engagement is not only an issue in mitigating the harmful effects of climate change but the issue. The heart of the solution comes down to collectively realising the rapid speed of our own development, the destructive consequence of our current actions and imagining an alternative future that is desirable and sustainable. Given the stakes, we need to be free in our thinking and bold in our actions to do whatever it takes to start this conversation without delay.

"The climate crisis also offers us the chance to experience what very few generations in history have had the privilege of knowing: a generational mission; the exhilaration of a compelling moral purpose; a shared and unifying cause; the thrill of being forced by circumstances to put aside the pettiness and conflict that so often stifle the restless human need for transcendence; the opportunity to rise." 275

${ }^{275}$ Al Gore, An Inconvenient Truth, op. cit., p. 10 


\section{References}

\section{R.1 Bibliography}

Abbasi, D., "Americans and Climate Change: Closing the Gap Between Science and Action", Yale School of Forestry and Environment Studies, 2006.

Anderson, K. L., “UK SCE Scenarios”, Tyndall Centre for Climate Change Research, UMIST, UK, 16 February 2000.

Ashton, J. and Burke, T., “Climate Change: Changing the Frame“, London, February 2005.

Axford, I., "Climate change: reflections on the science", in Boston, J. et al (eds.), Confronting Climate Change, Victoria University Press, Wellington, 2006.

Beck, U., Ecological Politics in an Age of Risk, London, Polity Press, 1995.

Bhaskar, R., The Possibility of Naturalism, (3rd Edition), Routledge, London, 1998.

Bishop, J., "The trouble with climate zealots and politicians”, The National Business Review, 10 April 2006.

Black, R., “Media Attacked for “Climate Porn’”, BBC News Website, 2 August 2006.

Bornstein, D., "How to Change the World: Social Entrepreneurs and the Power of New Ideas", Oxford University Press, 2004.

Boston, J., "The Public Interest, Climate Change and the Future of the Planet: Reducing the Sins of Emissions", Institute of Policy Studies, Victoria University of Wellington, 2006.

Boykoff, M. T., Boykoff, J. M., "Balance as bias: global warming and the US prestige press", Global Environmental Change 14, 2007.

Burton, M. L., Hicks, M. J., "Hurricane Katrina: Preliminary Estimates of Commercial and Public Sector Damages." Marshall University: Center for Business and Economic Research. September, 2005.

Caldwell, J. and Brown, C., 8 Tribes - The Hidden Classes of New Zealand, Wicked Little Books, 2007.

Casswell, S. et al, "Economic Values: A Report from the New Zealand Values Study", Centre for Social and Health Outcomes Research and Evaluation \& Te Ropu Whariki, Massey University, 2005. 
Chapman, R., "A Way Forward on Climate Change Policy for New Zealand", in Boston, J. et al (eds.), Confronting Climate Change, Victoria University Press, Wellington, 2006.

Chapple, I., "Kiwis warm fast to saving planet”, Sunday Star Times, 7th January 2007.

Collins, J. et al, "Carrots, Sticks and Sermons: Influencing Public Behaviour for Environmental Goals", Green Alliance, Demos, 2003.

Cowe, R. \& Williams, S. “Who are the ethical consumers?", The Co-operative Bank, 2001.

Darnton, A., “Driving Public Behaviours for Sustainable Lifestyles”, Centre of Information, UK, 2004.

Darnton, A., "The Impact of Sustainable Development on Public Behaviour", Centre of Information, UK, 2004.

de Freitas, C., "How Al Gore distorts science and spreads speculation", The National Business Review, 3 November 2006.

Department of Environment, Food and Rural Affairs, "Top line Summary Attitudes to Climate Change - Wave 1-3", Centre of Information, UK, March 2005-2006.

Diamond, J., Collapse, Allen Lane, Victoria, 2005.

Docwra, R., “Why is it so Hard to Change People's Behaviour?", Changestar, November 2006.

Easterbrook, G., “Some Convenient Truths”, The Agenda, September 2006.

Ereut, G. and Segnit, N., “Warm Words”, Institute of Public Policy Research, 2006.

Frameworks Institute, “Talking Global Warming”, The Climate Message Project, 2002.

Futerra, "Climate Change: Large-Scale National Activities”, 2005.

Futerra, “Climate Fear v Climate Hope”, London, 2006.

Futerra, “Communicating Sustainability”, UNEP, 2005.

Futerra, “Recommendations: UK Communications Strategy on Climate Change”, London, 2005.

Futerra, "The Rules of the Game: Principles of Climate Change Communications", London, 2005.

Galbraith, J. K., The Age of Uncertainty, Houghton, Boston, 1977.

Gibson, N., “By Jove, it’s Bellamy”, The National Business Review, 17 October 2006.

Gladwell, M., The Tipping Point, Abacus, 2000.

Gore, A., An Inconvenient Truth, Rodale, New York, 2006.

Gray, C. S., Modern Strategy, Oxford University Press, Oxford, 1999.

Grimm, K., “The Activation Point”, Spitfire Strategies, December 2006. 
Guba, E. G. and Lincoln, Y. L., "Competing paradigms in Qualitative Research”, Handbook of Qualitative Research, Sage Publications, 1994.

Halpern, D., et al., "Personal Responsibility and Changing Behaviour: the State of Knowledge and its Implications for Public Policy", Prime Minister's Strategy Unit, UK, February 2004.

Hart, C., Doing Your Masters Dissertation, Sage, London, 2005.

Hatfield-Dodds, S. and Jollands, N., "Issues in Communicating the Impacts of Climate Change Policy Options", New Zealand Centre for Ecological Economics, 2006.

Heskett, J., Toothpicks and Logos: Design in Everyday Life, Oxford University Press, 2002. Intergovernmental Panel on Climate Change, "Impacts, Adaptation and Vulnerability: Summary for Policymakers", Cambridge University Press, Cambridge, 2001.

Intergovernmental Panel on Climate Change, "Synthesis Report", Cambridge University Press, Cambridge, 2001.

Intergovernmental Panel on Climate Change, "The Scientific Basis: Summary for Policymakers", Cambridge University Press, Cambridge, 2001.

Jackson, T., "Models of Mammon”, Centre for Environmental Strategy, University of Surrey, 2004.

Jackson, T., "Motivating Sustainable Consumption", Sustainable Development Research Network, 2004.

Kahneman, D., and Tversky, A., "Loss Aversion in Riskless Choice: A Reference Dependent Model", Quarterly Journal of Economics 106, 1991.

Kaplan, S., "Human Nature and Environmentally Responsible Behavior”, Journal of Social Sciences, Vol. 56, No. 3, 2000 .

Kiong, E., "As the World Warms, Kiwis are Reducing Their Energy Use", New Zealand Herald, 4 January 2007.

Leiserowitz, A., "Communicating the Risks of Global Warming: American risk perceptions, affective images and interpretive communities", in S. Moser and L. Dilling (eds.), Communication and Social Change: Strategies for Dealing with the Climate Crisis, Cambridge University Press, 2007.

Liedtka, J. and Mintzberg, H., “Time for Design”, Design Management Journal, Spring 2006.

Liedtka, J., “Is Your Strategy a Duck?”, Journal of Business Strategy, Vol. 27, No. 5, 2006. 
Liedtka, J., "Linking Strategic Thinking with Strategic Planning”, Strategy and Leadership, October 1998.

Liedtka, J., “Strategic Thinking: Can it be Taught?”, Long Range Planning, Vol. 31, 1998.

Liedtka, J., “Strategy as design”, in Rotman Management, Winter 2004.

Lovelock, J., Revenge of Gaia, Allen Lane, Victoria, 2005.

Lowe, T., “Dangerous Claims: Is the Way We Perceive Climate Change Leading to a Precautionary Approach or an Irrational Response", Tyndall Centre for Climate Change Research, Norwich, November 2005.

Lupia, A. and McCubbins, M. D., The Democratic Dilemma, Cambridge University Press, Cambridge, 1998.

Mair, J. and Seelos, C., "Executive Summary: What Can Companies Learn From Social Entrepreneurs?" IESE, September 2005.

Mair, J. et al, Social Entrepreneurship, Palgrave Macmillan, Basingstoke, 2006.

McClelland, D., The Achieving Society, D. Von Nostrand Company, Princeton, 1961.

McClure, J., “Guidelines for Encouraging Householders' Preparation for Earthquakes in New Zealand", Building Research, Wellington, 2006.

McKenzie-Mohr, D., and Smith, W., Fostering Sustainable Behaviour: An Introduction to CommunityBased Social Marketing, New Society, British Columbia, 1999.

McKibben, B., "Can you imagine? A Warming World Needs Art", Published on Open Democracy, 22 April 2005.

Metz, B. and van Vuuren, D., "How, and at What Costs, can Low-Level Stabilisation be Achieved? An Overview”, in Schellnhuber, H.J. et al (eds.), Avoiding Dangerous Climate Change, Cambridge University Press, Cambridge, 2006.

Millennium Ecosystem Assessment Board, "Living Beyond Our Means: Natural Assets and Human Well-Being", 2005.

Ministry for the Environment, “National Inventory Report: 1990-2004”, April 2006.

Ministry of Health, “Te Tahuhu - Improving Mental Health 2005-2015”, 2005.

Mintzberg, H., "Developing Leaders? Developing Countries? Learning from another place", Development in Practice, February 2006. 
Monbiot, G., Heat, Allen Lane, Victoria, 2006.

Moxie Design, "Solution Seekers: A New Market Opportunity", 2005.

New Zealand Government, "Climate Change Solutions: Whole of Government Climate Change Work Programmes', June 2006.

Oram, R., “The Politics of Energy”, Sunday Star Times, Sunday, 17 December 2006.

Oreskes, N., "The Scientific Consensus on Climate Change", Science, Vol. 306, 3 December 2004.

Pfeffer, J., and Sutton, R., “Evidence-Based Management”, Harvard Business Review, Vol. 84 issue 1, January 2006.

Pilalis, T. and Associates, "Perceptions and Opinions About Climate Change", Joule and the British Council, Wellington, May 2006.

Prahalad, C.K. and Hamel, G., Competing for the Future, Harvard School Press, Boston, 1994.

Prime Minister's Strategy Unit, “Strategy Survival Guide”, UK Cabinet Office, July 2004.

Roberts, S. and Thumim, J., "A Rough Guide to Individual Carbon Trading”, Centre for Sustainable Energy, November 2006.

Roger Martin, D., “The Design of Business”, in Rotman Management, Winter 2004.

Rose, C., et al, "Climate Change Communications - Dipping a Toe into Public Motivation", May 2005.

Sample, I., "Scientists offered cash to dispute climate study", The Guardian, 2nd February 2007.

Schwartz, P. and Randall, D., "An Abrupt Climate Change Scenario and Its Implications for United States National Security", October 2003.

Schwartz, P., The Art of the Long View, Currency Doubleday, New York, 1996.

Senge, P., The Fifth Discipline, Random House, Sydney, 1990.

ShapeNZ, "Welcome Survey”, New Zealand Business Council for Sustainable Development, September 2006.

Shellenburger, M. and Nordaus, T., “The Death of Environmentalism”, The Break Through Institute, 2004.

Siegenthaler, U., et al, "Stable carbon cycle-climate relationship during the late Pleistocene", Science 310, 2005

Sloman, L., Car Sick: Solutions for Our Car-addicted Culture, Green Books, Devon, 2006. 
Steffen, W., "Sleeping Giants: Surprises in the Climate and Earth System", in Boston, J. et al (eds.), Confronting Climate Change, Victoria University Press, Wellington, 2006.

Stern Review on the Economics of Climate Change, "What is the Economics of Climate Change", HM Treasury, London, 31 January 2006.

Stern Review on the Economics of Climate Change, "The Economics of Climate Change: Executive Summary", HM Treasury, London, November 2006.

Stern, P., "Toward a Coherent Theory of Environmentally Significant Behaviour", Journal of Social Issues 56, 2000.

Summary of Key Points, "Panel on Communicating Climate Change", CIREO, COP, Nairobi, November 2006.

The New Zealand Listener, Vol 205, No. 3466, 14-20 October 2006.

Turley, C., "Ocean Acidification and its Impacts", in Boston, J. et al (eds.), Confronting Climate Change, Victoria University Press, Wellington, 2006.

Turner, M., The Literary Mind: The Origins of Thought and Language, Oxford University Press, 1996.

UMR Research Limited, “Omnibus Results”, New Zealand Climate Change Office, May 2006.

UMR Research, "Summary Report: A Qualitative and Quantitative Study", New Zealand Business Council for Sustainable Development, November 2005.

UNFCCC, "Framework Convention on Climate Change", Article 1, 1992.

United Nations, “In Larger Freedom: Towards Development, Security and Human Rights for All”, 2005.

United Nations, “Millennium Declaration”, 2000.

van der Lingen, G. J., “The Anthropogenic Global Warming Doctrine”, The National Business Review, 21 February 2006.

Walker, P., “Different Planets: Belief, Denial and Courage”, Greener Management International, 48: Winter 2004/2005.

Watt, N., "Carry On Flying, Says Blair - Science Will Save the Planet”, The Guardian, Tuesday 9 January 2007.

Weingart et al. "Risks of communication: Discourses on Climate Change in Science, Politics, and the Mass Media”, Public Understanding of Science: 9, 2000. 
Wright, R., A Short History of Progress, Text Publishing, Melbourne, 2004.

Yin, R. K., Case Study Research: Design and Methods, Third Edition, Sage Publications, Thousand Oaks, 2003.

\section{R.2 Speeches, presentations and multimedia}

Barrett, P., "Evidence From the Distant Past”, Sleeping Giants: Climate Change Science, Policy and Action, Airplane Studios, 2006.

Beckett, M., “Foreign Policy and Climate Security” speech delivered in Berlin, 24 October 2006.

Boston, J., "Opening Remarks for Symposium on Climate Change: The Policy Challenges", Institute of Policy Studies, School of Victoria University of Wellington, 6 October 2006.

Cederberg Wodmar, J., Project Manager, “The National Climate Campaign”, presented at the Ministry for the Environment on 6th December 2006.

Futerra, "Free-Riders and the Sod-Offs Factor", Futerra Master Class, November 2006.

Gore, A., "Solving the Climate Crisis", speech delivered at New York University Law School on 18 September 2006.

Hamilton, K., "Opportunities for Business", Sleeping Giants: Climate Change Science, Policy and Action, Airplane Studios, 2006.

Hatfield-Dodds, S., "Building Momentum for Climate Policy Through Improving Communication and Incentive Alignment”, CSIRO Integration Network, presented at “Climate Change Policy Symposium', Victoria University of Wellington, 6 October 2006.

Mair, J., and Seelos, C., "Social Entrepreneurs as Competitors and Partners in Global Markets", presented at EABIS, Barcelona, 19 September 2005.

Miliband, D., "The great stink: towards an environmental contract", speech at the Audit Commission annual lecture, 19 July 2006.

Parker, D., "The way forward on climate change", Climate Change the Policy Challenges Symposium, Wellington, 6 October 2006.

Parsons, W., "Climate Change and Local Government”, presented at 'Climate Change: The Policy Challenges', Wellington, 6 October 2006. 
Shand, D., "Mitigation and adaptation within local government", presented at 'Climate Change: The Policy Challenges', Wellington, 6 October 2006.

Trenberth, K., "The Politics of Climate Change", Sleeping Giants: Climate Change Science, Policy and Action, Airplane Studios, 2006.

\section{R.3 Web resources}

“Critical Realism” accessed at http://en.wikipedia.org/wiki/Critical_realism 6 November 2006.

“Joint science academies' statement: Global response to climate change", 2005 accessed at http://www.royalsoc.ac.uk/document.asp?latest=1\&id=3222 21 September 2006.

Australian Business Roundtable on Climate Change, "The Business Case for Early Action”, 2006 accessed at http://www.businessroundtable.com.au/html/documents.html 2 November 2006.

BBC News, “Human Smuggling Eclipses Drugs Trade”, 20 June 2002 accessed at http://news.bbc.co.uk/2/hi/2056662.stm 26 October 2006.

Bhattacharya, S., “European Heatwave Caused 35,000 Deaths", NewScientist.com news service, 10 October 2003 accessed at http://www.newscientist.com/article.ns?id=dn4259 5 November 2006.

Campaign Strategy, "12 basic guidelines: Motivation not education", accessed at http://www.campaignstrategy.org/cr12_1.html 3 November 2006.

IEA, “World Energy Outlook 2005”, accessed at http://www.worldenergyoutlook.org/high.asp 13 October 2006.

Jackson, T., "Details of the Scientific Programme of the ERSC Research Group on Lifestyle, Values and Energy Consumption (RESOLVE)", accessed at http://www.surrey.ac.uk/resolve/ 14 January 2006

Luntz, L., interviewed by Little, A., “And Now, a Word From Our Detractor”, Grist, 31 January 2007 accessed at http://grist.org/news/maindish/2007/01/31/luntz/ 5 February 2007.

Ogilvy, J., "What Strategists Can Learn From Sartre”, 2003 accessed at http://www.strategybusiness.com/press/article/03405?pg=all 9 December 2006. 
Rose, C., "Commentary on the Death of the Environmentalism", 2004 accessed at http://www.campaignstrategy.org/ 10 January 2007.

Rose, C., "Why campaigning on climate is difficult", accessed at http://www.campaignstrategy.org/articles/climate_difficulty.html 3 November 2006.

World Health Organisation, "Climate and health", 2005 accessed at http://www.who.int/globalchange/news/fsclimandhealth/en/index.html 3 January 2007.

\section{R.4 Websites}

Ashoka - http://www.ashoka.org/

Grameen - http://www.grameen-info.org/index.html

Ontario Energy Board - http://www.oeb.gov.on.ca/index.html

The Apollo Alliance - http://www.apolloalliance.org/

The Australian Greenhouse Office - http://www.greenhouse.gov.au/

The Breakthrough Institute - http://www.thebreakthrough.org

The European Academy of Business in Society - http://www.eabis.org/default.aspx

The New Zealand Climate Science Coalition - http://www.climatescience.org.nz/

The Sustainable Development Unit - http://www.sustainable-development.gov.uk

The Yale Project on Climate Change - http://www.environment.yale.edu/climate/

Tomorrow's Climate, Today's Challenge - http://www.climatechallenge.gov.uk

United Nations Environmental Programme - http://www.unep.org/

The Encyclopaedia of New Zealand - http://www.teara.govt.nz/ 


\section{Appendix 1 - Sleeping Giants}

\section{A1.1 Information sheet}

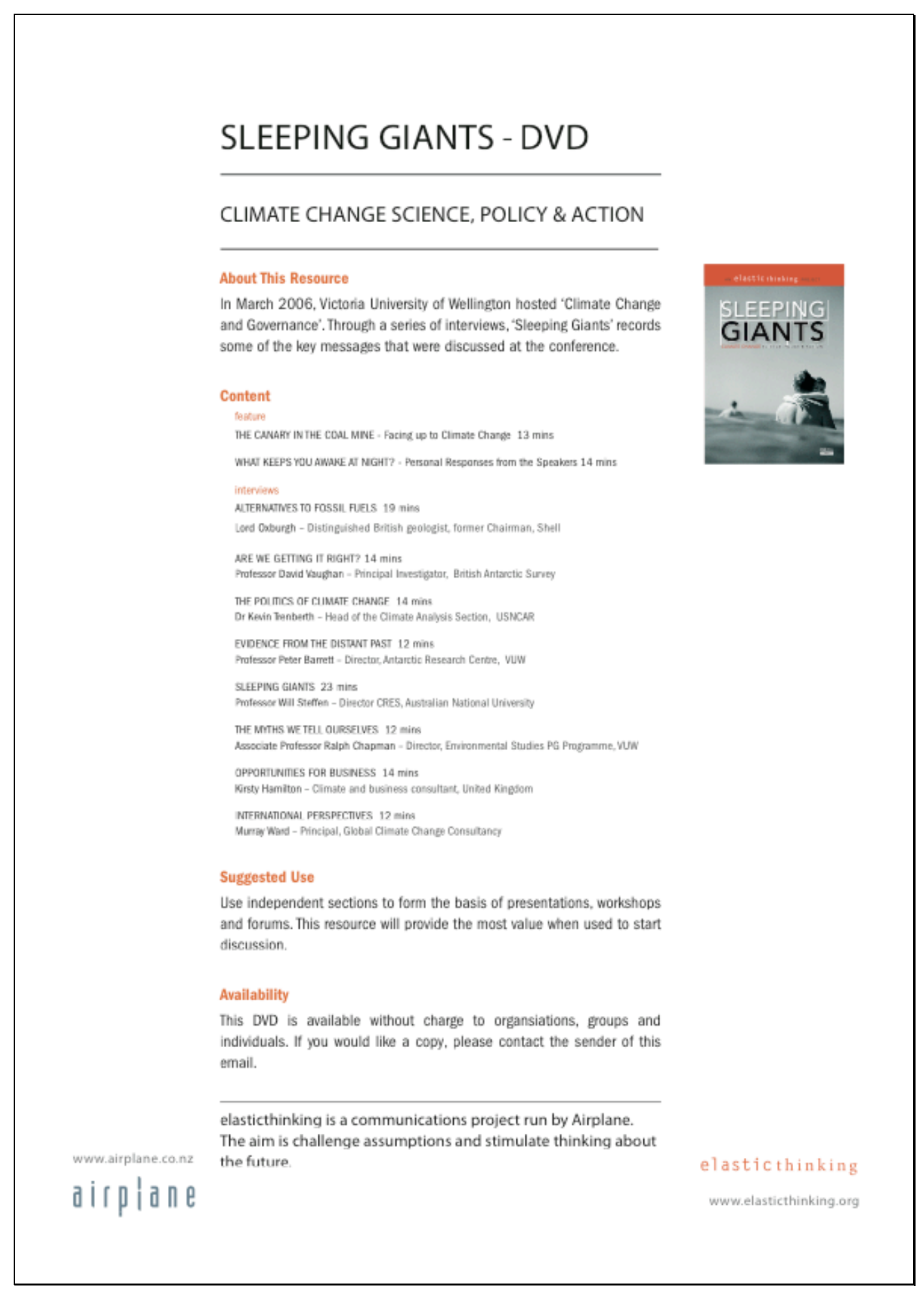




\section{Appendix 2 - Interview Process}

\section{A2.1 Ethics approval}

Approval for this research project was sought and obtained from Victoria University of Wellington's Human Ethic s Committee (appended A2.8).

\section{A2.2 Contact}

Potential interview participants were sent an email message outlining the research project and with an information sheet (appended A2.9). The email was followed up with a phone call. If the participant was willing to take part in the project an interview was arranged. Participants were asked to consider the Government's climate change communications and engagement objectives in advance of the interview.

\section{A2.3 Interview schedule}

\begin{tabular}{|c|c|c|c|}
\hline Participant & Organisation & Reason of selection & Interview Date \\
\hline Dairne Poole & $\begin{array}{l}\text { The Ministry for the } \\
\text { Environment }\end{array}$ & $\begin{array}{l}\text { Dairne Poole is a Senior Adviser for } \\
\text { Corporate and Community liaison at the } \\
\text { Ministry for the Environment }\end{array}$ & $12 / 01 / 07$ \\
\hline $\begin{array}{l}\text { Assoc. Prof. John } \\
\text { McClure }\end{array}$ & $\begin{array}{l}\text { School of } \\
\text { Psychology, Victoria } \\
\text { University of } \\
\text { Wellington }\end{array}$ & $\begin{array}{l}\text { John McClure has undertaken extensive } \\
\text { research in social perception, judgment and } \\
\text { decision-making. }\end{array}$ & $26 / 1 / 07$ \\
\hline Charlotte Serverne & NIWA & $\begin{array}{l}\text { Charlotte Serverne is focused on renewable } \\
\text { energy solutions for Maori communities for } \\
\text { NIWA }\end{array}$ & $11 / 01 / 07$ \\
\hline Andy Linton & Citylink & $\begin{array}{l}\text { Andy Linton has been involved with network } \\
\text { technology for over twenty years and was } \\
\text { instrumental getting the internet set-up in } \\
\text { New Zealand. He now works with Citylink as } \\
\text { a lead network engineer and is a member of } \\
\text { the .nz oversight committee. }\end{array}$ & $14 / 02 / 07$ \\
\hline Geoff Bertram & $\begin{array}{l}\text { School of } \\
\text { Economics and } \\
\text { Finance, Victoria } \\
\text { University of } \\
\text { Wellington }\end{array}$ & $\begin{array}{l}\text { Geoff Bertram has undertaken extensive } \\
\text { research in energy and environmental } \\
\text { economics, deregulation of natural } \\
\text { monopoly, employment, economic growth } \\
\text { and development. }\end{array}$ & $11 / 01 / 07$ \\
\hline Peter Salmon & Moxi Design & Peter is CEO of Moxie Design, a company & $12 / 01 / 07$ \\
\hline
\end{tabular}




\begin{tabular}{|l|l|l|l|}
\hline & & $\begin{array}{l}\text { that focuses on connecting organisations } \\
\text { with customers in meaningful, authentic and } \\
\text { sustainable ways. }\end{array}$ & \\
\hline Melissa Waters & The ORCHID project & $\begin{array}{l}\text { Melissa Waters is currently managing a peer } \\
\text { education programme for commercial sex } \\
\text { workers in Nagaland, India. }\end{array}$ & $1 / 02 / 07$ \\
\hline Shane Munn & $\begin{array}{l}\text { The Planning } \\
\text { Council, State of } \\
\text { Qatar }\end{array}$ & $\begin{array}{l}\text { Shane Munn has formally worked in the } \\
\text { State Services Commission and the Ministry } \\
\text { of Health. He is now works in a strategic } \\
\text { capacity building role for the State of Qatar }\end{array}$ & $2 / 02 / 07$ \\
\hline Dr Sandy Callister & The Providence & $\begin{array}{l}\text { Sandy Callister's career includes six years as } \\
\text { Saatchi \& Saatchi's Research Director, six } \\
\text { years with Television New Zealand as } \\
\text { General Manager of Marketing and Research } \\
\text { and five years as Strategic Planning Director } \\
\text { for Bates Generator. The Providence Report } \\
\text { takes a multi-disciplinary approach to } \\
\text { research and recently released 'Code Green', } \\
\text { A new framework for thinking about } \\
\text { environment and sustainability in the green } \\
\text { economy. }\end{array}$ & $12 / 07$ \\
& & &
\end{tabular}

\section{A2.4 Structure}

The interviews were deliberately undertaken in an informal and relaxed manner to encourage freeflowing conversation and allow the participants to explore the Government's communications and engagement objectives from their personal area of expertise and interest. Proceedings were prompted by the questions listed below.

\section{A2.5 Consent}

The interview participants were asked to sign a consent form (appended A2.10).

\section{A2.6 Sample interview questions}

- What are your first thoughts on how these objectives or elements of these objectives might be fulfilled?

- In your opinion, what resources and timescale would realistically be required to fulfil these objectives? 
- In your opinion, what are likely to be the most significant obstacles to fulfilling these objectives?

- Are there any case studies or approaches that you have come across that might be applicable to engaging people with climate change?

- In your opinion, what values drive New Zealanders and how might they be incorporated into a message that relates to climate change?

- From your experience, what do we need to know more about to develop a strategy around these objectives and how might we measure the effectiveness of a communications and engagement programme?

- Is there anything else that came into your thoughts when you were preparing for this discussion?

\section{A2.7 Data collection and analysis}

The interviews were tape recorded and transcribed. After the intewiews were transcribed the original tape recordings were destroyed. It was not considered necessary for transcripts to be sent back to participants for sign off because data was only used in an aggregated and non-attributed manner. The interview transcripts will be kept securely under password protection on a personal computer until April 2010, when they will then be deleted.

The interview transcriptions were summarised by key points and then synthesised with other interview results into an umbrella commentary of themes. This is presented in the results section of the final research report in aggregated and non-attributed bullet points. Aggregated and non-attributed results from the interviews may also be presented in further research publications and summary reports. An executive summary of the final research report will be made available for interested individuals and organisations in 2007.

Participants had the option to withdraw from the process at any time previous to the submission of the final research report. It was stated that upon withdrawal all record of the participant's involvement in the research process would be deleted. 


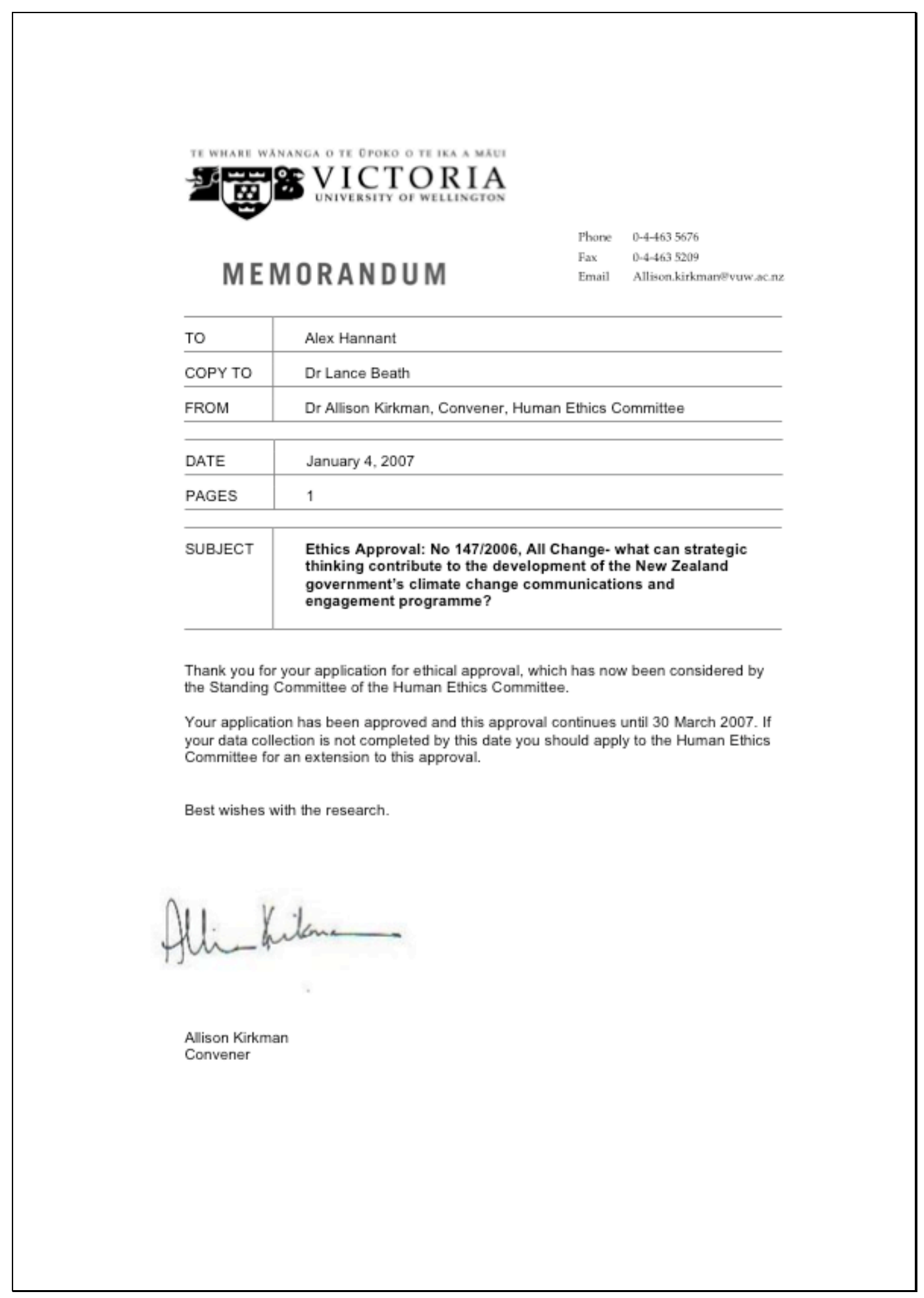


A2.9 Information sheet

te whare Wananga o te opoko o te ika a mau

Information Sheet

Purpose

I am currently undertaking a Masters research project at Victoria University of Wellington. The aim is to develop thinking around the Government's intended climate change communications and engagement strategy and propose an integrated framework of leading principles/possible solutions. The Government's objectives, as stated in "Climate Change Solutions: Whole of Government Climate Change Work Programmes' (June 2006), are:

1. For the people of New Zealand to:

- understand that the effects of climate change are here; that there are national and local implications for us all;

- shift their thinking towards longer-term action (buy-in) on reducing greenhouse gas emissions;

- begin preparing for the effects of climate change.

2. To place NZ climate change policy on the centre stage nationally and intemationally in terms of its vision and innovative approach; that is, to show leadership while stressing the importance of acting at all times in New Zealand's interest.

3. To ensure that policy development and decisions are well informed.

As part of my research I am conducting interviews to develop a broad range of input and insight as to how these objectives might be achieved. If possible, I would like to include you in the process. The interview will be brief, flexible and confidential.

\section{Structure}

The interview will take approximately 30 minutes and will be structured by questions based on the govemment's climate change communication and engagement objectives. I am primarily interested in your opinion, perspective and experience. Discussion could indude the practicalities of the objectives, what we need to know more about, relevant case studies/applicable theory, considerations for the New Zealand context, strategies for dealing with specific sector groups or possible opportunities.

\section{Process}

The interview will be tape recorded and transcribed. After the interviews have been transcribed the original tape recordings will be destroyed. Full transcripts of the interviews will be kept securely under password protection in electronic format on a personal computer for three years and then deleted. The interview 
transcripts will summarised and synthesised with other interview results into an umbrella commentary of themes in the results section of the final research report. Although your participation in the research project will be acknowledged, all opinions and discussion resulting from the interview will be presented in the main research report in an aggregated and non-attributed manner. Beyond the research report, aggregated and non-attributed results from the interview may be presented in further research publications and conference papers. An executive summary of the final research report will be made available for interested individuals and organisations in 2007

If you decide to withdraw from the process at any time previous to the submission of the final research report, all record of your involvement in the research process will be deleted.

\section{Further information}

If you have any questions or would like to receive further information about the project, please contact me: Alex Hannant, alex⿶ㅣㅁonz.org, 049708287,0212552278 or my supervisor Dr Lance Beath, lance.beatheruw.ac.nz, 044636792 


\title{
Consent form
}

'What can strategic thinking contribute to the development of the New Zealand Government's climate change communications and engagement programme?'

\section{A research project undertaken by Alex Hannant}

\begin{abstract}
- I agree to take part in this research project
- I understand that this interview will be tape-recorded and transcribed.

- I understand that after this interview has been transcribed the original tape recordings will be destroyed. - I understand that the transcriptions of this interview will be kept in a secure electronic format for three years after which it will be deleted.

- I understand that transcripts of this interview will be kept confidential with access limited to Alex Hannant (researcher) and Dr Lance Beath (research supervisor).

- I understand that although my participation in the research project will be acknowledged, any information or opinions I provide will be reported in an aggregated/non-attributable manner.

- I understand that the information I have provided for this research project may also be used in an aggregated/non-attributable manner in further research publications, conference papers and an executive summary of the final report (to be available to interested individuals and organisations from 2007). - I understand that I may withdraw from this study at any time before the final analysis of data without providing reasons. In this event all record of my involvement in the research process will be deleted.
\end{abstract}
Name:
Signature:

Date:

If you would like a copy of the final report please indicate here: 


\section{Appendix 3 - Making change - taking the initiative on climate change communications and engagement}

\section{A3.1 Invitation}

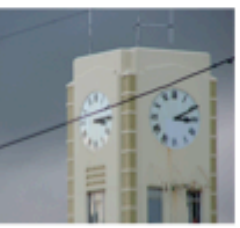

Making Change - taking the initiative on climate change communications

Old Government Buildings, Lecture Theatre 1 (situated at the back of the main building) Victoria University of Wellington

Wednesday $11^{\text {ta }}$ April 2007, 8.45am $-12.15 \mathrm{pm}$

This conference is for people who are interested in exploring how to engage New Zealanders with climate change more effectively. Representatives from all sectors are welcome and particularly those actively inwolved in public communications and communications planning with regard to climate change. At the end of the event, participants will be asked to give their feedback on communication initiatives that they would like see developed further.

\begin{tabular}{|c|c|c|}
\hline Time & Content & Session Leader \\
\hline $8.45-9.00$ & Introduction & Assac. Prof. Ralph Chapman (VuW) \\
\hline $9.00-9.30$ & $\begin{array}{l}\text { Where are we in New Zealand? - A } \\
\text { synthesis of relevant research relating to } \\
\text { awareness, attitudes and behaviours }\end{array}$ & $\begin{array}{l}\text { Peter Salmon (Maxie Design) and Nick } \\
\text { Jones (Nick Jones and Associates) }\end{array}$ \\
\hline $9.30-10.15$ & $\begin{array}{l}\text { The Rules of the Game' - An introduction } \\
\text { to climate change communications and } \\
\text { the work of Futerra (www.futerra.org) }\end{array}$ & $\begin{array}{l}\text { Solitaire Townsend and Lucy Shea, } \\
\text { (Futerra) - Videolnk. }\end{array}$ \\
\hline $10.15-10.35$ & \multicolumn{2}{|c|}{ Break } \\
\hline $10.35-11.05$ & $\begin{array}{l}\text { Pisk perception and theories of behaviour } \\
\text { change }\end{array}$ & Assac. Prof. John McClure (VUN) \\
\hline $11.05-11.35$ & $\begin{array}{l}\text { The media, climate change and getting } \\
\text { your story out there }\end{array}$ & Kim Griggs (freelance journalist) \\
\hline $11.35-11.55$ & $\begin{array}{l}\text { Closing the gap between science and } \\
\text { action in the USA - Insights from the Yale } \\
\text { Science to Action Collaboration }\end{array}$ & $\begin{array}{l}\text { Daniel Abbasi (Former Associate Dean } \\
\text { of Yale Forestry and Environment } \\
\text { School) - Wdeolink. }\end{array}$ \\
\hline $11.55-12.10$ & $\begin{array}{l}\text { Ideas for climate change communications } \\
\text { in New Zealand and audience feedback }\end{array}$ & $\begin{array}{l}\text { Alex Hannant (Mandarin } \\
\text { Communications) }\end{array}$ \\
\hline
\end{tabular}

89 BRITISH $\begin{gathered}\text { Institute } \\ \text { policy } \\ \text { studies }\end{gathered}$ Victoria 


\section{Booking your place}

To book a place at this event please RSVP to Alex Hannant at Mandarin Communications. While attendance is free of charge, capacity is limited. Places will be allocated on a first come first served basis.

To ensure an equitable and representative spread of participants, please ensure only the most appropriate individuals from your organisation are nominated to attend.

\section{Mandarin Communications}

This event has been developed and organised by Alex Hannant from Mandarin Communications in association with Victoria University of Wellington (Institute of Policy Studies and the School of Geography, Environment and Earth Sciences) and the British Council.

Alexeipnz.org

M 0212552278

T 049708287

The facts of climate change cannot be left to speak for themsewes. They must be actively communicated with the right words, in the right dosages, packaged with namative storytelling that is based rigorously on reality, personalized with human faces, made vivid through visual imagery - and delivered by the right messengers... Social science methods have not been adequately applied to date - and that must change, given the stakes." Daniel Abbasi 